\title{
NISTIR 89-4049
}

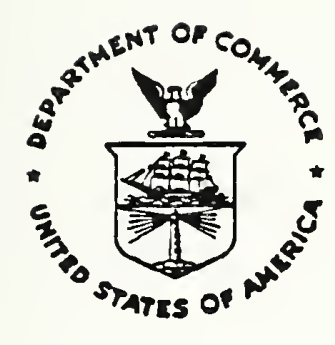

\section{Assessment of Need for and Design Requirements of a Wind Tunnel Facility to Study Fire Effects of Interest to DNA}

William M. Pitts

U.S. DEPARTMENT OF COMMERCE

National Institute of Standards and Technology

National Engineering Laboratory

Center for Fire Research

Gaithersburg, MD 20899

May 1989

Sponsored by:

Defense Nuclear Agency

Washington, DC 20305-1000 



\section{Assessment of Need for and Design Requirements of a Wind Tunnel Facility to Study Fire Effects of Interest to DNA}

William M. Pitts

U.S. DEPARTMENT OF COMMERCE

National Institute of Standards and Technology

National Engineering Laboratory

Center for Fire Research

Gaithersburg, MD 20899

May 1989

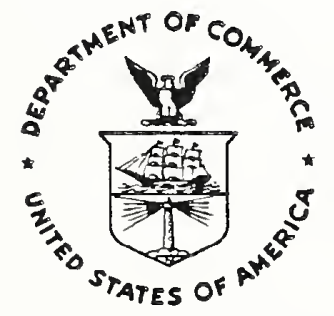

National Bureau of Standards became the

National Institute of Standards and Technology

on August 23, 1988, when the Omnibus Trade and

Competitiveness Act was signed. NIST retains

all NBS functions. Its new programs will encourage

improved use of technology by U.S. industry.

Sponsored by:

Defense Nuclear Agency

Washington, DC 20305-1000

U.S. DEPARTMENT OF COMMERCE

Robert Mosbacher, Secretary

NATIONAL INSTITUTE OF STANDARDS

AND TECHNOLOGY

Raymond G. Kammer, Acting Director 



\section{TABLE OF CONTENTS}

LIST OF TABLES

Page

LIST OF FIGURES

vi

ABSTRACT

ix

1. INTRODUCTION

2. DEFINITIONS OF MASS FIRE, FIRE STORM, AND CONFLAGRATION

3. URBAN MASS FIRE HISTORY

4. ROLE OF FIRE IN THE DESTRUCTIVE FORCE OF NUCLEAR WEAPONS

5. BRIEF HISTORY OF FIRE RESEARCH IN THE UNITED STATES

6. COMMENT ON JAPANESE RESEARCH ON URBAN FIRE

7. PREVIOUS RESEARCH ON AND MODELS FOR PREDICTING URBAN MASS FIRES AS

A RESULT OF NUCLEAR DETONATION

7.1. Spatial and Temporal Distribution of Thermal Radiation.......

7.2. Distribution of Significant Fire Starts in an Urban Environment

7.3. Fire Spread in the Urban Environment Following a Nuclear

Detonation

7.3.1 Stochastic Modeling of Urban Fire Spread

7.3.2 Deterministic Modeling of Urban Fire Spread

7.4. Mass Fire Behavior.

7.4.1. Criteria For the Formation of Fire Storms

7.4.2. Modeling of Mass Fire Behavior

7.4.3. Experimental Investigations of Mass Fire Behavior

8. PREVIOUS EXPERIMENTAL AND THEORETICAL INVESTIGATIONS OF FIRE SPREAD .

8.1. General Discussion of Fire Spread Behavior

8.2. Fire Studies in the Absence of Wind

8.2.1. Fire Spread Studies 


\section{TABLE OF CONTENTS (continued)}

14.4. Projected Role of Wind Tunnels in Improving the Understanding

of Urban Fire Spread Following a Nuclear Attack . . . . . . . . . 129

15. ANALYSIS OF THE NEED FOR A NEW WIND TUNNEL FACILITY TO

INVESTIGATE WIND EFFECTS ON FIRE SPREAD AND FLAME BEHAVIOR 。 . . . 130

15.1. Currently Existing Wind Tunnel Facilities for Investigating

Wind-Aided Fire Spread and Wind-Fire Interactions . . . . . . . . 131

15.2. Other Important Considerations in the Design of Wind Tunnels

for Fire Studies . . . . . . . . . . . . . . . . . . . 146

15.3. Desired Capabilities of a Wind Tunnel For Investigating

Problems of Relevance to Urban Fire Spread . . . . . . . . . . . 149

15.4. Requirement for Development of a New Wind Tunnel Facility . . . 155

16. GENERAL SPECIFICATIONS FOR A WIND TUNNEL FACILITY DESIGNED FOR

STUDIES OF FIRE CHARACTERISTICS RELEVANT TO URBAN FIRE BEHAVIOR . . 159

16.1. Overal1 Tunne1 Specifications . . . . . . . . . . . . . . . . 159

16.2. Enclosed Test Section . . . . . . . . . . . . . . 163

16.3. Test Chamber .. . . . . . . . . . . . . . . 167

16.4. Fan and Flow Conditioning Sections . . . . . . . . . . . . 170

16.5. Other Considerations . . . . . . . . . . . . . . . . . 174

17. FINAL COMMENTS . . . . . . . . . . . . . . . . . . . . . . . 176

18. ACKNOWLEDGEMENTS . . . . . . . . . . . . . . . . . . 178

19. REFERENCES . . . . . . . . . . . . . . . . . . . . 180

20. EXECUTIVE SUMMARY . . . . . . . . . . . . . . . . 195 


\section{LIST OF TABLES}

Table 1. Areas Where Fire Research is Required Table 2. Wind Tunnels Used for Fire Studies . . . . . . . . . . . . . . 134

Table 3. Recommended Wind Tunnel Specifications . . . . . . . . . . . . 160

Table 4. Estimated Pressure Drops Through Sections of the Proposed Wind Tunne1 . . . . . . . . . . . . . . . . 175 


\section{LIST OF FIGURES}

Figure 1. Example of stochastic approach to assessment studies of urban fire vulnerability. Figure reproduced from [15].

Figure 2. Example of deterministic approach to assessment studies of urban fire vulnerability. Figure reproduced from [15].

Figure 3. Steady-state burning through cribs of white fir wood with different specific gravities. Figure reproduced from [92].

Figure 4. Intensity distributions for two line fires, Frandsen and Rothermel [108]. Figure reproduced with permission of author from [82].

Figure 5. Temperature, rise of fuel in front of still-air fire.

Figure reproduced from [88].

Figure 6. Temperature rise of air and fuel in front of a wind-driven fire. Figure reproduced from [88].

Figure 7. Flaming zone combustion characteristics in the presence of wind. Figure reproduced from [88]. . . . . . . . . .

Figure 8. Effect of wind velocity on rate of fire spread.

Parameters: fuel bed voidage: 0.809 and fuel loading density: $0.441 \mathrm{lb} / \mathrm{ft}^{2}{ }^{2}$. Figure redrawn with permission of author from [111].

Figure 9. Temperature profile in the fuel bed, parameters:

headfires, wood shavings, fuel length: 1 in., $30 \%$ R.H., fuel bed voidage: 0.918 , and fuel loading density: 0.193 1b./ft. ${ }^{2}$. Figure redrawn with permission of author from [111].

Figure 10. Radiative or convective heat flux versus distance from flame front. Parameters: headfires, short match-splints, $30 \%$ R.H., wind velocity: $2.11 \mathrm{ft} / \mathrm{sec}$., fuel bed voidage: 0.783 , and fuel loading density: $0.812 \mathrm{lb} . / \mathrm{ft} .^{2}$. Figure redrawn with permission of author from [111].

Figure 11. The effects of wind speed and stick spacing on rate of fire spread in cribs of white fir wood. Figure reproduced from [94].

Figure 12. The maximum distance at which cotton fibers were ignited downwind from the edge of a square pool of burning alcohol plotted against wind speed. Figure reproduced from [94].

Figure 13. The relation between rate of spread and wind speed is shown for headfires (curve A) and backfires (curve B) for fires burning in wood cribs 1.56 inches high and 11.6 inches wide constructed of $1 / 4$-inch white fir sticks. Figure reproduced from [115]. 
Figure 14. Propagation of fire in cribs. Figure reproduced with

permission (after Thomas [116]). . . . . . . . . . . 62

Figure 15. The fire front position, $\mathrm{x}_{f}$, (distance downwind of the leading edge of the fuel bed, from thermocouple measurements with $673 \mathrm{~K}$ taken as the temperature at the time of flame front passage) is presented as a function of time $t$ since ignition. Figure reproduced from [123]. . .

Figure 16. Flame speed $v_{f}$ as a function of fuel loading $\sigma$ at wind speed $U=200 \mathrm{~cm} / \mathrm{s}$ and bed width $\mathrm{W}=55 \mathrm{~cm}$. The curve is given by $v_{f}=0.034(U / \sigma)^{\frac{1}{2}}$. Figure reproduced from [123].

Figure 17. Flame speed $v_{f}$ as a function of test-section width $W$ at wind speed $U=200 \mathrm{~cm} / \mathrm{s}$ and fuel loading $\sigma=0.02208$ $\mathrm{g} / \mathrm{cm}^{2}$. Figure reproduced from [123]. . . . . . . . .

Figure 18. Effect of wind speed and burning rate on flames. Figure reproduced from [127].

Figure 19. Relationship between flame bending angle and Froude number. Figure redrawn with permission of author from [111].

Figure 20. Schematic diagram of fire whirl development behind a bonfire. The whirls are reported to be formed when one of the "smoke rolls" breaks off from near a null-point in back of the wood structure. Figure reproduced from [153].

Figure 21. Schematic diagram of flame merging table, plan view.

Figure reproduced from [161].

Figure 22. Burning rates of interacting 6 -inch $n$-hexnae fires.

Figure reproduced from [161].

Figure 23. Correlation of center burning rates for all fuels. Figure reproduced from [161].

Figure 24. Burning rate as a function of the distance between cribs.

Figure reproduced from [12].

Figure 25. Relationship between $\theta_{\mathrm{dn}} / \theta_{\mathrm{up}}$ and spacing Froude number $\mathrm{U}^{2} / \mathrm{sg}$. Figure reproduced from [119].

Figure 26. A very idealized description of the environment surrounding ground zero following a nuclear detonation above an urban area is depicted. Note that no distance scale is provided.

Figure 27. A schematic of the combustion facility of the U.S.D.A. Forest Service located in Missoula, MT. Note the presence of two wind tunnels. Figure reproduced from [186]. . . . 
Figure 28. Layout of the flame wind tunnel located at the University

Figure 29. Main components of the wind tunnel used for flame studies at the University of New Brunswick. Figure redrawn with permission of author from [111]. . . . . . . . . . . 140

Figure 30. Schematic diagram of the flame-spread wind tunnel located at TRW, Redondo Beach, CA. Figure reproduced from [121].

Figure 31. Arrangement of flow-conditioning elements in the windtunnel inlet section of the TRW facility. The last flowconditioning element is $2.2 \mathrm{~m}$ upstream of the test section, to allow imprints on the airflow to dissipate. Figure reproduced from [121]. . . . . . . . . . .

Figure 32. Rough schematic for a wind tunnel designed specifically for investigations of fire phenomena relevant to fire spread in an urban environment following a nuclear detonation. 


\section{ABSTRACT}

The objective of this study is to recommend whether or not a new wind tunnel facility should be designed and constructed for the investigation of wind-aided fire spread. The focus is on the types of mass fire which can be expected following a nuclear detonation above an urban environment. The final conclusions of the report are: 1) The need for an improved understanding of urban fire spread as it relates to nuclear weapon effects is overwhelming, 2) At the present time, predictive capabilities for estimating fire damage in an urban environment following a nuclear attack are very limited and uncertain, 3) Wind tunnel experiments will not provide all of the required information, but will offer the opportunity to improve substantially the understanding of the problem, 4) Most existing wind tunnels were designed decades ago and are not well-suited for the required experimentation, and 5) Some progress can be and is being made in existing facilities, but substantial improvements in understanding require a new facility and a sustained commitment for support. An executive summary is provided. 



\section{INTRODUCTION}

The three principal destructive effects of a nuclear explosion are radiation, blast, and fire [1]. By far, the most poorly characterized of these effects is fire. Numerous fires are expected to result from both primary ignitions (due to the thermal radiation released by the explosion) and secondary ignitions (due to blast effects). The development and spread of mass fires (this term will be discussed below; for now, it may be considered as a large, high-energy-release rate fire) as a result of these ignitions significantly increases the destruction associated with a nuclear explosion.

Despite the critical role fire plays in the destructive power of a nuclear explosion, the physics responsible for fire behavior remains very poorly characterized and predictions of the fire effects of a nuclear explosion are very imprecise. The resulting uncertainty in the fire damage which will occur following a nuclear burst severely handicaps those who must predict the effects of these weapons as well as those who must plan for the response of our society in the event that such an explosion ever takes place. Very recently, it has been suggested that predictions of the number of civilian casualties resulting from a nuclear attack may be seriously underestimated by neglect of mass fire effects [2]

The importance of understanding fire effects has increased significantly with the recent suggestion that the smoke which would be released by the innumerable fires ignited by a general nuclear exchange might be dense enough to significantly block sunlight from reaching the earth's surface [3]. In some scenarios, the average temperature of the earth could be reduced significantly for a long period, the so-called "nuclear winter". Such an occurence would create severe hardship for all of mankind. Uncertainties concerning the amount of burning which takes place following a nuclear 
explosion is a major obstacle in assessing the possibility of the occurrence of a nuclear winter.

One of the major uncertainties associated with fire behavior is the role of wind. It is well known that the vast majority of "natural" forest and urban mass fires occur during periods of high winds. The presence of wind significantly increases the probability and rate of fire spread. There is also significant anecdotal evidence that fires can become so large that they can create their own meterological effects. The current physical

understanding of these fire processes is very poor, and for this reason it is nearly impossible to predict the behavior of a mass fire or even if a mass fire will develop for a given set of initial conditions.

Due to the large role wind plays in the development and behavior of mass fires and the lack of understanding of the physical processes which are responsible, the Defense Nuclear Agency requested the Center for Fire Research of the National Institute of Standards and Technology (formerly the National Bureau of Standards) to assess the need for a new research facility devoted to the study of wind effects on fire behavior, and, if such a facility is found to be necessary, to provide recommendations and general specifications for its construction. Since the greatest losses in economic, strategic, and human terms are expected to occur in urban areas, the study is concerned primarily with urban fire. As will become clear from subsequent discussions, the understanding of fire spread behavior in wildland environments is significantly advanced compared to that for cities.

The approach to the problem which has been taken is quite general. As a first step the current understanding of fire behavior following a nuclear burst has been assessed and, in particular, the role of wind effects has been emphasized. Mathematical models which have been developed to predict urban 
fires following a nuclear explosion have been reviewed to identify the physical mechanisms which are assumed to be responsible, and this information has been utilized to assess the validity of these models.

The current understanding of wind-aided fire spread and the air flows associated with mass fires has been reviewed. Past studies which have investigated wind effects on fire behavior have been summarized. Particular attention has been focused on experiments performed in wind tunnels. The important question of whether the understanding of large fires can be improved by the use of reduced-scale physical models is addressed. Previous wind tunnel facilities which have been developed for fire studies have been characterized.

Based on this analysis, it is concluded that the present understanding of wind effects on fire in general, and for urban fire in particular, is very poor. Predictions of the fire effects associated with a nuclear burst must be characterized as highly uncertain. Further, it is argued that the construction of a new wind tunnel for fire investigations will result in significant experimental findings which will substantially improve the understanding of wind effects on fire behavior and at the same time provide the information necessary for more accurate predictions of the destructive fire effects expected from a nuclear explosion. Recommendations are provided for the type of wind tunnel which should be constructed and general specifications are suggested.

The information which forms the basis for the recommendations has been obtained from numerous sources. An extensive literature review has been undertaken. Several bibliographies dealing with fire are available. Two of these [4,5] appeared during 1982 and provide extensive lists of relevant work. The availability of the extensive fire research archives of the Fire Research 
Information Services of the Center for Fire Research has been invaluable. The existing literature which is available for the areas discussed in this report is immense and the time period available was short. Even though the literature review is believed to be comprehensive, it is certain that some past research efforts have been overlooked and no claim is made that the pertinent literature has been completely reviewed.

Discussions with several investigators in fire research and related fields took place during the course of this investigation. These discussions have provided important insights into the problems of wind effects on fire. Site visits to two existing wind tunnel facilities used for fire research contributed greatly to the recommendations which are made concerning a new facility for such studies.

Finally, it must be emphasized that the conclusions which are reached in this report are those of a single author based on a detailed review of the field. It is recognized that many of these conclusions will be controversial and subject to differing interpretations. The only defense offered is that every effort consistent with the time frame available for the study has been made to provide a complete review of the field and to use this review as the basis for unbiased analysis.

\section{DEFINITIONS OF MASS FIRE, FIRE STORM, AND CONFLAGRATION}

The term "mass fire" is often utilized to describe the types of fires which are expected following the detonation of a nuclear weapon. No precise definition of a mass fire is possible. The discussion of the term provided by Countryman [6] in his manuscript on the phenomenon is one of the best available. He defines mass fires as those fires which exhibit particularly 
violent fire behavior. These behaviors are associated with fires which cover large areas and which have very high energy release rates.

Two general types of mass fires are recognized--fire storms and conflagrations. The behaviors of these fire events are different, but their characteristics do provide additional insight into the question of what constitutes a mass fire. Countryman's discussion [6] will again be followed. Fire storms form when a large number of ignitions occur simultaneously over a large area. The individual fires may coalesce into a single large fire which burns very intensely. Whether or not coalescence occurs, the percentage of the involved area which is burning is high. Fire storm development occurs only during periods of light ambient winds. There is a great deal of convective activity in these fires and extremely tall convective columns form. Flame heights are abnormally high. Very strong surface winds develop which have been reported as being of hurricane force. Large fire whirls are often observed. Destruction of exposed combustible materials in the affected area is complete. Due to the high inward wind speeds and low ambient winds the fire storm does not spread and the destruction is localized.

Conflagrations are large area fires which burn quite intensely, but have fire fronts which move very rapidly into unburned fuel. The depth of burning is often considerably less than the length of the fire front. These fires normally occur during periods of high ambient wind. Tall convection columns may or may not be observed. Whirlwinds and fire whirls are features of these fires, but are considerably more localized than a fire storm and last for shorter periods of time. Due to the rapid rate of spread, these fires often burn over very large areas. 


\section{URBAN MASS FIRE HISTORY}

There are numerous examples of large urban fires which have occurred from single ignition sources or from multiple ignition sources associated with natural events such as earthquakes. A short discussion of historical fires is given by Brode [7]. Among the most famous fires of this type are London (1666), Chicago (1871), and San Francisco (1906). Even though such large fires are relatively rare, history clearly shows that large, highly destructive urban fires do occur. Despite numerous examples of large city fires, it has not been possible to learn a great deal about fire behavior since very few accurate observations are recorded during the emergencies.

As recently as 1973, a mass fire destroyed eighteen blocks of Chelsea, MA. Lee and Granito [8] have provided a vivid description of the fire behaviox. It is ironic that an earlier fire in 1908 consumed very nearly the same portion of the city. This recent fire demonstrates that large areas of existing American cities remain vulnerable to mass fires.

The possibility of mass fires destroying large urban areas has increased dramatically in modern times with the advent of strategic wartime bombing of cities. During World War II many mass fires in German and Japanese cities were ignited by fire bombing using conventional weapons and in the Japanese cities of Hiroshima and Nagasaki by nuclear weapons. It is significant that fire was found to be much more efficient than conventional high explosives in destroying targets.

Brode has provided a short description of the effects of conventional bombing on German and Japanese cities [7]. One fire which has been the focus of a great deal of attention is the firestorm which occurred in Hamburg in July, 1943. This fire totally destroyed an area of $\approx 14 \mathrm{~km}^{2}$ and resulted in the death of $15 \%$ of the population in the affected area [9]. The firestorm 
developed approximately two hours after the attack and burned intensely for about four hours. The firestorm generated ground level winds of at least 20 $\mathrm{m} / \mathrm{s}$ with estimates as high as $50 \mathrm{~m} / \mathrm{s}$. The fire formed a single convective column which rose to an altitude of seven kilometers $[10,11]$. This fire did not propagate from its original location.

It is generally believed that a firestorm formed in Hiroshima following the detonation of a $14 \mathrm{kT}$ nuclear weapon [7]. The area destroyed by the blast and fire was on the order of $11 \mathrm{~km}^{2}$ [7]. The bombing of Nagasaki resulted in intense burning, but apparently a fire storm did not form. There was a moderate ambient wind and a conflagration developed [12] which halted only when it entered a valley with a low fuel loading.

This short discussion supports two very important conclusions. First, mass fires do develop in large urban areas and result in immense destruction and loss of life. Second, even relatively small nuclear explosions such as those over Hiroshima and Nagasaki are sufficient to cause mass fires.

\section{ROLE OF FIRE IN THE DESTRUCTIVE FORCE OF NUCLEAR WEAPONS}

With the advent of nuclear weapons near the end of World War II both military and civilian leaders were justifiably concerned with characterizing the effects of nuclear weapons on targets. Such information was not only required for the effective military use of and defense from these weapons, but it was also necessary to consider the effects of the use of such weapons on the civilian population and the socioeconomic structure of the country.

Immediately following the war large research efforts were initiated to characterize these weapon effects. The three primary destructive consequences of a nuclear explosion were recognized as blast damage resulting from the shock wave, radioactive fallout, and fires ignited by the intense thermal 
radiation emitted by the fireball and by blast effects. Initial efforts focused on the characterization of blast effects and radioactive fallout. These priorities were apparently dictated by military planners' fascination with the destructive potential of the nuclear blast shock wave and the justifiable emotional response of the general population to the possibility of radiation illness following exposure to radioactive fallout [5]. It is significant that fire is still considered by military planners as a "bonus effect" [13] and is not considered in strategic targeting. It is also true that blast and radiation effects are considerably easier to quantify than the effects to be expected from fire. Fire is the only one of the primary destructive effects which can become self-sustaining following a nuclear explosion.

In the late 1950 s researcher's became aware that the fire effects related to a nuclear explosion could be very significant. The 1963 review of Broido [14] discusses this point. Utilizing estimates for the effects of 1 Mt and 10 Mt blasts this author concludes that the areas of thermal ignition resulting from such detonations would be considerably larger than the areas sustaining significant blast damage and also larger than the downwind areas subject to significant radioactive fallout. Other analyses support this conclusion [15]. Broido also notes that, given the proper conditions, fires can propagate, and the possibility exists of fire spreading to originally unignited regions of significantly greater area than the area originally ignited by a nuclear burst. Broido concludes [14] "thermal radiation effects, which for so long played second fiddle first to blast effects and then to fallout, are belatedly being recognized as capable of producing more damage for greater distances and with greater production of casualties than any other effect of a nuclear detonation." 
It should be mentioned that Broido made an additional observation [14] which has apparently not received a great deal of attention. He described experiments which indicated that the presence of a large fire could significantly alter the fallout pattern resulting from a nuclear explosion. Synergistic effects of this type have not been widely discussed in the literature.

Despite the realization over thirty years ago that fires resulting from a nuclear detonation are likely to be highly destructive, Reitter et al. [5] concluded as recently as 1982 that "the thermal radiation and consequent fire threat are unique features of nuclear weapons and have perhaps not received the appropriate amount of attention." These authors note that fire effects are generally not considered in strategic targeting and that all fire damage is considered to be a collateral effect.

Section 7 summarizes research efforts which have been designed to understand and predict the behavior of fires resulting from nuclear explosions. However, it is clear from the discussion above that such fires are capable of contributing significantly and perhaps decisively to the death, injury, and property damage resulting from a nuclear explosion. At the same time, it is also obvious that the role of fire is often underestimated, and that fire is the most poorly characterized and difficult to predict effect of such a detonation.

\section{BRIEF HISTORY OF FIRE RESEARCH IN THE UNITED STATES}

Before summarizing past research into fire behavior following nuclear explosions and on flame spread in general, it is worthwhile to briefly consider the historical development of fire research in the United States. Before the late 1940 s some isolated examples of fire research are available, 
but no discipline known as fire research was recognized. Due primarily to the devastating effects of fire bombing in World War II and the large and continuous losses resulting from forest and building fires in the nation, significant interest in improving the understanding of fire developed. This movement received additional impetus with the realization of the immense fire problem associated with nuclear detonations.

By the late 1950s this interest had grown to such an extent that fire researchers began to organize, and a national program on fire research was proposed [16]. This proposal emphasized the large gaps in the understanding of fire behavior and the need for a large, concerted program to improve fundamental knowledge.

During the 1960s fire research efforts increased significantly. A large fraction of this research effort was funded by agencies concerned about the mass fire effects of nuclear weapons. As a result of this concern, a "crash" program designed to improve the understanding of this problem was developed. At the same time, significant programs on forest fires and building fires were continued along with research programs in more specific areas. The combined effort of all of these programs was a significant expenditure of resources and personnel.

The programs on mass fire ranged from theoretical efforts and the use of small physical models to attempts to create large scale fires in the Flambeau tests [17]. Much of the emphasis was on delineating the conditions necessary for the formation of firestorms and characterizing their properties. During this period initial attempts were begun to create models which were capable of predicting fire ignitions in urban environments by a nuclear burst [18] and also the damage resulting from subsequent growth and spread of the nascent fires (e.g., [19-21]). 
Near the end of the 1960s the crash program in mass fires began to wind down and funding levels were greatly reduced in this area [22]. Research efforts during the two past decades have concentrated on improving fire start and spread methodologies developed during the earlier program and, with a few notable exceptions (e.g., [23]), there has been very little experimental effort to improve the understanding of the physical mechanisms responsible for fire spread and mass fire behavior. This is unfortunate since, as will be discussed in later sections, our present understanding of the underlying physics of fire in the urban environment is so poor that this reviewer has concluded that existing models which are designed to predict the growth and behavior of urban mass fires must be highly uncertain.

The development of fire research in the other two major areas of interest in the United States--wildland fires and building fires-occurred differently than the program on large urban fires. Wildland and building fires occur with a depressing regularity and the annual financial and human losses each year are staggering. Primarily for this reason, it has been possible to maintain modest, but continuous, research efforts on the behaviors of these fires since the early 1960s. Federal efforts on wildland fire have been centered in the Forest Service of the Department of Agriculture and those on building fires in the Center for Fire Research of the National Institute of Standards and Technology.

Fundamental research has been incorporated into both efforts and, as a result, the understanding of the complex physics and chemistry responsible for fire behavior in wildland and building fires has been substantially improved during the past two decades. Even though the current understanding is far from complete, models of fire growth and behavior based on the physics and 
chemistry of fire behavior have been developed and tested for both wildland $[24,25]$ and building fires $[26,27]$.

The advances made in the understanding and modeling of wildland and building fires suggest that long-term programs which incorporate fundamental studies designed to delineate the underlying physical behaviors can significantly improve predictive capabilities for fire behavior. It can be argued that the complex nature of fire requires that systematic, long-term research programs designed to provide incremental increases in understanding be utilized instead of massive, short-term efforts which attempt to solve the problem quickly.

\section{COMMENT ON JAPANESE RESEARCH ON URBAN FIRE}

It was implied above that one reason it has been impossible to maintain a long-term experimental research program on urban mass fires in the United States is the relatively infrequent occurrence of these events. The research effort on this topic in Japan provides an interesting contrast. Despite the fact that a large fraction of the relevant literature is in Japanese and therefore not available to this researcher, it became apparent during the literature review that a sustained research effort on large urban fires has occurred during the past several decades. Examples of this work range from papers dealing with urban fire spread $[28,29]$, to a handbook to aid in the design of cities to minimize fire damage [30], to experimental measurements of air flows around burning buildings [31], to very important papers on the possibility of utilizing reduced-scale models to predict the behaviors of mass fires $[32,33]$.

Very few references are found in the English literature to the Japanese work on urban mass fires. Perhaps the 1963 report of Chandler et al. [34] is 
the most useful. This twenty-five year old report indicates clearly that an active research program on urban fire spread and mass fire was underway in Japan at that time and the reports cited above suggest this effort has continued until the present. Chandler et al. mention that the Japanese efforts are based on the possibility of mass fires resulting from earthquakes. They note that the use of nuclear weapons is so repugnant to the Japanese public that there is little support for research on urban fires as the result of nuclear detonations.

Based on the limited research published in or translated into English, it appears as if the Japanese understanding of urban fire may be superior to that of United States researchers and that there is likely to be a great deal of information which can be utilized to improve and test models for urban fire development and spread. This should not be surprising in light of the continuous and long-term efforts of Japanese researchers in this area.

\section{PREVIOUS RESEARCH ON AND MODELS FOR PREDICTING URBAN MASS FIRES AS A RESULT OF NUCLEAR DETONATION}

There has been an immense amount of research effort devoted to the development of predictive models for fire damage in urban environments resulting from nuclear detonations. Extensive recent bibliographies are available in the works of Groce and Mckay [4] and Reitter et al. [5]. As Reitter et al. have noted [5], work in this area "has tended to be published only in contract reports, rather than in the technical literature; such reports seldom provide an overview of the problem or references to work by those outside of the civil defense community." This lack of a distillation of material, peer review, and critical analysis is an obstacle to summarizing and assessing the current state of knowledge concerning fire development and spread following a nuclear explosion. Another deleterious effect of the 
approach to research in this area is that there has been significant duplication of efforts and neglect of earlier research.

A complete review of the relevant literature is beyond the scope of the present work. Only a brief summary of past work is provided. The goal is to identify assumptions concerning the underlying physical mechanisms which are utilized in models of urban fire behavior and to indicate aspects, particularly with regard to wind effects, where uncertainties exist. Readers are referred to the references cited as well as those 1 isted in recent bibliographies [4,5] for details.

Renner et al. [15] have provided an excellent overview of the unique and complex problems which are faced in the development of models for urban fire behavior. This complexity is obvious by considering the general flow diagrams provided by Renner et al. [15] (reproduced here as Figures 1 and 2) for assessing urban fire vulnerability. Such an assessment requires a quantification of all of the various steps listed in these figures. It should be obvious that there are uncertainties associated with each and that the computational effort required for realistic treatment is immense.

The two general approaches for treating the behavior of urban fire are typified by Figures 1 and 2. These are known as "stochastic" and "deterministic". A stochastic approach attempts to predict the probable behavior based on averaged conditions and estimates of behavior derived from past experience or experiment. This approach is useful for dealing with processes having a large number of variables which are difficult to specify or are expected to vary with time. A deterministic approach attempts to specify the conditions with the greatest detail possible and to consider the direct effects of a particular event. Assuming that initial conditions are known and that the physical mechanisms responsible for the event are sufficiently well 


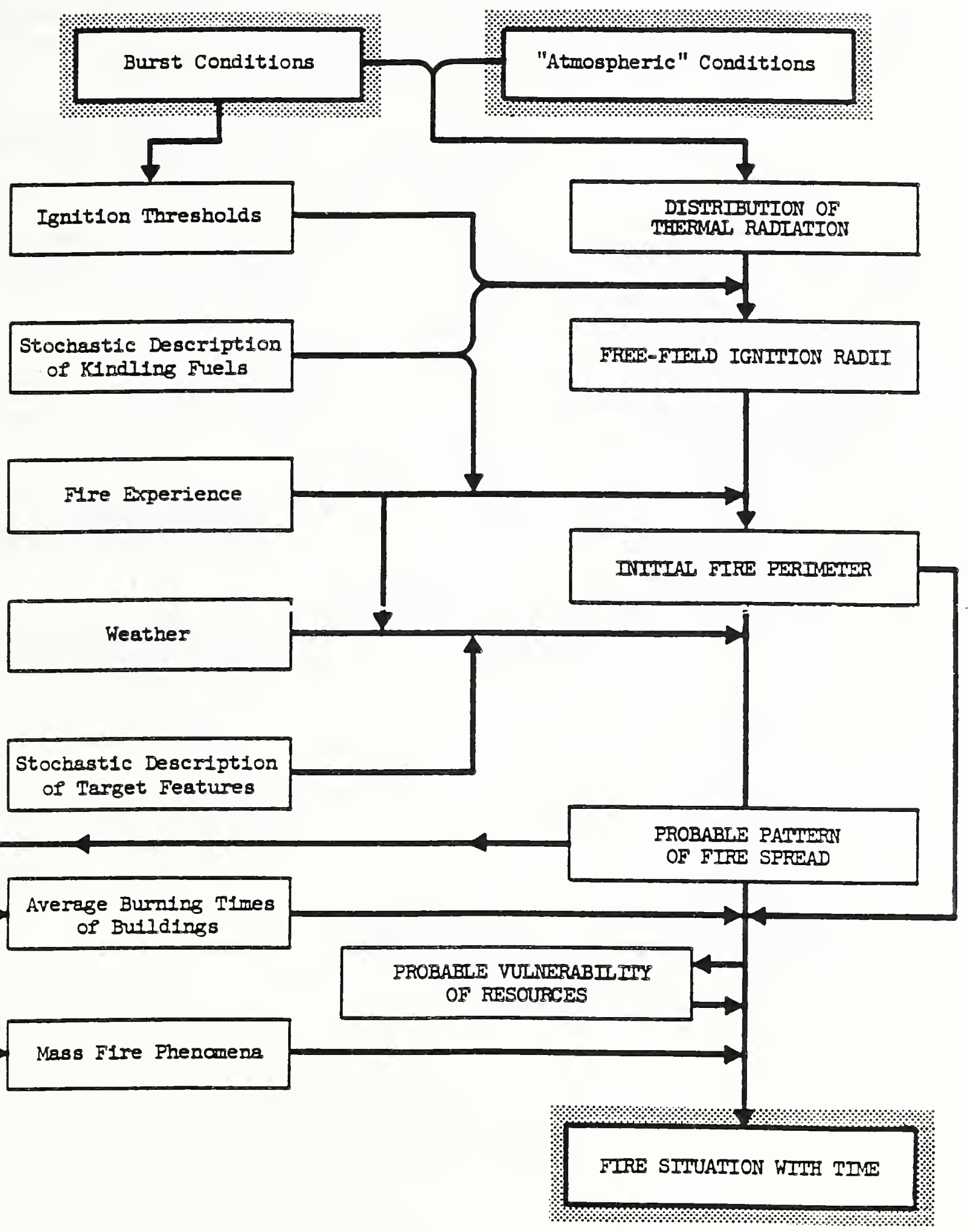

Figure 1. Example of stochastic approach to assessment studies of urban fire vulnerability. Figure reproduced from [15]. 


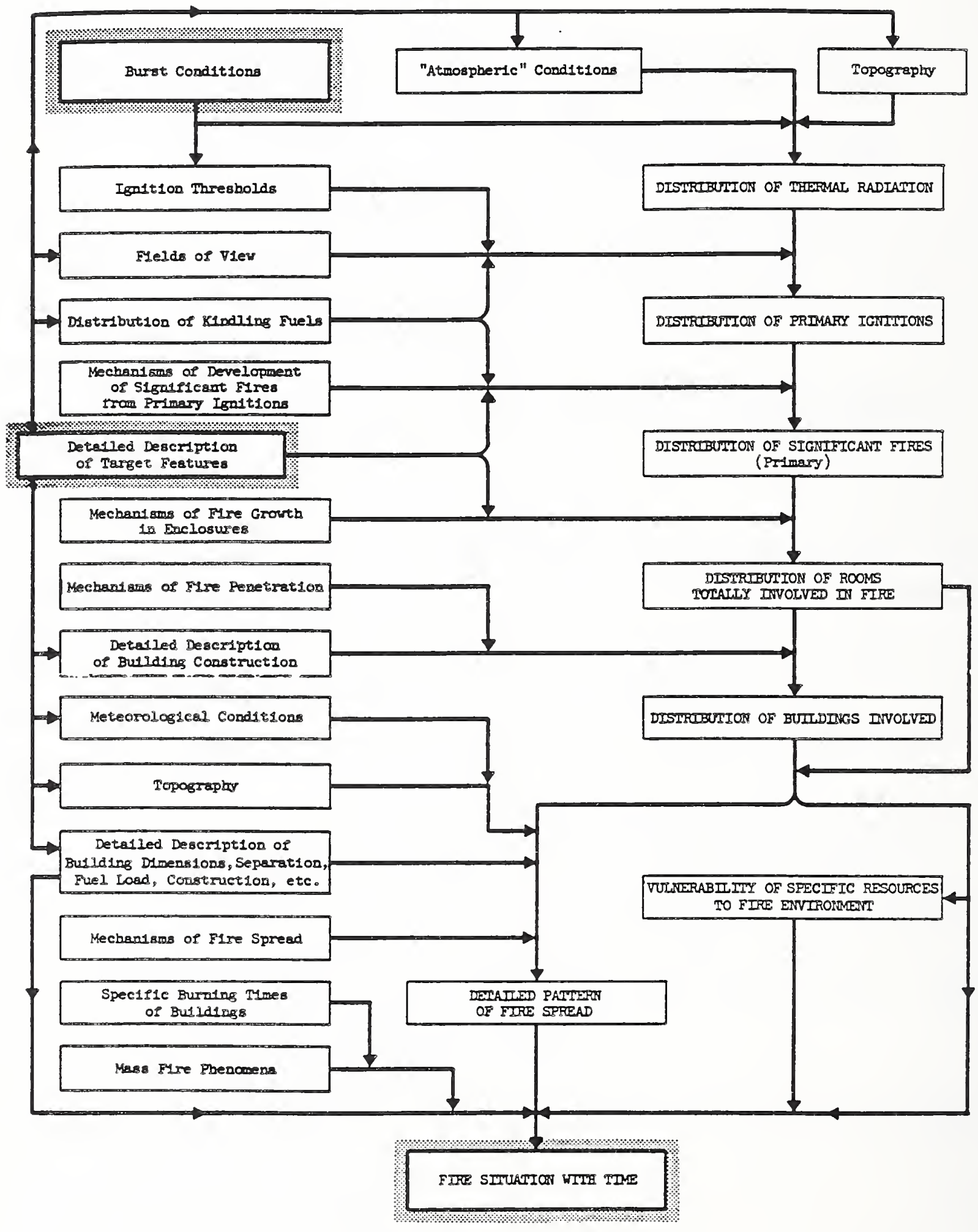

Figure 2. Example of deterministic approach to assessment studies of urban fire vulnerability. Figure reproduced from [15]. 
understood, a deterministic approach will provide a much more accurate, prediction of a particular event than a stochastic model.

There are several assumptions which are utilized in treatments of initial fire development following a nuclear detonation. The physical mechanisms underlying these assumptions are generally believed to be correct. "An important source of fire starts is the thermal radiation emitted by the fireball. Fires which are initiated in this way are referred to as primary fires. Other fires may be started as the result of the blast wave (secondary fire starts) or other reasons. It has been argued by some that primary fire starts predominate [15], but others [13] have suggested that secondary fire starts can significantly increase the damage radius. Fires due to the thermal pulse result from ignitions of kindling fuels such as newspaper, curtains, or some fabrics. Early research had demonstrated that thick fuels do not sustain combustion when irradiated by short thermal pulses [1,5].

It is customary to divide calculations of fire starts, growth, and spread into several different phases. For our purposes these phases can be listed as: 1) Determine the temporal and spatial distribution of thermal radiation resulting from a nuclear burst, 2) Calculate the probability of fire starts in kindling fuels, 3) Predict the development of fires in buildings where ignitions occur, 4) Predict fire spread from initially burning buildings to unignited structures, 5) Determine whether or not a mass fire will develop and, if so, predict its behavior.

\subsection{Spatial and Temporal Distribution of Thermal Radiation}

The distribution of thermal radiation from a nuclear detonation is a complex function of yield, detonation height, atmospheric scattering and transmission, and meterological conditions [1,35]. The general consensus is 
that the physics which determine these processes is well characterized and that the thermal energy as a function of distance can be predicted if initial conditions are well specified [5].

\subsection{Distribution of Significant Fire Starts in an Urban Environment}

In order to calculate the probability of fire starts in a building it is not only necessary to know whether the intensity of thermal radiation for a given distance from ground zero is sufficient to induce flames in kindling fuels, but also whether or not thin fuels are exposed to the radiation. (Note that the possible existence of the ENCORE effect, immediate flashover of a room due to trapped thermal radiation $[13,36]$, is not considered in this discussion.) Since the important thin fuels are normally inside buildings, it is necessary to determine whether these fuels will be exposed to sufficient thermal energy to result in ignition. The physics is straightforward but very difficult to implement. For a deterministic analysis it is necessary to calculate the angle of view of the fireball for every opening in an enclosure (note this includes blocking and shading effects due to buildings and vegetation) and to also consider whether scattered radiation is important. Effects of window glass and coverings must be included. Once the thermal radiation levels inside the enclosure have been estimated it is possible to identify kindling fuels which receive enough thermal energy to ignite. The thermal energy required to ignite such fuels has been extensively studied and is reasonably well characterized for cellulosic materials, but there are some uncertainties for recently developed polymers [5].

As should be obvious, it is nearly impossible to obtain the detailed information required for a deterministic calculation of fire starts over the several tens of square kilometers of an urban environment which would be 
thermally irradiated by a nuclear detonation [37]. At some level it is necessary to utilize a stochastic analysis in which types of buildings, window orientations, furnishings, etc. are assumed to have some distribution and the resulting probability of ignition of thin fuels for a given building calculated. These probabilities are often derived from surveys of actual cities (e.g., [38-40]), but it should be noted that no extensive surveys have been performed since the 1960s.

Once the distribution of ignited kindling fuels has been calculated, it is necessary to estimate which fires will grow and become large enough to destroy the building of origin. This will depend on the spatial relationships between the kindling fuel and other fuel sources in the room. In some cases the ignited kindling fuel will burn out before fire growth begins. In other cases the kindling will ignite more substantial fuel sources and the fire intensity will increase until it is sufficient to result in flashover. Once the fire becomes large enough to flashover a room, it is usually assumed the entire structure will be lost.

At least four models have been developed to calculate initial fire starts resulting from a nuclear explosion. These are referred to as the URS [41], SSI [42], IITRI [43], and NASL [44] models by Miller et al. [18] who have provided a critical evaluation of these models and reported extensive comparisons of calculational results. The most instructive comparison is that for a test calculation using three of the models (URS, SSI, and IITRI) for an assumed nuclear burst of 5 Mt over San Jose. Calculated probabilities of fire starts as a function of distance from the burst are reported [18]. There are significant differences between the curves which indicate that uncertainties exist in the prediction of fire start distributions. 


\subsection{Fire Spread in the Urban Environment Following a Nuclear Detonation}

The detonation of a nuclear device will result in the development of a large number of fires in a band surrounding ground zero. It is generally believed that for "normal" transmission of the atmosphere and for an airburst of greater than 1 Mt yield, the range of initial ignitions will extend a considerable distance beyond the range of severe blast damage $[14,15]$. Following the attack one might therefore expect (moving outward from ground zero):

1) A central core which is totally destroyed,

2) A severely blast-damaged ring in which an extremely high number of ignitions have occurred, and the fuel bed is a continuous, inhomogeneous mixture of combustible and incombustible materials.

3) A blast-damaged ring in which an extremely high number of ignitions have occurred, and for which the fuel is localized spatially as highly-damaged buildings and piles of debris.

4) A ring of lightly-damaged buildings where a high density of ignitions has occurred, and

5) An outer ring which is relatively intact and meets existing fire codes where the number of fire starts falls off with increasing distance from ground zero.

The total damage resulting from fire will be determined by the total number of fire ignitions and subsequent fire spread within regions 3,4, and 5 and possible fire spread beyond region 5 into areas which were initially unaffected by the blast and fireball.

Due to large variations in building density and land uses found in urban areas it is very difficult to predict urban fire spread. Building types, building separations, and potential firebreaks such as parks or rivers are highly variable properties of cities. One need only contrast the variations in fire spread behavior expected for skyscrapers in a business center of a large city, a highly industrialized area, or a residential area consisting of 
single family homes or townhouses to appreciate the complexities involved.

Variations in cities can also affect the interaction of blast effects and fire behavior. Consider these examples. It is likely that a strong shock wave will collapse a skyscraper with the result that much of the combustible fuel within such a structure will be buried beneath incombustible rubble and will therefore be unavailable for burning. In contrast, blast effects in a residential area of single family homes would be expected to open up and scatter the combustible contents contained within and result in faster fire spread.

There is often a tendency for modelers to deal with the densely built up areas of cities due to the large fuel loadings of these areas and the importance of the activities in these areas to the economies and infrastructure of the city. An example of early work of this type is the paper by Stanbury [38]. On the other hand, MacFarlane notes that "in most cities single unit dwellings preponderate over all other types of buildings, monumental structures, or slums" [45]. Modern American cities tend to develop as a central downtown surrounded by large suburban tracts which may be interspersed with smaller urban areas. It seems clear that studies which deal with urban fire spread over large areas must contend with the wide variations which are found in urban regions and that the most important buildings in terms of total area of coverage will be individual dwellings.

Despite the complexities and uncertainties, there has been a great deal of effort to develop models for fire spread in urban areas following multiple ignitions. This effort is justified by the immense fire damage which is possible due to a nuclear detonation. Modeling efforts have ranged from purely stochastic efforts to highly deterministic calculations which incorporate physical mechanisms for fire spread. 


\subsubsection{Stochastic Modeling of Urban Fire Spread}

Stochastic modeling is hampered by a lack of information concerning fire spread probabilities. As was noted earlier, neither historical or test data are available which allow fire spread rates to be accurately estimated for urban fires under varying conditions. For this reason, stochastic modeling serves primarily to identify possibly important parameters. Several examples of this type of model will be mentioned.

Sometimes it is simply assumed that a certain fraction of buildings adjacent to initially ignited houses will be consumed. The number which is often used is that each fire start will result in the destruction of one additional building (e.g., [38]). This estimate is based on bombing results of German cities during World War II. MacFarlane [45] argues that this estimate is too low for Canada and recommends that values of four buildings lost per initial ignition be utilized for structures built prior to 1948 and three per initial start for buildings constructed after 1948. Based upon the large number of ignitions expected from a nuclear detonation, it is clear that a lack of accurate estimates concerning the number of unignited buildings consumed will introduce a great deal of uncertainty into estimates of fire damage .

Models have also been developed which treat fire spread as a purely probabilistic event. An example is the work of Albini and Rand [46]. These workers used their analysis along with a model of fire spread based on flame radiation to derive an expression for the minimum ratio of height of building to building separation which is required for fire spread. Their analysis was then extended to predict the fraction of several cities (Philadelphia, Baltimore, Washington, Cleveland, and San Francisco) which could be burned by 
a spreading fire. Other examples of models based on stochastic treatments are $[19,20,28,47]$

Related treatments of fire spread have attempted to handle the complexities of fire spread using physical analogies. An example of this type of approach is the work of Reitter [48,49] who suggests using heat transfer models as analogies for fire spread.

\subsubsection{Deterministic Modeling of Urban Fire Spread}

Several models [41-43] have been developed which are designed to predict fire spread probabilities and rates of spread for fires in urban environments. Note that these models are actually submodels of systems designed to predict fire starts (SSI, URS, and IITRI models discussed earlier) and subsequent fire spread as the result of a nuclear detonation. Since the number of buildings affected by a nuclear explosion is quite large, these models are generally employed to generate fire spread behavior for a tract of buildings having a common type and distribution, and the result is then employed as the input into a more stochastic calculation. All three models ignore the effects of blast damage and are therefore strictly applicable only for distances from ground zero at which blast effects are unimportant.

Weisbecker and Lee [21] have provided a summary of these models along with a critical appraisal. All of the models assume that any and all fires are isolated in individual buildings and that there are no modifications of fire behavior as a result of interactions between fires in different buildings. The primary mechanism for fire propagation from one building to another is postulated to be heating of unignited structures by flame radiation from adjacent flaming structures, but the IITRI model [43] contains a submodel for firebrand flame spread which Weisbecker and Lee [21] characterize as 
"speculative at best" and the URS report [41] attempts to estimate the relative importance of firebrand effects compared to radiation transfer.

For the purposes of this report it is important to consider how these models handle wind effects. The URS model [41] does not include any wind effects. The SSI model [42] treats wind effects by allowing for fire spread distance probabilities which vary for three different ambient wind ranges of $0<U_{0}<3.6 \mathrm{~m} / \mathrm{s}, 3.6 \mathrm{~m} / \mathrm{s}<U_{0}<7.2 \mathrm{~m} / \mathrm{s}$, and $U_{0}>7.2 \mathrm{~m} / \mathrm{s}$. The approach is not based on a physical analysis. Wind effects are not incorporated into the submodel for flame radiation transfer in the IITRI model, and the influence of wind on fire spread is only considered in the firebrand submodel.

In the absence of firebrands, flame propagation to an unignited building is only possible when the nearby flaming structure is fully involved and thermal radiation levels are high enough to induce ignition. For this reason, fire spread tends to occur through a series of steps. Fire develops in a building which has been ignited either by the nuclear fireball or by a nearby fully involved building. Eventually the fire grows large enough to involve the entire structure, and fire spread to adjacent structures due to flame radiation becomes feasible. Fire spread takes places if a suitable unignited building is situated nearby. Since approximately twenty to sixty minutes is required for a building fire to become fully involved and a fully involved building burns for about one hour, the fire spread rate tends to be rather slow.

The most important components of the three models are the submodels utilized to estimate the thermal radiation per unit area, the effective source area for a particular burning building, and the characteristics of the receiving building. Weisbecker and Lee [21] point out that the thermal radiation per unit of burning area which is assumed in each model differs. 
The IITRI model uses radiation intensities falling in the range of 2 to 4

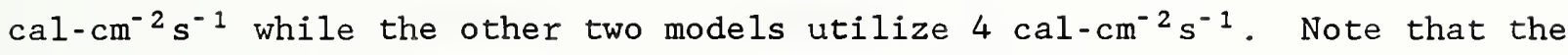
value of $4 \mathrm{cal}-\mathrm{cm}^{-2} \mathrm{~s}^{-1}$ can be traced back to the work of Law [50]. Note that maximum radiation intensities of less than $4 \mathrm{cal}-\mathrm{cm}^{-2} \mathrm{~s}^{-1}$ were measured by Tsukagoshi [51] in recent full-scale fire tests. The IITRI and URS models assume ignition of the receiver building occurs if the radiation level exceeds $0.4 \mathrm{cal}-\mathrm{cm}^{-2} \mathrm{~s}^{-1}$. A more complicated submodel is employed in the SSI development.

Due primarily to the differences in submodels, the three models yield very different estimates for the area burned following a simulated attack on San Jose, CA. Weisbecker and Lee [21] find that the fire spread percentages predicted by the URS model are five times larger than those for the same burst scenario predicted by the SSI model. The results for the IITRI model were similar to those for the SSI model, but the effects of including a firebrand submodel could not be separated.

In more recent work, Reitter et al. [52] have exercised the IITRI model extensively. Calculations were done for a hypothetical uniform city and for the cities of San Jose, CA and Detroit, MI as they existed in 1968. As part of their study, values of various input parameters were varied and the sensitivity of the total area calculated to be consumed by fire to changes in the values of the parameters assessed. The possible importance of fire spread mechanisms which are omitted from the analysis are discussed briefly.

It should be noted that an extensive experimental program was carried out at IITRI which was designed to address many of the questions raised concerning these models. Experiments were performed to characterize the formation of firebrands by various roofing materials [53] and the ability of firebrands to ignite various materials [54]. Many full-scale burns of structures [55,56] 
were carried out in order to improve the knowledge of fire growth, thermal radiation production, and firebrand generation and transport by such fires. Apparently, these research findings were not utilized to improve the IITRI fire spread model.

Weisbecker and Lee [21] point out that fire spread occurs through a heating process for which the possible mechanisms are (1) direct flame contact, (2) convective heating, (3) radiative heating, and (4) firebrand contact. They conclude that the models discussed here are "virtually limited to the radiation fire spread mechanisms, but both the IITRI and URS models included speculative treatments of fire spread by firebrands." For future reference it is important to emphasize that wind effects are virtually ignored, no fire interactions are allowed, fire spread is assumed to occur only in undamaged areas, and no provisions are included for treating mass fire effects.

\subsection{Mass Fire Behavior}

As was noted in Section 2, no precise specification is possible for what constitutes a mass fire, but observations of actual fires have shown repeatedly that large, intense fires display behaviors which are different and more deadly than less vigorous fires. Important effects which are often cited are high winds and temperatures, increased burning rates, formation of fire whirls, tall convective plumes, and, in the case of conflagrations, much higher fire spread rates.

Due to the possibility of the ignition of a large number of fires following the detonation of a nuclear bomb in the vicinity of an urban enviromment, there has been a justifiable concern about the development of mass fires. Unfortunately, the understanding of these fires is so incomplete 
that mass fire behavior has not been included in the models for fire starts and spread following a nuclear detonation discussed in Section 7.3.2. At the same time, there has been a great deal of primarily theoretical, but also some experimental, research on mass fire behavior.

The large majority of research has focused on the characteristics and conditions required for the formation of firestorms. This interest arose primarily from the realization that the occurrence of fire storms during World War II (in particular, the Hamburg firestorm of 1943) resulted in high levels of damage and loss of life. There has been very little effort to improve the understanding of conflagrations despite the fact that this type of mass fire provides a mechanism for significantly extending the fire damage area resulting from a nuclear explosion and may be very important in fire spread. This imbalance in research efforts was noted by Reitter et al. [22] in their assessment of research priorities for dealing with blast and fire effects of nuclear weapons on urban areas. These authors "give a higher priority to conflagrations than firestorms because virtually nothing has been done for conflagrations and because the rapid spread of conflagrations may give them greater destructive power than stationary firestorms."

\subsubsection{Criteria For the Formation of Fire Storms}

The conditions necessary for firestorm formation have been the subject of speculation and research for decades. Based on an analysis of expected fire starts from hypothesized nuclear detonations over Liverpool and Birmingham along with the conditions which led to the formation of the Hamburg firestorm, Stanbury [38] concluded "that a nuclear explosion could not possibly produce a firestorm." The occurrence of a firestorm at Hiroshima following the detonation of a relatively small, by today's standards, nuclear device 
certainly brings this conclusion into question and the large number of research reports on firestorms indicates that most researchers feel that firestorms are possible following such explosions.

Baldwin [9] has provided an useful introduction to firestorms. The earlier report by Rodden et al. [57] also contains an excellent discussion. The latter authors [57] provide estimates of the minimum conditions required for the formation of firestorms. These include a fuel loading equal to or greater than $3.9 \mathrm{~g} / \mathrm{cm}^{2}$, more than 508 of structures in an area greater than $1.3 \mathrm{~km}^{2}$ initially ignited, and unstable atmospheric conditions. These estimates are based on experiences during World War II.

Carrier and coworkers $[10,11]$ have provided a more fundamental analysis of the conditions required for firestorm formation. These authors propose that firestorms are actually mesocyclones (a rotating local storm) which result from the coalescence of the plumes formed by individually burning fires into a single, strong convective column. The entrainment into this column of ambient air having vorticity leads to a "spin-up" of the column and the entire column begins to rotate. The observation of strong radially-inward winds at the surface below the column are consistent with the existence of a rotating convection column. Note that similar behaviors have been observed in very smal1 fires by Emmons and Ying [58], Byram and Martin [59], and in the recent modeling studies of Soma and Saito [33].

Based on their analysis, Carrier et al. $[10,11]$ conclude that the necessary conditions for firestorm formation are a localized heat release on the order of $10^{19}$ ergs/s for a period of 2-3 hours, a preexisting weak vortex near ground level corresponding to $4 \mathrm{~m} / \mathrm{s}$ at a radius of $8 \mathrm{~km}$, absence of a strong ambient crosswind, and a very dry-adiabatic lapse rate in the lowest few kilometers of the atmosphere. 
In a series of papers discussed in the next section, Small and coworkers [7,60-62] argue that the high winds associated with firestorms can be understood by modeling a strongly buoyant plume and it is not necessary to invoke a spin up of the entire convective column. An analysis by Weihs and Smal1 [63] has suggested, in fact, that the likelihood of spin up of the large convective column of a mass fire is unlikely.

Some additional insight is obtained by experimental results reported by Church et al. [64]. These authors observed that for two of many test burns of the Météotron the entire thermal plume above the fire began to rotate. The Météotron consists of 105 fuel oil burners, covers an area of $0.02 \mathrm{~km}^{2}$, and has a power output of $1000 \mathrm{MW}$. Rotation of the entire fire plume is observed only when the atmosphere is very unstable and winds are calm. Note that the orientation of the individual burners may introduce vorticity into air entering the convective column.

Palmer [65] also discusses the behavior of large experimental fires. Observations and measurements suggest that full rotation of the thermal plume is observed in some cases. This author states that "it seems assured that the firestorm phenomena is associated with the isolated single line vortex."

The discussion above demonstrates that a great deal of controversy exists concerning the mechanisms responsible for firestorm formation. That this is true forty-five years after the Hamburg firestorm and more than three decades after serious and sustained efforts began to understand the conditions required for the formation of these devastating events is a testament to the complexity of the mass fire problem. 


\subsubsection{Modeling of Mass Fire Behavior}

Initial attempts to model the winds associated with a firestorm were based on the weak plume techniques pioneered by Morton, Taylor, and Turner [66]. However, it quickly became apparent that this model did not predict the high winds observed during firestorms. Corlett [67] provides a clear discussion of this point. The idea that a rapidly rotating convective column occurs above firestorms was introduced as a possible means for overcoming this limitation [68].

Work by Smith et al. [69] indicated that the deficiency of the weak buoyant plume theories was the neglect of dynamic pressure effects. Carrier et al. [70] have incorporated these effects into calculations of the behaviors of large thermal plumes. Small and coworkers [7,60-62] have considered pressure effects, but they have also included the role of large density variations in their model. Based on their view of mass fire, they have developed a calculational procedure which focuses on the hydrothermodynamic processes occurring in and near the combustion zone. Note that the fire is treated as a single large heat source and the details of the fire structure are ignored. The results of their analysis indicate that strong inward surface winds are predicted with velocities increasing from roughly $15 \mathrm{~m} / \mathrm{s}$ for a fire of $10 \mathrm{~km}$ diameter and leveling off at $\approx 40 \mathrm{~m} / \mathrm{s}$ for fires greater than $20 \mathrm{~km}$ in diameter [62].

Small et al. have attempted to calculate results for past test fires. A time-dependent simulation of Flambeau fire 460-7-66 [71] is described in [62]. Excellent agreement between calculated and observed velocities is found.

Recently, Baum and McCaffrey [72] have reported a different type of analysis of the air flows resulting from mass fires. The theoretical development considers the kinematic relationships between the velocity, 
vorticity, and heat release fields of unconfined fires. In contrast with earlier investigations, this model treats the individual fire plumes of a large area fire and does not assume a single large convective plume or uniform heat release. The vorticity behavior of an individual plume is derived from an earlier plume correlation reported by McCaffrey [69]. Comparisons reported in the paper suggest the derived correlations are valid over a size range of four orders of magnitude.

Large fires such as that formed by the burning of a large number of individual structures are treated as having approximately the same heat release and vorticity behavior as isolated plumes. The velocity field is then calculated as a composite of the individual fires.

In order to test this model, calculations were made for a series of randomly distributed fires of varying area having a heat release rate of $3 \times 10^{5} \mathrm{~W} / \mathrm{m}^{2}$. Such a calculation for 100 fires distributed over an area of one $\mathrm{km}^{2}$ and having a total heat release rate of $4.7 \mathrm{X} 10^{10} \mathrm{~W}$ is reported. Peak induced-wind velocities are on the order of $10 \mathrm{~m} / \mathrm{s}$. The authors compare this result with an experimental fire of Adams et al. [74] and find encouraging agreement. When a line of five $1 \mathrm{~km}^{2}$ fires is considered by the calculational procedure, the largest induced-wind velocity increases to $50 \mathrm{~m} / \mathrm{s}$ [72].

It is interesting to compare the predicted fall off of wind velocity with distance from the fire for the models of Small et al [62] and Baum and McCaffrey [72]. For a $10 \mathrm{~km}$ radius Small et al. [62] find that the surface winds are on the order of $50 \mathrm{~m} / \mathrm{s}$ at the fire edge and fall off rapidly to the order of $10 \mathrm{~m} / \mathrm{s}$ at $20 \mathrm{~km}$ and approach zero by $35 \mathrm{~km}$. On the other hand, the analysis of Baum and McCaffrey [75] indicates that velocity falls off as the inverse of the distance from the fire to the $1 / 3$ power. This suggests that 
relatively high induced-wind velocities will extend out considerably further than predicted by the model of Small et al. [7,60-62]. In either case, significant induced, radially-inward winds are predicted to extend well beyond the fire edge. This conclusion has significance for fire spread behavior following a nuclear attack as is discussed in Section 13.

Sanderlin et al. [76] have reported the development of a computer model designed to predict fire spread during a mass fire. The smallest area unit employed is a city block. The physical mechanisms utilized are very crude, but models are included for firebrand transport and ignition and contiguous spread due to convection and flame radiation. Unlike the fire spread models discussed in Section 7.3.2, convection is assumed to be the dominant mechanism for local fire spread in the presence of wind.

Examples of outputs are provided [76] for a variety of initial fire start distributions and ambient wind speeds. Due to the crudeness of the physical models employed, the fire spread behavior is not expected to be highly realistic. On the other hand, this work is significant because it develops a framework for treating many of the complex physical phenomena which are believed to be important in mass fires.

\subsubsection{Experimental Investigations of Mass Fire Behavior}

Since the late 1950 s there have been several ambitious efforts to generate fire storms and investigate the behavior of stationary mass fires. References $[17,64,65,74,77-81]$ describe some of these experiments. These tests are quite useful because they have provided a great deal of qualitative information concerning large fires. For instance, the formation of fire whirls is clearly demonstrated by these tests. 
Unfortunately, the quantitative information which has been generated is not very extensive and has not been fully analyzed [5]. For this reason, except for general comparisons, the results of these costly experiments have not been widely utilized for comparing predictions of mass burning models with actual experiments.

\section{PREVIOUS EXPERIMENTAL AND THEORETICAL INVESTIGATIONS OF FIRE SPREAD}

Understanding the mechanisms of fire spread has been one of the most difficult problems faced by fire scientists. Such an understanding is very important since the spread of fire is probably the most important characteristic of unwanted fires determining the destructiveness of the phenomenon. There are innumerable references available which deal with fire spread. The extensive literature on fire spread across individual solid surfaces will not be reviewed since, even though such fire spread is very important in the growth of fires in buildings, it is not particularly relevant for understanding fire spread between buildings. It is the fire spread between individual fuel elements which will determine fire spread behavior in urban environments. Examples of fuel beds which are considered to be relevant are wood cribs, random packing of light fuels, and systematic arrangements of fuel elements. Very few studies have been identified where fire spread between buildings has been investigated.

In the discussion which follows some basic ideas concerning fire spread are introduced. The experimental findings concerning fire spread in fuel beds which are deemed to be relevant to the topic of this report are then summarized. Fire spread mechanisms are often found to change depending on whether or not an ambient wind is present. The discussion will be broken down into sections on fires burning in the absence and presence of wind. Since 
fire spread is often intimately connected with other properties such as burning rate or flame height, these fire behaviors will also be discussed briefly. Many attempts have been made to develop theoretical models to describe fire spread behavior. Some of these will be mentioned to provide an indication of how ideas concerning fire spread have evolved over time.

In Section 7.3.2 it was noted that there are four possible mechanisms for the heat transfer which is necessary for fire spread: (1) direct flame contact, (2) convective heating, (3) radiative heating, and (4) firebrand contact. Note that for solid fuels heat conduction may also be very important and will certainly influence the burning behavior of thick fuels. Due to the nature of the fuel beds which have been chosen for consideration, conduction is not expected to play a large role and will be omitted from the discussion. Fire spread by firebrands is very poorly characterized despite the large role this mechanism plays in urban fire spread. Since the vast majority of fire spread studies do not deal with firebrands, this topic will be discussed in a separate section. A major goal of the summary of the understanding of the fire spread is to identify the relative importance of heat transfer mechanisms (1) - (3) for different conditions.

\subsection{General Discussion of Fire Spread Behavior}

Introductions to fire spread are provided by the review papers of Emmons [68] and Steward [82]. The discussion of Hottel et al. [83] in their paper on fire spread modeling also contains a very useful description of the physical processes which are responsible for fire spread.

A general understanding of the conditions necessary for flame spread is readily obtained. Consider a fire propagating into a fuel bed consisting of many solid elements which may be in contact or have gaps between the fuel 
elements. The fire sustains itself by heating (either by conduction, convection, or radiation) the solid fuel which in turn produces pyrolyzed gases which mix with air and release heat by combustion. Combustion at the surface of solid fuels can also occur.

Regions outside of the fire also receive heat from the combustion zone with the amount of heat received per unit area decreasing as a function of distance from the combustion zone. Due to this heating, surface temperatures of fuels located outside of the combustion zone begin to rise. The rate of rise and final temperature achieved are determined by the balance of heat input and losses. Eventually a temperature is reached where the nonburning fuel begins to pyrolyze and produces gases which are combustible. These gases leave the surface and mix with surrounding air. If these gases come in contact with flame they will be ignited and the fire will spread to this portion of the fuel bed by a process known as piloted ignition. It is also possible for the temperature of the fuel surface and the gases above it to reach a high enough temperature for spontaneous ignition to occur. Piloted ignition of cellulosic fuels occurs for surface temperatures on the order of $350 \mathrm{C}$ while spontaneous ignition requires temperatures on the order of $600 \mathrm{C}$. The heat fluxes sufficient to produce these surface temperature fall in the range of 0.3 to several cal- $\mathrm{cm}^{-2} \mathrm{~s}^{-1}$

Even though the general mechanism of fire spread is fairly well characterized, it has not been possible to develop accurate models for the process. This is due to the great complexity of the interacting physical processes which are responsible. A consideration of a few of these processes should serve to illustrate this point. Combustion is a complex, chemical, multiphase process. Pyrolysis of cellulosic fuels such as wood results in the production of gas phase fuel molecules by the thermal breakdown of an organic 
polymer. It is also possible for air to diffuse to the fuel surface and react to produce glowing combustion. An understanding of these process is complicated by char formation which often occurs at the fuel surface and modifies pyrolysis behavior as well as surface combustion. Combustion above the bed is turbulent and involves complex chemistry. The current understanding of soot formation (which is important for characterizing radiant heat transfer) is poor.

The physical processes responsible for heat transfer (in this context: direct flame contact, convection and thermal radiation) are also complex and difficult to model even in the absence of interactions with complex chemical and aerodynamic processes which greatly complicate the situation. As a result, it has proven very difficult to predict heat transfer from a fire using first principles.

Thermal radiation is very important in discussions of heat transfer from fires. De Ris [84] has provided an excellent review. Radiation not only occurs from the flames above a solid fuel, but is also emitted by the heated, pyrolizing fuel surfaces. The thermal radiation emitted from a volume is often described by the Stefan-Boltzman law,

$$
\mathrm{E}=\sigma \epsilon \mathrm{T}^{4}
$$

where $\sigma$ is the Stefan-Boltzman constant, $\epsilon$ is emissivity, and $\mathrm{T}$ is temperature. Note the very strong dependence on temperature. Since radiation is emitted from a volume, the radiation flux at the surface of a flame increases with flame volume. Due to absorption processes, a flame size is eventually reached where the flux of thermal radiation becomes constant and does not change as the flame volume grows, but this generally requires quite large flames. 
The increase in flame radiation with increasing flame volume greatly complicates the modeling of heat transfer and flame spread. For small area fires where flame volumes are sma11, radiation transfer may be insignificant. However, as the flame volume grows, radiation at the flame surface can increase substantially and may become the dominant heat transfer mechanism. This discussion suggests that the physical processes which determine fire spread behavior may well change with fire size.

Early attempts to model fire spread through fine fuels tended to assume that the most important source of heat transfer was from overhead flames (e.g., [68,83]. Later experiments to be described in the following sections have shown that in many cases the most important sources of heat transfer are radiation from the fuel surface and convection. This point was discussed in the 1960s by Chandler [85]. This author writes "Over the years, many models have been proposed where radiation is postulated as the governing mechanism of the fire spread. In fact, nearly everyone in the fire research business has, at one time or another, constructed a radiation model of fire spread. . . But unfortunately, it has become more and more evident over the past few years that radiation is not the governing mechanism of fire spread for the situations of greatest interest, i.e., where a fire is spreading rapidly under the influence of wind. There is also an accumulating body of evidence that, even under situations where radiation is of importance to fire spread, it is not radiation from flames. Although the evidence for these statements is largely indirect, it appears overwhelming."

As noted above, the role of radiation in flame spread is expected to become more dominant for larger fires. It is worthwhile to note here that no research has been identified during the current review which allows the size 
of fire necessary for a change in the heat transfer mechanism to one dominated by flame radiation to be quantified.

In theoretical and experimental studies of fire spread the idealization of a "line fire" is often invoked. Such a fire burns in a straight line across a fuel bed which is assumed to be infinite. In real fires it is necessary that the fire bed be wide enough so that end effects do not significantly modify fire behavior. In this case the fire can be considered to be two dimensional. The use of the concept is justified by this simplification and by the observation that the width of many spreading fires in nature are much greater that the fire depth and even though such a fire is not likely to be two dimensional over its full width, it may be considered to be a line fire over shorter portions of the fire front.

\subsection{Fire Studies in the Absence of Wind}

\subsubsection{Fire Spread Studies}

The vast majority of fire spread studies in multi-element solid fuels have been performed by workers whose interest is the understanding of fire spread during wildland fires. Since the spread rates of these fires are often determined by burning in fine fuels, most controlled experiments have dealt with fire spread through randomly distributed, continuous fuel beds of fine fuels such as pine needles or excelsior. Due to a desire to investigate we11defined fuel beds which are less subject to random variations, studies on wood cribs and well-ordered fuel arrays have also been reported.

Among the most informative studies of fire spread through randomlydistributed, continuous beds of thin fuels are those of Anderson and Rothermel [86-89], Fang and Steward [90], and Wilson [91]. In the earliest of these papers Anderson [86] reported measurements of fire spread rates through fuel 
beds of pine needles. His results indicated that reproducible and linear fire spread rates could be generated in laboratory settings. Spread rates were shown to be dependent on such fuel properties as moisture content, fuel bed thickness, and type of pine needle. Other fire properties such as flame temperatures, radiant fluxes, flame depth, and flaming time were also reported. In [87] and [88] additional measurements of fire spread and flame properties in the absence of wind are discussed. It is noted that, in the absence of wind, the convection column stands vertically and the fire must propagate against the inflowing air entrained by the fire.

In [89] Anderson utilized measurements of fire spread rate, radiation intensities from overhead flames and the fuel bed, and an analysis of the heat transfer required to heat a fuel element to the piloted ignition temperature to estimate the fractions of the total heat transfer required for flame spread due to radiation and convection. He concluded that only $40 \%$ or less of the total heat flux necessary for sustaining a spreading fire was due to radiation and that "convective heat transfer at the interface of the combustion zone and the new fuel probably accounts for the rest." Note that this convective heat transfer must occur against the inflowing air into the convection column.

In an independent investigation, Fang and Steward [90] reached conclusions that are very similar to those of Anderson [89]. These authors investigated fire spread through packed wood shavings [90]. Radiation flux meters were utilized to record radiation from overhead flames and the fuel bed (burning fuel embers). By utilizing fine thermocouples to record the temperature within the fuel bed it was possible to record the thermal history of the fuel and estimate the total heat flux received. Their measurements showed that most of the radiative heat flux received by the fuel was due to the burning embers. Furthermore, they found that $60 \%$ of the thermal energy 
required for ignition was received by the fuel over a distance less than 2.5 $\mathrm{cm}$. This heat transfer is attributed to uncharacterized convective and radiative heat transfer effects. Note that the value of $60 \%$ of total heat transfer is the same amount attributed to convective heat transfer by Anderson $[89]$.

Taken together, these results on fire spread [86-90] in randomly-packed, continuous fuel beds confirm the arguments of Chandler [85] that radiation contributes only a fraction of the heat required for fire propagation, and also that the radiation which is important comes primarily from burning embers.

In more recent work, Wilson [91] has reported extensive measurements of fire spread through excelsior as a function of such fuel bed properties as fuel moisture, packing ratio, and fuel depth. The results are used to confirm inputs for the earlier model proposed by Rotherme1 [24].

Wooden cribs have also been utilized for investigations of fire spread behavior [92-96] in the absence of wind. Cribs are constructed from lumber arranged to form a crisscross pattern. The fuel bed structure used for fire spread studies is generally elongated in one direction and the fire is allowed to propagate in this direction. Important properties of these cribs include the size of the individual fuel elements, the spacing of the elements, and the overall dimensions.

Fons et al. [92,93] showed that the fire spread rate through such cribs was a linear function of time. Figure 3 demonstrates this behavior for white fir having variable specific gravities. One of the principal findings of this study is that the same correlations of flame properties derived for stationary flames (e.g., flame length) are applicable to the propagating fires. The convective and radiative heat outputs as well as temperatures in the 


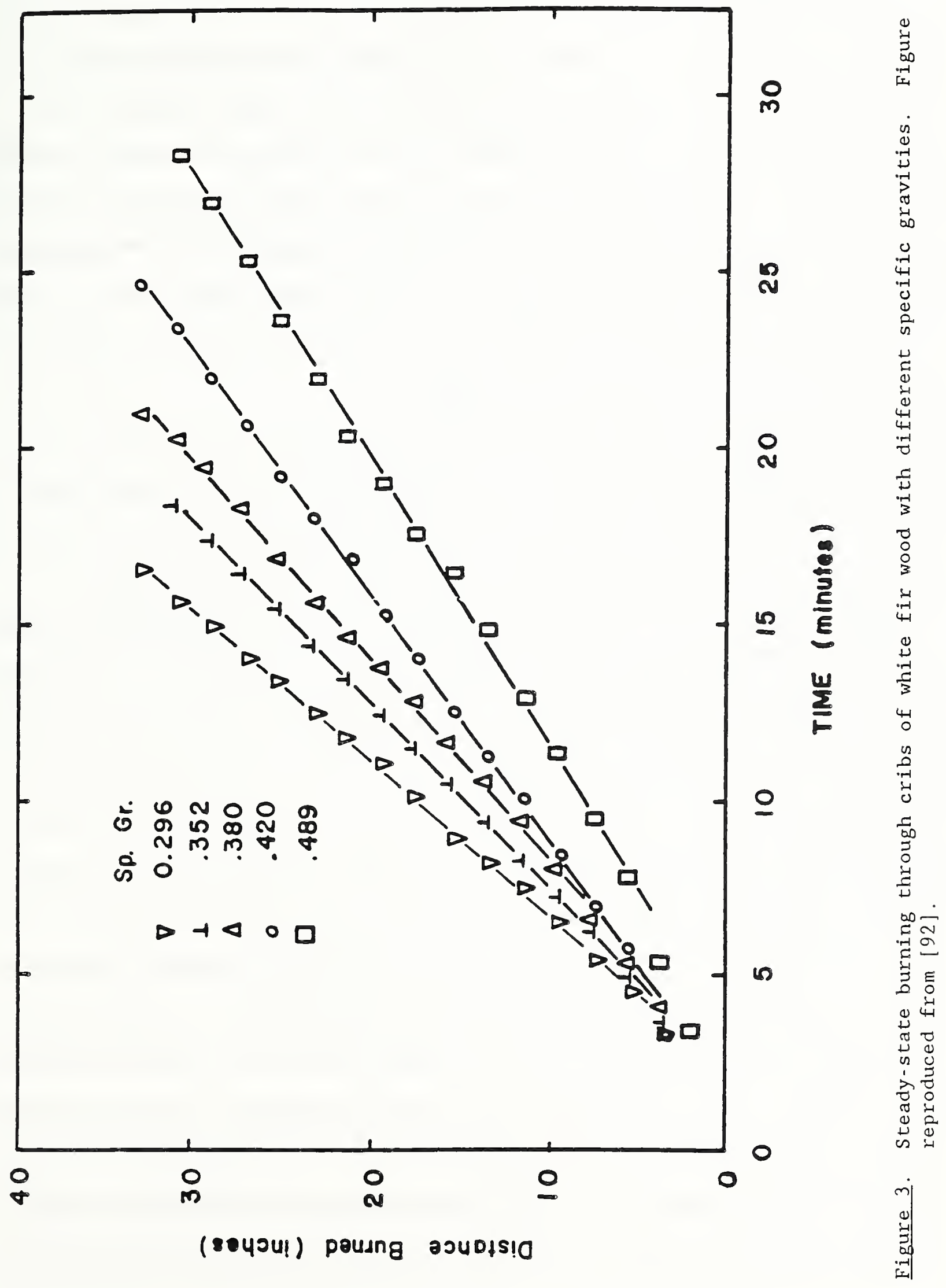


convective column are also reported. Later work by this same group [94] considered the effects of stick size and spacing on the spreading rate.

McCarter and Broido [95] have reported a study of fire spread in wood cribs which provides important insights into the physical mechanisms which are responsible. Their goal was to test the common assumption made up to that time that "the bulk of the heat evolved from free-burning fires in cellulosic fuel beds, such as forests or cities, originated in the luminous flames of the burning wood, and that radiation from the flames is the principal method of heat transfer responsible for fire spread."

These authors made careful measurements of the heat losses due to radiation, convection, and incomplete combustion from several burning wood cribs. Their measurements showed that, on the average, the total heat of combustion for the wood appeared as $43 \%$ radiated, 55\% convected, and $2 \%$ incomplete combustion. Of the total thermal radiation, roughly half was shown to be due to glowing embers (i.e., surface combustion). Tests were conducted in which the unburned fuel bed in front of the propagating fire was shielded from radiation emitted by the overhead flames, and in which the overhead flames were quenched by carbon dioxide. In both cases the fire spread rate showed little, if any, decrease. These experiments indicate that the overhead flames are unimportant for flame spread through this type of fuel matrix.

Thomas and coworkers [96] measured the flame spread behavior of wood cribs as functions of crib height and width, stick size and spacing, and covering and uncovering the sides of the cribs. Radiation measurements were made from the flames above the cribs and within the burning zone. The results confirmed the findings of McCarter and Broido [95] that the radiation transfer from the overhead flames was much less important for flame propagation than radiation transfer through the crib. It was also shown that the measured 
rates of heat transfer through the cribs varied with the burning rate of fuel as required by flame spread theory.

The fuel beds discussed thus far are continuous in that individual fuel elements touch and a continuous path extends from one end of the bed to the other. Some fire spread measurements have been reported for fuel matrices where the individual fuel elements are oriented vertically and are not in physical contact with other nearby fuel elements. Generally, the spacings and distribution of the fuel elements are uniform. It is intuitively obvious that these types of fuel beds are more characteristic of urban environments (particularly so, for typical urban residential tracts in the absence of blast damage) than the randomized fuel beds utilized to simulate wildland fuel beds. It must be kept in mind, however, that the fuel sizes are vastly different.

Vogel and Williams [97] measured fire propagation rates along single rows of matchsticks having square cross-sectional areas of $\approx 9 \mathrm{~mm}^{2}$. Measurements were made as a function of matchstick height (13 - $89 \mathrm{~mm})$ and spacing (5 $14 \mathrm{~mm})$. Flame would only propagate for the range of spacings investigated. During the experiments it was observed that the unignited matchstick next to a burning matchstick began to darken and emit smoke at the upper corner nearest the flame and that when flame first propagated to the fuel it appeared at the same location. The authors presented a theoretical analysis of the fire spread which assumed radiation was unimportant and that convection was the correct mechanism. The agreement between the theory and experiment was excellent, supporting the contention that convection is the dominant heat transfer mechanism for flame spread in small flames of this type.

Steward and Tennankore [98] investigated fire spread through fuel matrices formed by variable-diameter birch dowels arranged in multiple columns and rows. During the experiments, measurements were made of the weight loss 
behavior of a single dowel in the array in order to investigate the burning time of an individual fuel element. The experiments show that the burning time for an individual dowel is proportional to the dowel diameter raised to the $3 / 2$ power. Visual observations describe the flame transfer behavior as occurxing in a manner similar to that observed by Vogel and Williams [97]. Steward and coworkers have reported measurements of fire spread rates, temperatures, and total and radiative heat fluxes for the same type of fuel beds in other publications $[99,100]$.

\subsubsection{Introduction to Fire Properties}

An extremely large number of fire property measurements, correlations, and theoretical treatments are found in the literature. A brief review is provided here because these fire characteristics are often utilized in treatments of fire spread, and it is impossible to consider fire spread in the absence of other fire properties.

One of the most widely investigated properties is flame length. A series of papers [101-106] have shown that the ratio of flame length to a characteristic fuel bed length D (for circular fires D is the diameter while for other shapes the total area $\left.=\pi D^{2} / 4\right)$ is proportional to $\left(\dot{\mathrm{m}}^{2} / g \mathrm{~g}^{5}\right)^{\mathrm{x}}$, where $\dot{\mathrm{m}}$ is the mass burning rate and $\mathrm{x}$ is an exponent which is expected to approach 0.2 for large $\dot{\mathrm{m}}^{2} / \mathrm{gD}^{5}$. The constant proportionality factor depends on other physical properties. These physical properties vary somewhat between formalisms, but the numerical value changes very little for typical organic fuels. Note that the expression for $L / D$ can be rewritten in terms of the heat release rate, $Q$, when it is noted that $Q=\dot{m}_{c}$, where $H_{c}$ is the heat of combustion. Several assumptions made in the derivation of this equation are discussed in the original references. 
Results of a large number of flame length measurements have been correlated utilizing this analysis. In general, the exponential $x$ is found to have values between 0.2 and 0.3 and to approach 0.2 as $\dot{\mathrm{m}}^{2} / \mathrm{gD}^{5}$ increases. For a line fire, the expression can be rewritten [103] as

$$
L / D=f\left(\dot{m}^{\prime 2} / g D\right)
$$

where $\dot{m} "$ is the mass loss rate per unit length. Measurements by Thomas et al. [107] show that experimental values of L/D for cribs are correlated when plotted against $\dot{\mathrm{m}}^{2} / \mathrm{gD}$ raised to the 0.41 power. Fons et al. [93] found nearly the same exponent, 0.43 , for propagating fires.

Another important property of line fires is the fire intensity [82] which is defined as the energy liberated by combustion per second along a unit length of fire front and has units of $c a l-\mathrm{s}^{-1} \mathrm{~cm}^{-1}$. Note that as defined, fire intensity is determined by all of the heat release of the fuel from ignition at the front of the fire until the end of glowing combustion at the rear of the fire. With this definition,

$$
I^{\prime \prime}=\Delta H_{c} m f R
$$

where $\Delta \mathrm{H}_{\mathrm{c}}$ is the heat of combustion, $m$ is the fuel loading density, $f$ is the fraction of fuel consumed by the fire, and $R$ is the rate of fire spread. A fire intensity time distribution function can also be defined. This function describes the time behavior of the energy release across the fire. Note that the integral under the energy release function is the fire intensity.

Frandsen and Rotherme1 [108] have developed a method for measuring the time behavior of the energy release by recording the mass loss of fuel across a propagating line fire. Figure 4 shows examples of their findings [108] (figure is reproduced from Steward's [82] review article). It is clear that 


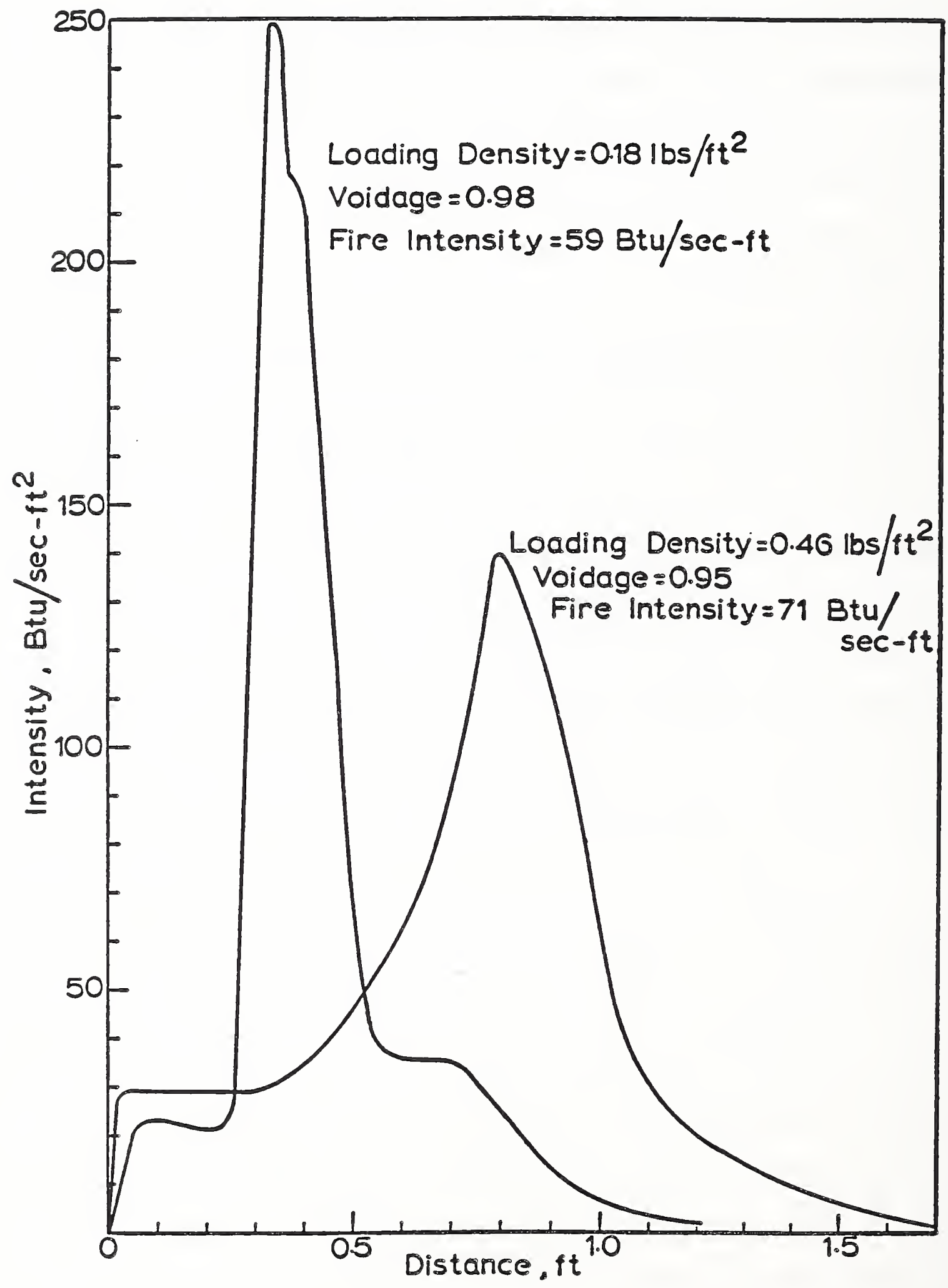

Figure 4. Intensity distributions for two line fires, Frandsen and Rothermel [108]. Figure reproduced with permission of author from [82]. 
the time behavior of energy release varies significantly depending on fire conditions.

Other important fire properties which are often reported are fuel burning time, temperatures near and in the burning fuel, temperature in the plume above the fuel bed, local flow velocities in the plume, and radiation and convective heat measurements. Some results of these types of measurements are mentioned above and others can be found in the references cited.

\subsection{Fire Studies in the Presence of Wind}

\subsubsection{Fire Spread Studies}

The rate of spread for a fire subject to an ambient wind has always been of great interest due to the large increases in fire spread rate which are observed compared to the case with no wind. Observations of this effect have been made in wildland fires for nearly a century. Attempts to make measurements of wind-aided fire spread in well-controlled laboratory facilities extend back to at least the early 1940s [109]. Fons [110] reported measurements of fire spread through pine needles and vertical twigs. Some experiments were performed in a low-speed wind tunnel to assess the effect of wind on the rate.

In the period from the late 1950 s to the late 1960 s several low-speed wind tunnels were designed and constructed for fire studies (see the discussion in Section 15.1). Workers at these facilities have generated a great deal of information concerning wind-aided fire spread. Most experiments have been performed in fuel beds similar to those discussed in Section 8.2.1. The following discussion will parallel that of this earlier section.

Measurements of wind-aided fire spread rate through randomly-packed fine fuels have been reported by workers at the Northern Forest Fire Laburatory in 
Missoula, MT $[24,87,88]$, the University of New Brunswick [111], and the Southeastern Forest Experiment Station [112]. Anderson and Rothermel [81] reported measurements of spread rate, $R$, for fires propagating with a wind through beds of ponderosa and white pine needles as a function of wind velocity, $U_{0}$. As expected, for a given moisture content, the fire spread rate increased dramatically with $U_{0}$. For wind velocities up to $3.6 \mathrm{~m} / \mathrm{s}$, the derivative of $R$ versus $U_{0}$ increased with $U_{0}$. Data for ponderosa pine needles were found to obey an exponential form,

$$
R=R_{0} e^{r U_{0}}
$$

where $R_{0}$ is the rate of spread in the absence of wind and $r$ is constant for given initial conditions. Both $R_{0}$ and $r$ depend on moisture content. Interestingly, the best fit for white pine needles was a power law,

$$
R=K U_{0}^{n} \text {, }
$$

where $\mathrm{K}$ is constant and $\mathrm{n}$ depends on moisture content.

Anderson and Rothermel [87] reported several other interesting observations and conclusions in their paper. Flame depth was determined by thermocouples and was found to be a linear function of $\mathrm{R}$. The authors also noted that, "contrary to accepted impressions, burning efficiency decreases as air velocity increases." It was noted that the overhead flames are tipped forward in the presence of wind. The increase of $R$ with $U_{\circ}$ was attributed to increased radiation impinging on the fuel bed due to the tipped overhead flames. Other measurements reported in this paper [87] will be discussed in the following section.

Fire spread experiments were extended in the work of Rothermel and Anderson [88]. Similar measurements of $R$ were made for the two types of pine 
needles. However, considerably more sophisticated diagnostics were employed. Small thermocouples were placed in individual needles and the increase of temperature recorded as the fire approached. Figures 5 and 6 show the results for fires propagating in still air and in a wind. Note that an aspirating thermocouple was utilized in the fuel bed for Figure 6 . The measurements in Figure 6 show that the air temperature is always higher than the needle temperature and indicates that convection may be an important heat transfer mechanism. This conclusion is different from that reached by these authors earlier [87]. It was confirmed that the overhead flames were playing a role in the fire spread by an experiment in which an asbestos sheet was placed over the fuel bed just outside of the fire and moved to maintain the same position relative to the fire front. In the absence of wind, the flame speed decreased from $0.60 \mathrm{~cm} / \mathrm{s}$ to $0.37 \mathrm{~cm} / \mathrm{s}$ or 398 . For a $2.2 \mathrm{~m} / \mathrm{s}$ wind, $\mathrm{R}$ was $2.3 \mathrm{~cm} / \mathrm{s}$ in the absence of the cover and $0.72 \mathrm{~cm} / \mathrm{s}$ with the cover in place, a reduction of 68.58 .

Rothermel and Anderson [88] observed that fingers of flame were carried downstream from the fire. Figure 7 is their pictorial for this process. They speculated that this behavior might be a very important factor in the increased fire spread rates observed in the presence of an ambient wind.

Rothermel [24] reported limited wind-aided fire spread measurements through excelsior as part of his efforts to characterize fire spread in different sized fuels and to obtain a correlation for use in his fire spread mode1.

Fang [111] has made extensive measurements of fire spread behavior through fuel beds of poplar wood shavings (width $\approx 1 \mathrm{~mm}$, thickness $\approx 0.4 \mathrm{~mm}$, four lengths utilized: $1.3 \mathrm{~mm}, 2.5 \mathrm{~mm}, 5.1 \mathrm{~cm}$, and $7.6 \mathrm{~cm}$ ) and poplar matchsticks (2.6 $\times 2.6 \times 51 \mathrm{~mm}$ and $2.3 \times 2.3 \times 43 \mathrm{~mm})$. Fire spread rates are 
TEMPERATURE RISE OF FUEL

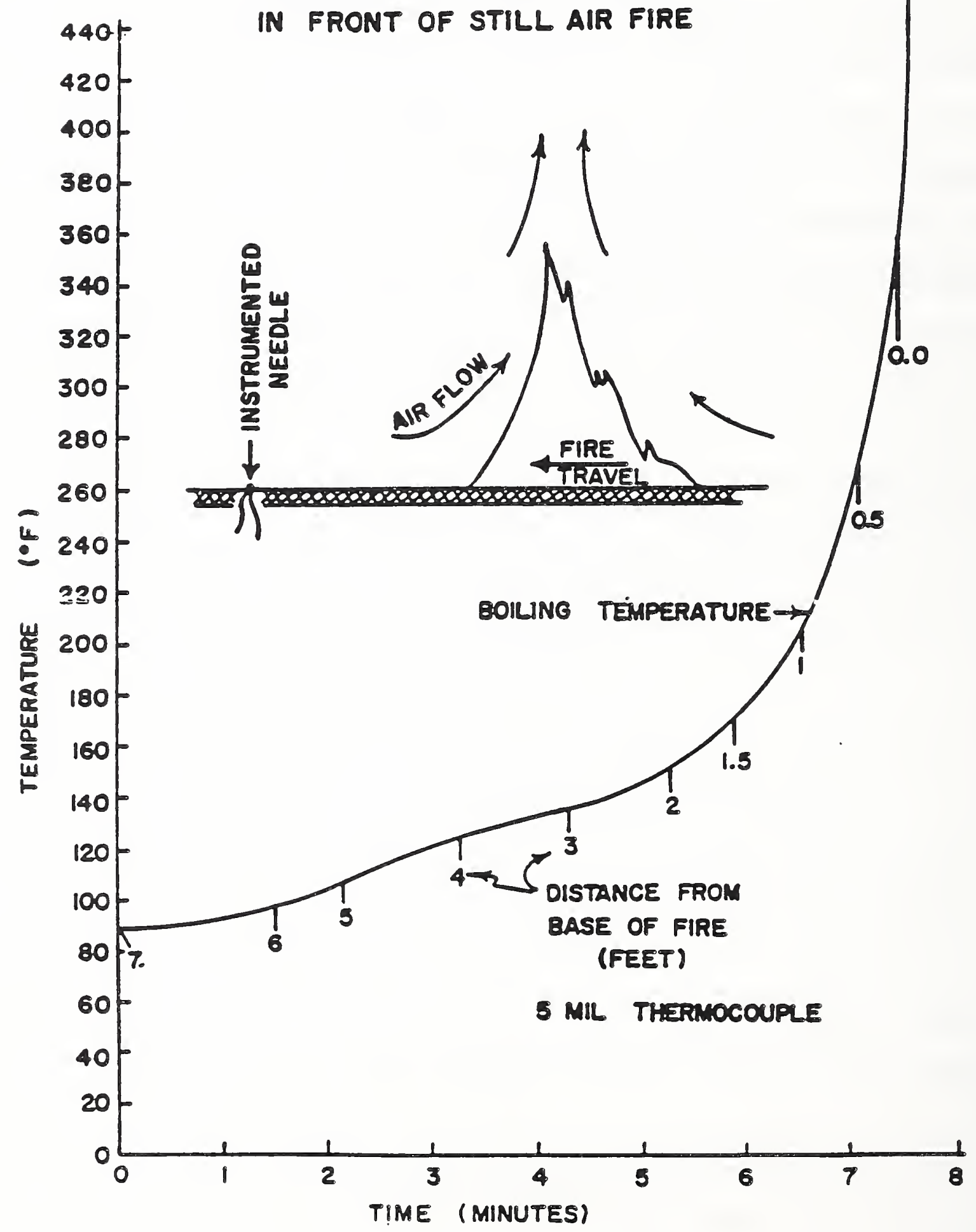

Figure 5. Temperature rise of fuel in front of still-air fire. Figure reproduced from [88]. 


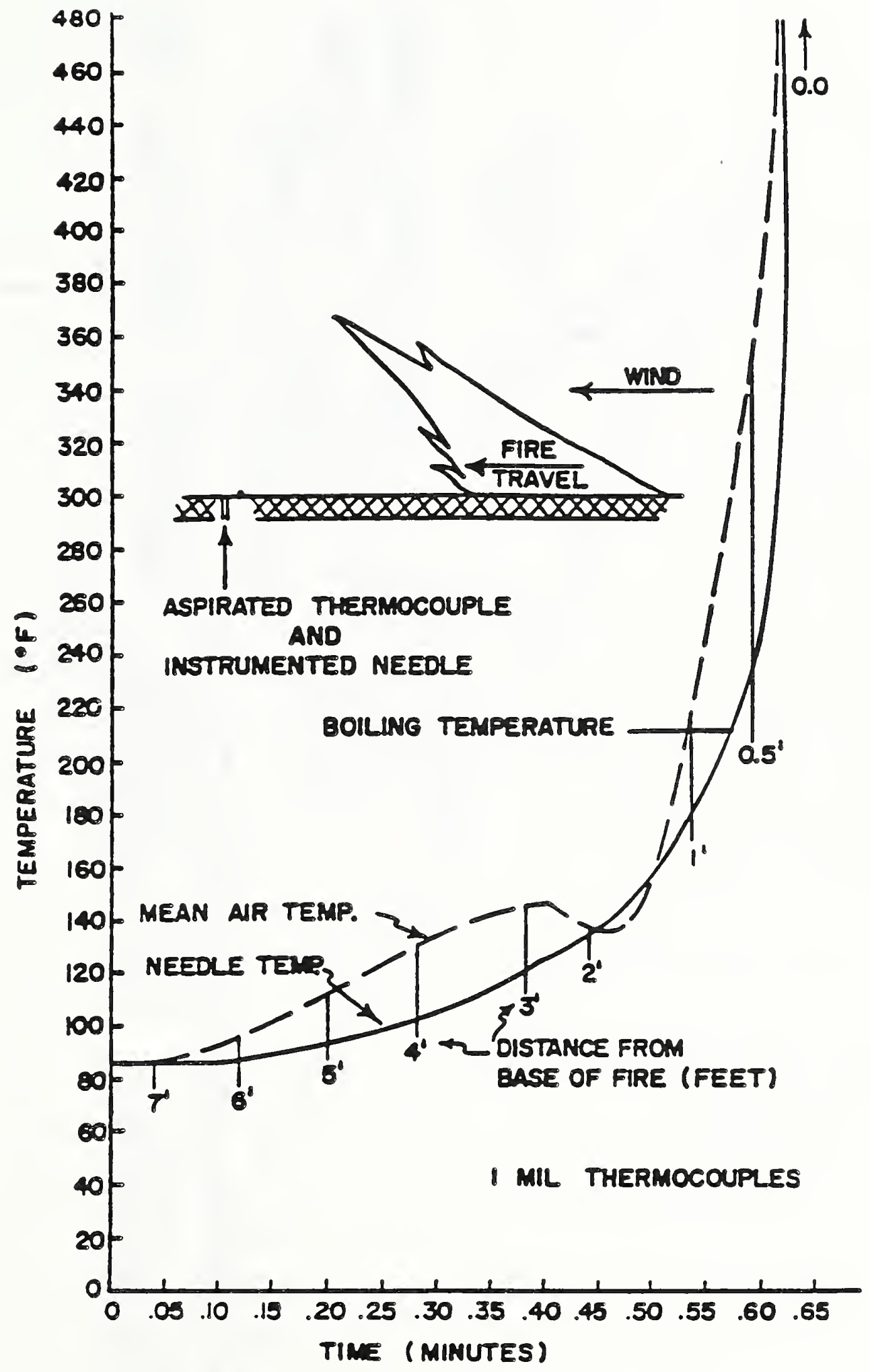

Figure 6. Temperature rise of air and fuel in front of a wind-driven fire. Figure reproduced from [88]. 


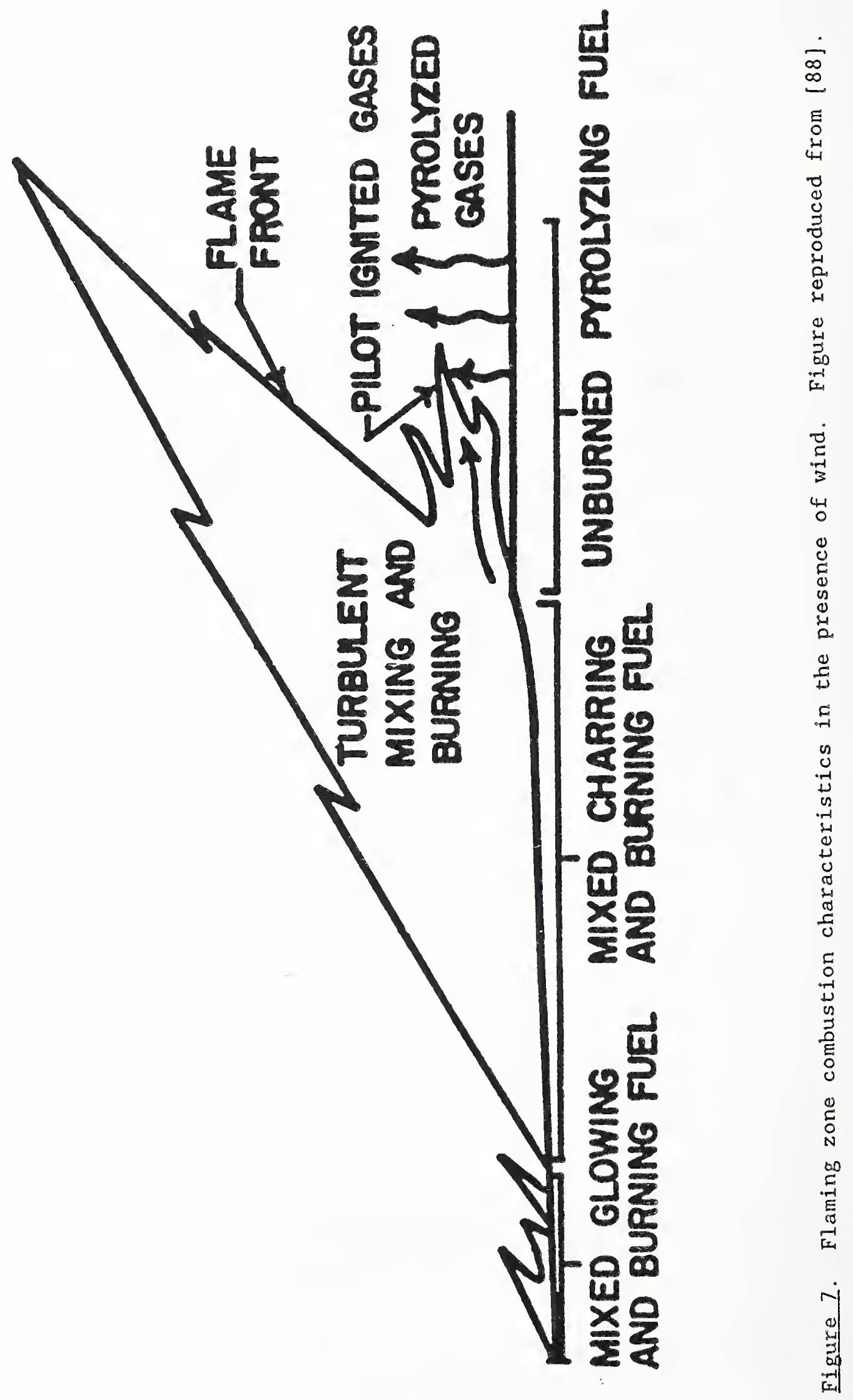


reported as functions of fuel moisture, fuel bed voidage, fuel size, slope of fuel bed, and wind velocity (maximum of $3.7 \mathrm{~m} / \mathrm{s}$ ). Figure 8 is taken from his work and shows how the rate of fire spread varies as a function of wind velocity, relative humidity, and fuel type.

Fang also measured the time behavior of the temperature for fuel elements located downstream of the fire front and the heat fluxes due to both convection and radiation. Figures 9 and 10 (taken from [111]) show examples of the results. Figure 9 indicates that the distance of preheating of fuel increases with increasing wind velocity. The heat flux measurements in Figure 10 provide an indication of the mechanism by which the fuel is preheated as the flame front approaches. For this relatively low wind velocity $(0.6 \mathrm{~m} / \mathrm{s})$, it can be seen that most of the preheating at large distances is a result of convection from the overhead flames, and, as the flame approaches the fuel element, the major heating mechanism is convection from the fuel bed. Based on measurements of this type, Fang concluded that heat transfer by convection contributes $\approx 60 \%$ of the total heat flux required for flame propagation.

In a study concerned primarily with flame characteristics, Nelson and Adkins [112] have reported fire spread rates for slash pine needles and slash pine needles with palmetto fonds.

Wind-aided fire spread along wood cribs has also been extensively studied [94,113-118]. The first reports of such a study were short descriptions of results [113,114] from the Fire Research Station, Borehamwood, United Kingdom. Results of fire spread rates through cribs constructed from $12.7 \mathrm{~mm}$ square sticks were reported for wind velocities from zero to $9.1 \mathrm{~m} / \mathrm{s}$. Values of $R$ were found to increase rapidly with increasing wind velocity at the lower velocities, but to then increase less rapidly as the velocity was increased further. At the highest wind velocities the fire spread rate was nearly 


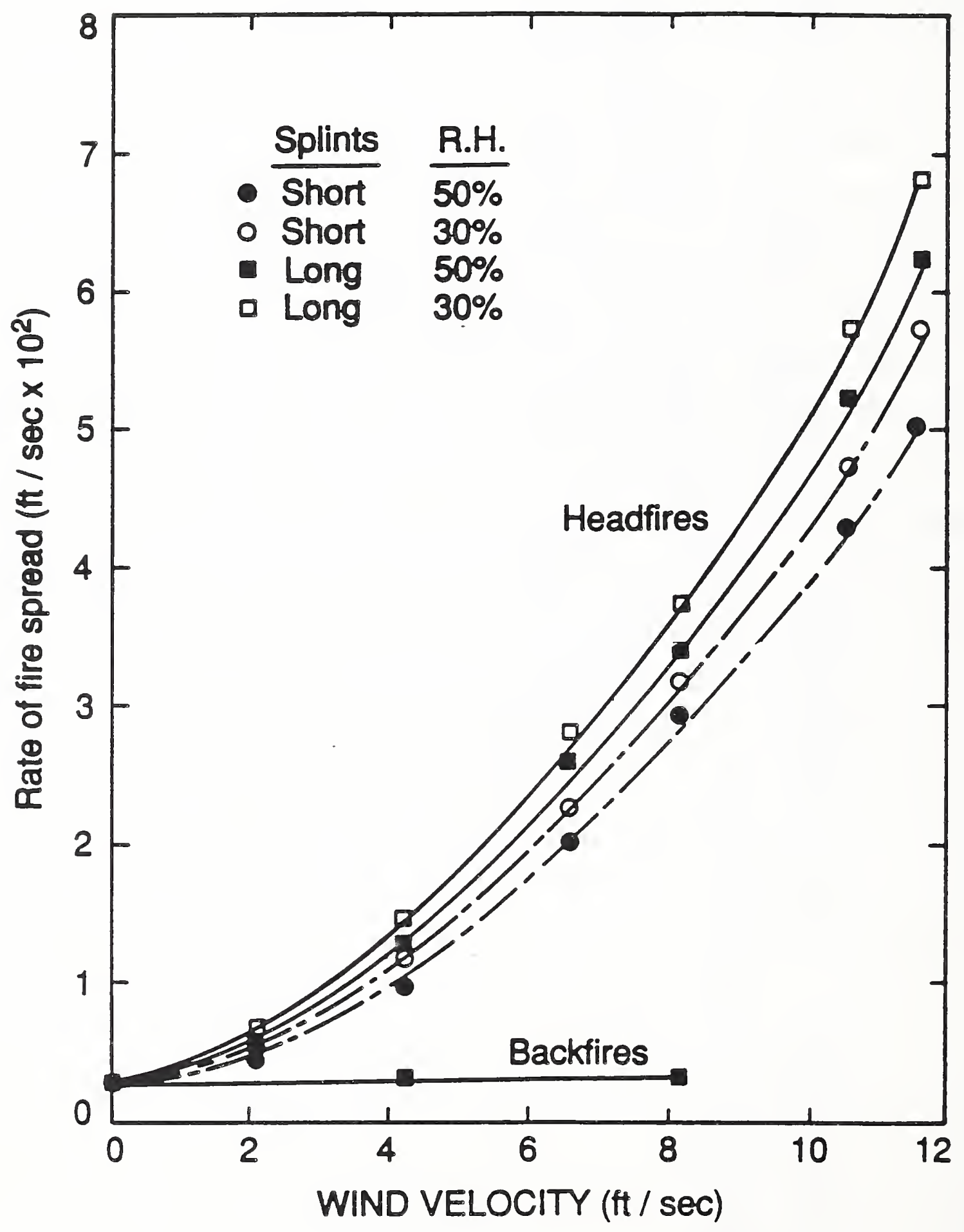

Figure 8. Effect of wind velocity on rate of fire spread. Parameters: fuel bed voidage: 0.809 and fuel loading density: $0.441 \mathrm{lb} / \mathrm{ft} .^{2}$. Figure redrawn with permission of author from [111]. 


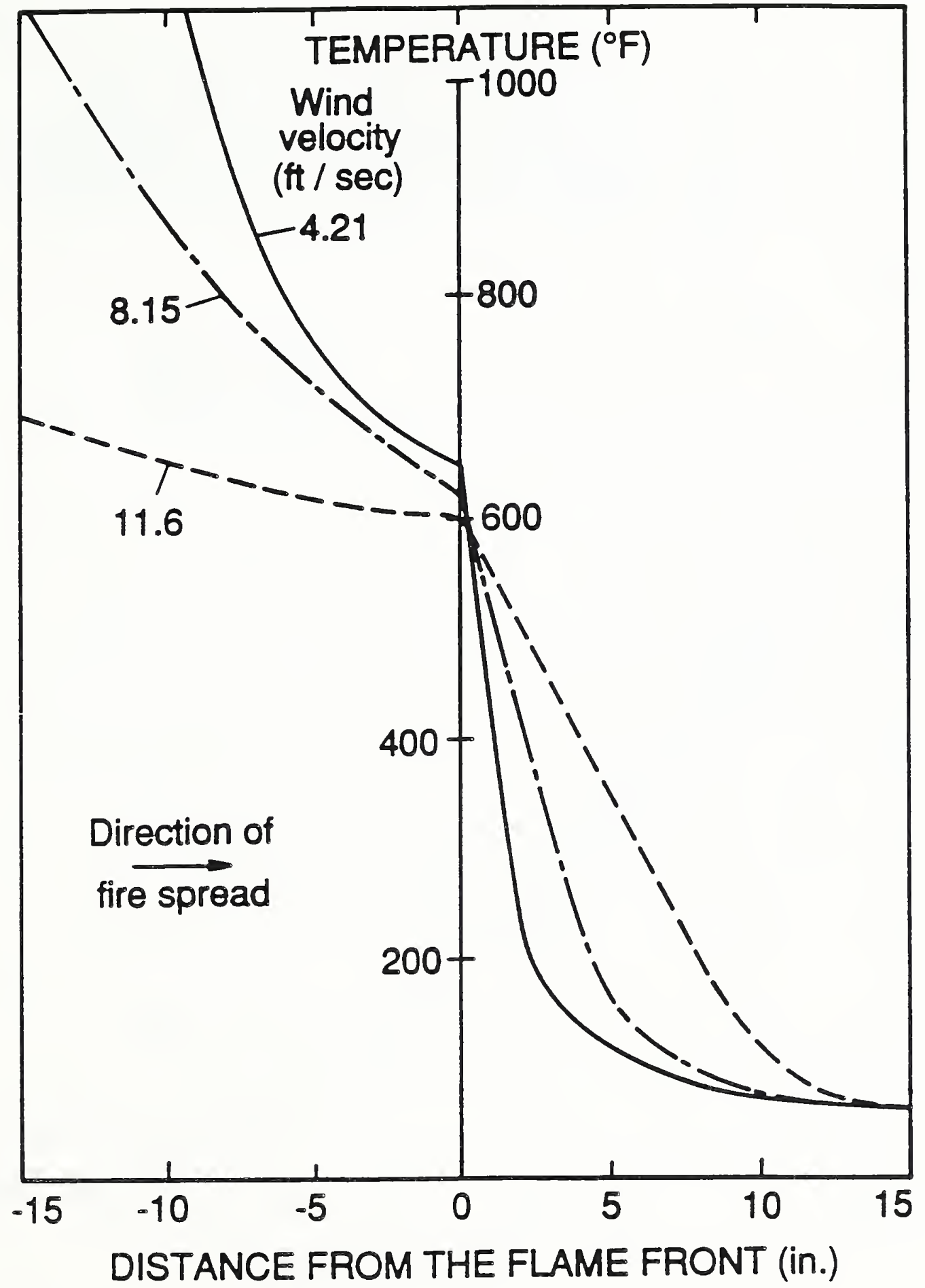

Figure 9. Temperature profile in the fuel bed, parameters: headfires, wood shavings, fuel length: 1 in., 308 R.H., fuel bed voidage: 0.918 , and fuel loading density: $0.193 \mathrm{lb} . / \mathrm{ft} .^{2}$. Figure redrawn with permission of author from [111]. 


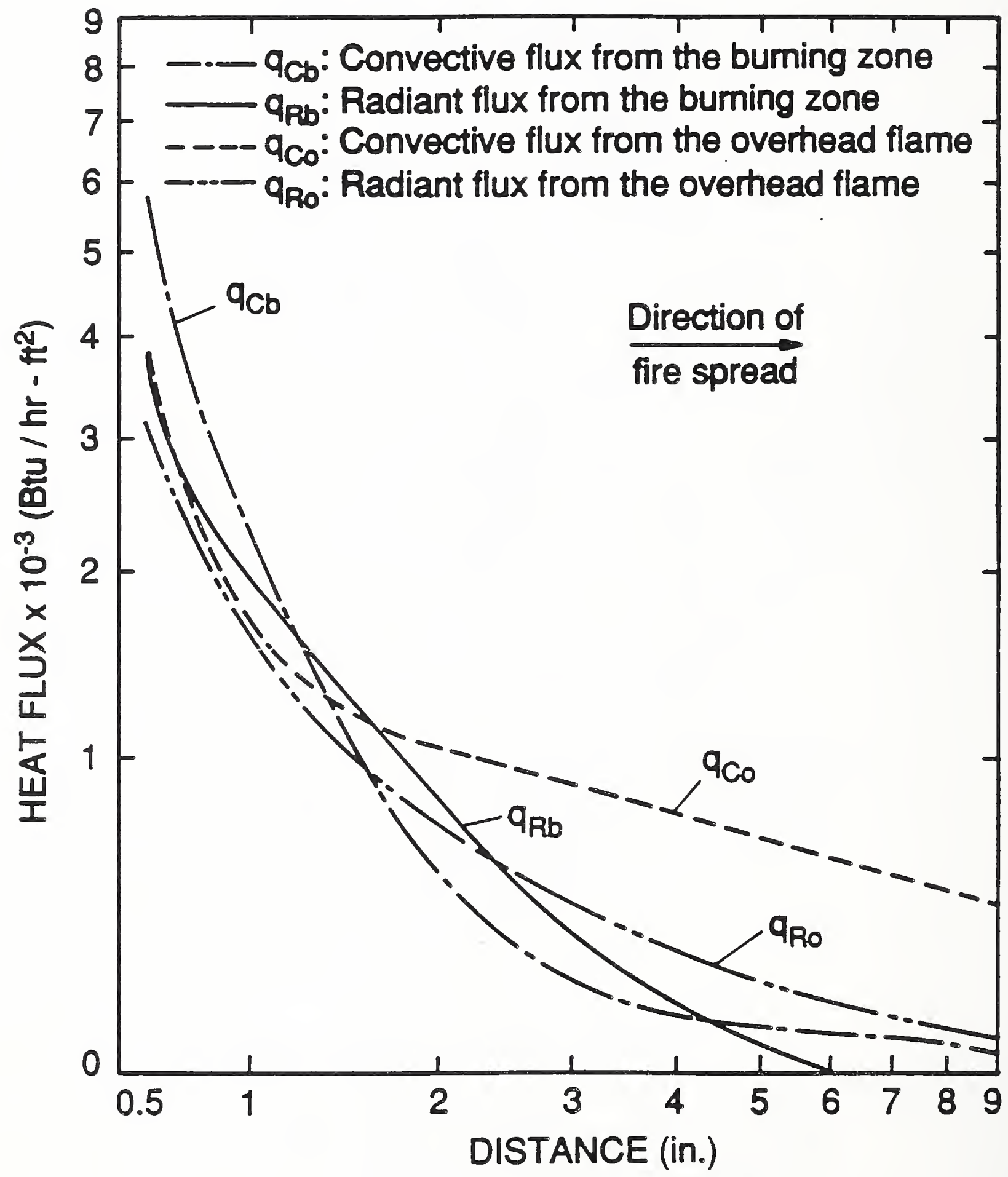

Figure 10. Radiative or convective heat flux versus distance from flame front. Parameters: headfires, short match-splints, $30 \%$ R.H., wind velocity: $2.11 \mathrm{ft} / \mathrm{sec}$, fuel bed voidage: 0.783 , and fuel loading density: $0.812 \mathrm{lb} . / \mathrm{ft} .^{2}$. Figure redrawn with permission of author from [111]. 
independent of $U_{0}$. Contrast this behavior with that discussed above for fine fuels.

For wind speeds from zero to $4.0 \mathrm{~m} / \mathrm{s}$ Byram et al. [94] found that for cribs constructed from $6.4 \mathrm{~mm}$ square sticks the fire spreading rate was a linear function of wind speed. Figure 11 is taken from their work and shows the fire spread behavior as functions of wind velocity and the spacing of the sticks forming the crib.

Qualitative observations of the crib fires [94] suggested an enhanced flame spread rate due to ambient wind similar to that for fine fuels. For a short distance in front of the fire front flames enveloped the fuel, and further downstream fingers of flame periodically impinged on the fuel surface. A series of simple tests in which ethanol pool fires were burned in the wind tunnel support a direct fire impingement mechanism for downstream heating. Cotton tufts were placed on the downwind side. When flames contacted the tufts they would ignite. For constant convective heat output, the distance at which tufts were ignited increased rapidly with wind speed as shown in Figure 12 [94]. Thermocouple measurements showed that radiation was unimportant in igniting the tufts.

In a later report [115] Byram et al. reported measurements of fire spread rate for wood cribs which gave a different dependence on wind velocity. Figure 13 shows the results for cribs formed from $6.4 \mathrm{~mm}$ square sticks with a spacing of $25.4 \mathrm{~mm}$. Differences in fire spread behavior are attributed to differences in fuel bed structure or a possible failure to attain a constant fire spread rate. In this study it was shown that the burning zone depth is linearly proportional to the fire spread rate. This requires that the flame residence time be a constant which is independent of $U_{0}$ for any given position in the fuel bed. 


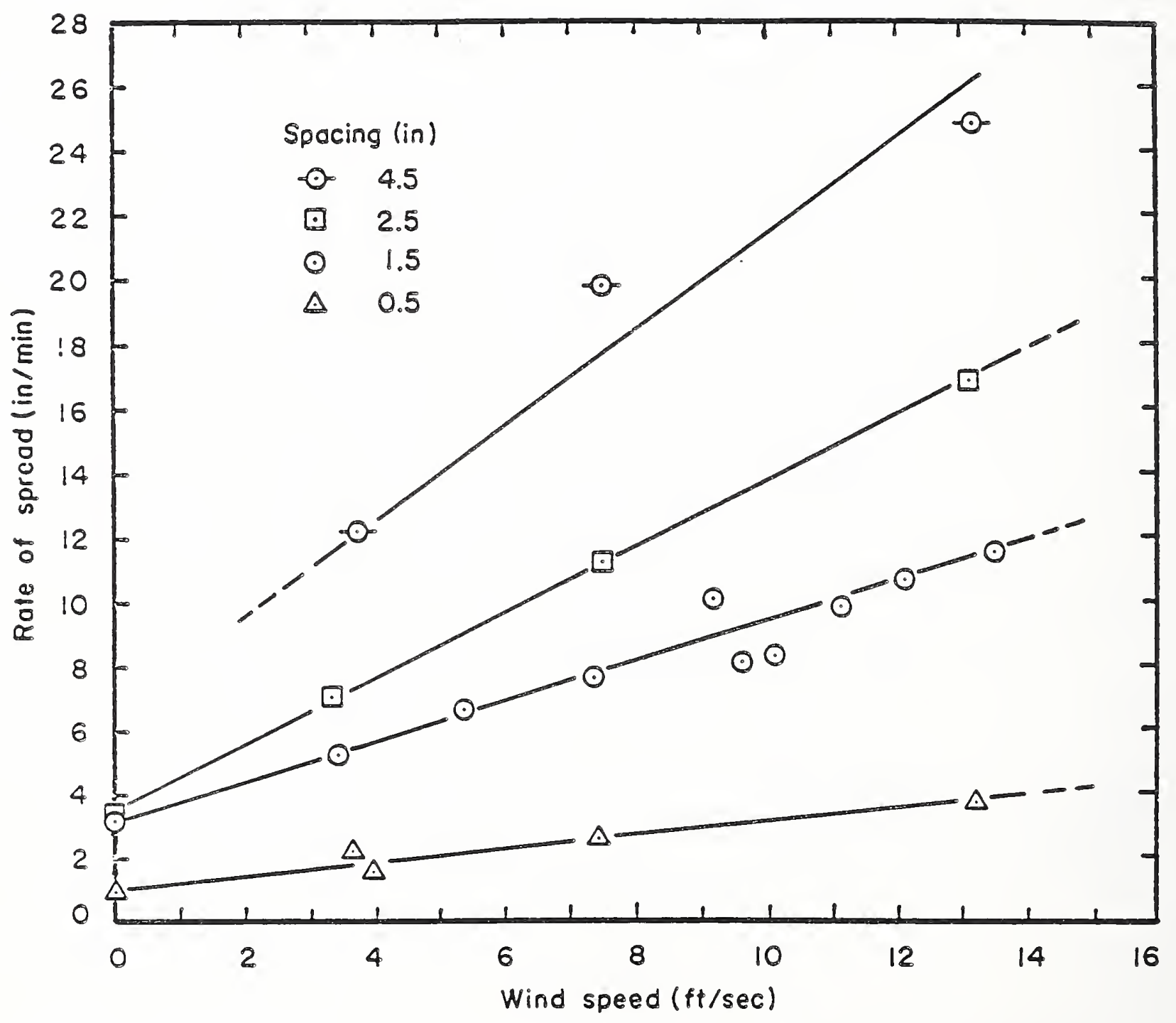

Figure 11. The effects of wind speed and stick spacing on rate of fire spread in cribs of white fir wood. Figure reproduced from [94]. 


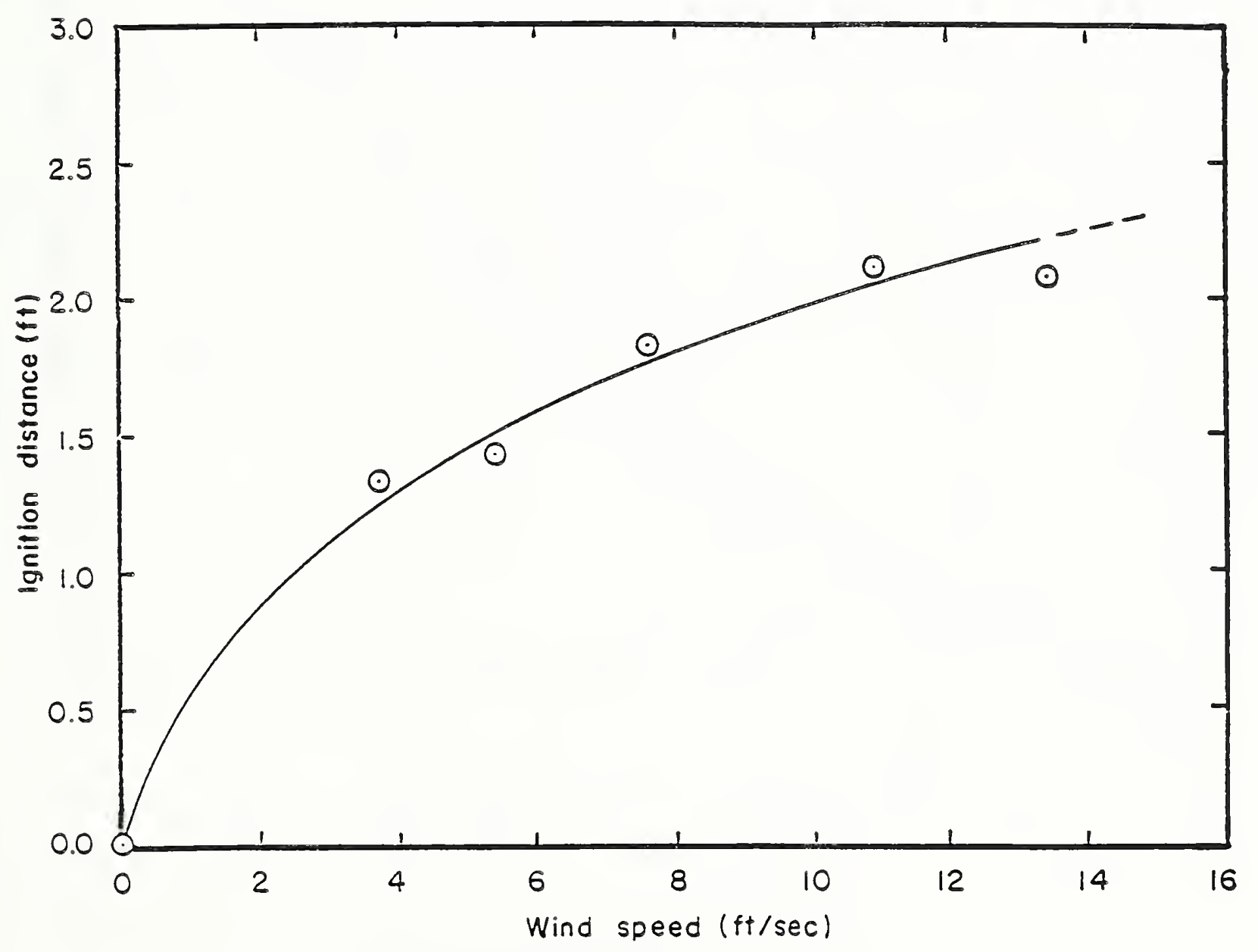

Figure 12. The maximum distance at which cotton fibers were ignited downwind from the edge of a square pool of burning alcohol plotted against wind speed. Figure reproduced from [94]. 


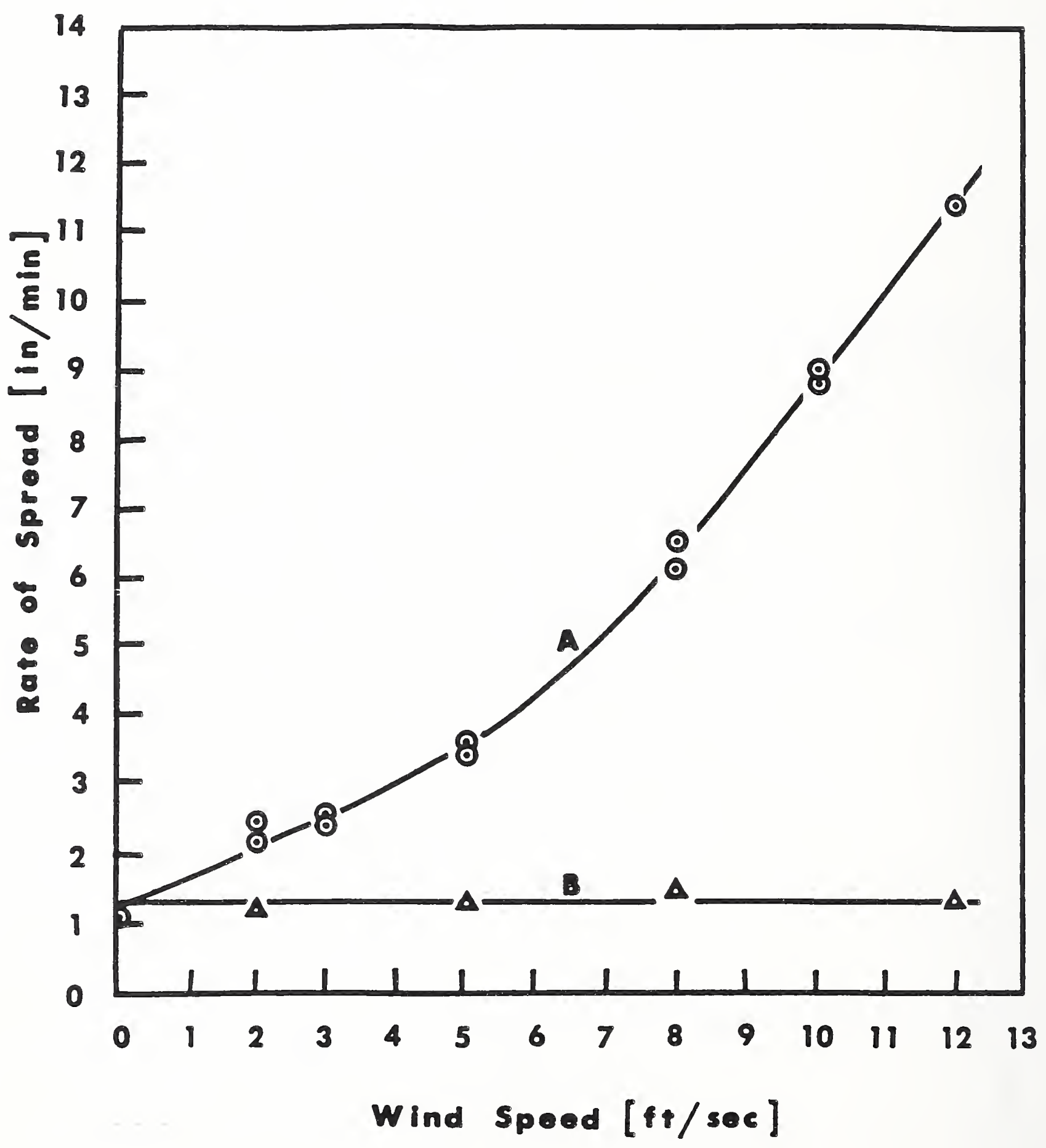

Figure 13. The relation between rate of spread and wind speed is shown for headfires (curve A) and backfires (curve B) for fires burning in wood cribs 1.56 inches high and 11.6 inches wide constructed of 1/4-inch white fir sticks. Figure reproduced from [115]. 
Thomas [116] provides an interesting analysis of wind-aided fire spread behavior based on experiments performed at Borehamwood $[113,114]$ and the work of Byram et al. [88]. These studies had reported the angle, $\phi$, of the overhead flames relative to the perpendicular from the fuel bed. Thomas proposed that the flame front in the fuel would have the same angle (see Figure 14) and furthermore that the burning velocity perpendicular to this front would be a constant. For a given type of wood crib, he found an accurate correlation when $R$ was plotted against secant $\phi$. He showed that the data for cribs formed from different sized sticks were correlated using the mass-weighted fire spread rate, $R \rho_{b}$, where $\rho_{b}$ is the bulk density of the fuel bed. Thomas [116] argues that overhead flames probably contribute little to heating of the fuel compared to radiation through the fuel bed and variations in fire spread rate with wind speed are attributable to the inclined angle of the flame front in the fuel bed.

In an investigation concerned primarily with interactions of two propagating wood crib fires in an ambient wind, Rios [117,118] has reported some measurements of wind-aided fire spread for single cribs. These results were plotted on log-log paper as $R$ versus the depth of the flame zone, D. A straight line was obtained which gave,

$$
\mathrm{R}=\mathrm{KD} 0.67
$$

Note that this result disagrees with that of Byram et al. [115] where such a plot also gave a straight line, but with a slope of 1 .

Interest in wind-aided fire spread through noncontinuous (i.e., porous) fuel beds has increased during the past few years. Since the early work of Prahl and $\mathrm{T}^{\prime}$ ien [119] on single arrays of matchsticks, a long-term, ongoing 


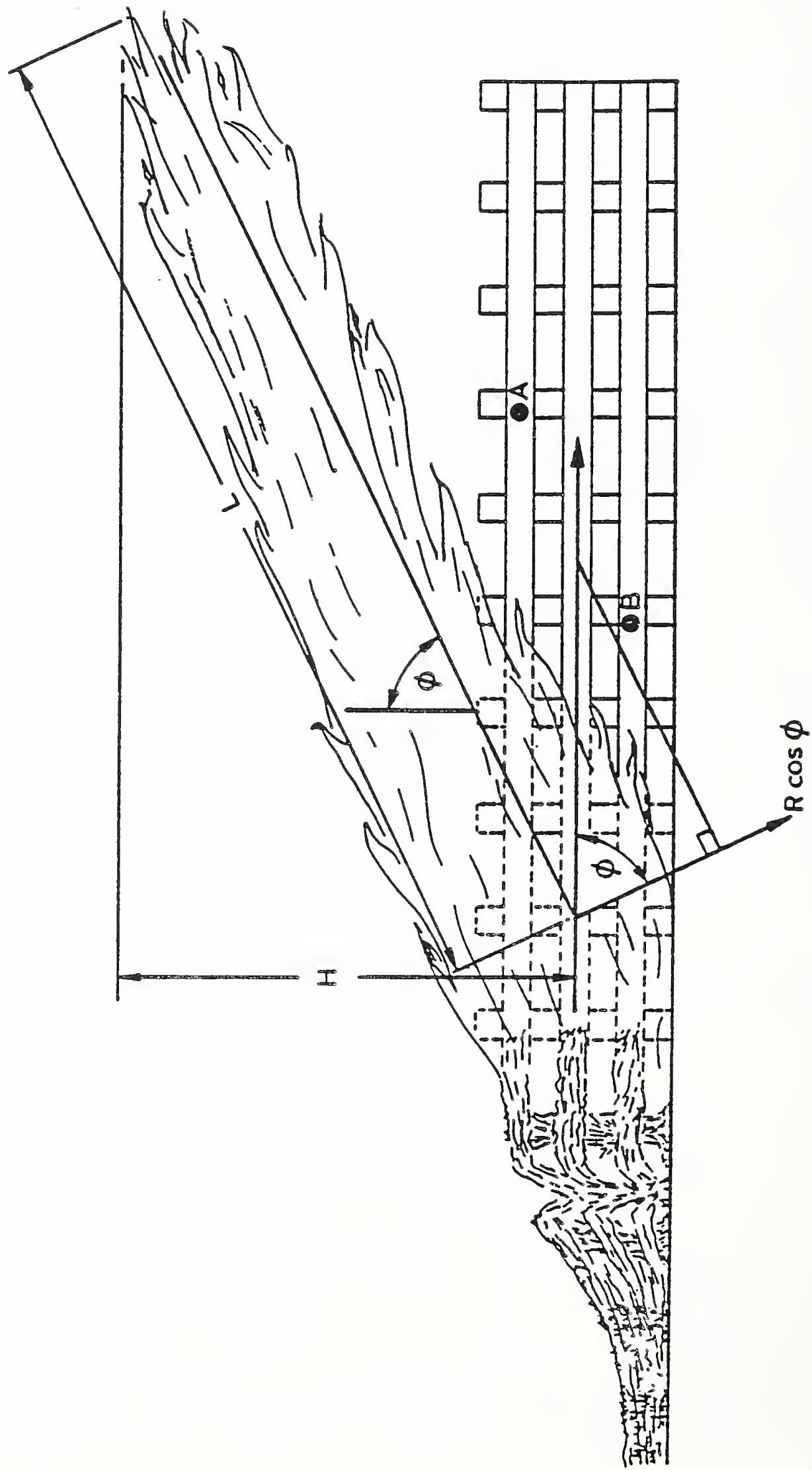

ב⿱

先

I

兽

4

5
0
-1
0
0
0
0
0
0
0
0

게 
program has been developed to characterize flame spread in this type of fuel $\operatorname{matrix}[120-123]$.

Prahl and $T^{\prime}$ ien [113] measured wind-aided fire spread along single rows of vertically-oriented matchsticks in which the fuel element spacing was varied. Marginal flame probabilities were determined in terms of spacing nondimensionalized by toothpick height and wind velocity nondimensionalized by a characteristic natural convection velocity ( $U^{\prime}$ is proportional to $\left.\left(g L\left(T_{f}-T_{0}\right) / T_{0}\right\}^{\frac{1}{2}}\right)$. Measurements of fire spread rate with and against ambient winds are presented along with results for the flame depth and angle of charring on the fuel elements. Fire spread rate first increases rapidly with wind velocity and then begins to level off as the wind velocity is increased further.

Rothermel [24] made fire spread measurements in fuel beds formed by arranging rows of double tripods created by stapling together three sticks of either $6.4 \mathrm{~mm}$ or $12.7 \mathrm{~mm}$ square cross section. The tripods were set upright and arranged at various spacings to achieve desired fuel loadings. This arrangement forms a type of porous fuel bed. Data were not presented directly, but were used to derive correlation parameters for determining the wind coefficient to be utilized in Rothermel's treatment of fire spread [24]. Steward and Tennankore $[98,100]$ reported mass loss measurements for an individual dowel in a fuel bed subject to an ambient wind. It was noted that the fire spread behavior was very different than found in the absence of wind where the fire jumped from one row to the next. In the case of a wind-driven fire, "the dowels began to darken or give off smoke while the fire was still several rows away and the distinct single flames on the individual dowels were not observed" [98]. It was also noted that the fire spread rate increased by a factor of 5 when the wind velocity was changed from $0.3 \mathrm{~m} / \mathrm{s}$ to $2.8 \mathrm{~m} / \mathrm{s}$. One 
of the most interesting observations was that the time required for burning of a dowel (defined as the period for weight loss of $80 \%$ to $20 \%$ of initial weight) was very nearly independent of wind velocity. This requires that the burning width be directly proportional to the rate of fire spread.

Workers at TRW have made measurements of wind-aided fire spread through matrices of vertical toothpicks, wooden skewers, and popsicle sticks [120123]. Measurements have been reported as a function of fuel loading, fuel crystallinity (arrangement of fuel), and wind speed. Generally, fires in the TRW experimental system are found to spread with curved flame fronts. This is attributed to effects at the edges of the fuel beds. Nevertheless, the fire spread rate measured along the centerline of the fuel bed attains a constant rate. Figure 15 [123] shows an example of the flame position as a function of time. Figures 16 and 17 [123] show results of wind-aided fire spread measurements for different fuel loadings as a function of wind velocity and fuel crystallinity.

Measurements [123] have shown that fire spread rates as functions of wind velocity, $U_{\circ}$, fuel loading, $\sigma$, and fuel bed width, $W$, can be correlated as

$$
R-W\left(U_{0} / \sigma\right)^{\frac{1}{2}}
$$

Flame front curvature, fire plume tilt, and flame front thickness are also found to be dependent on the same experimental parameters.

The TRW effort is ongoing [124] and monthly reports describing the effort have been made available to the author of this report. Efforts have focused on upgrading instrumentation, confirmation of the above empirical equation for flame spread, characterizing the plume temperatures and flame angles as a function of wind velocity, measuring the effect of inserting noncombustible elements (e.g., nails) in the fuel bed, and the development of a theoretical 


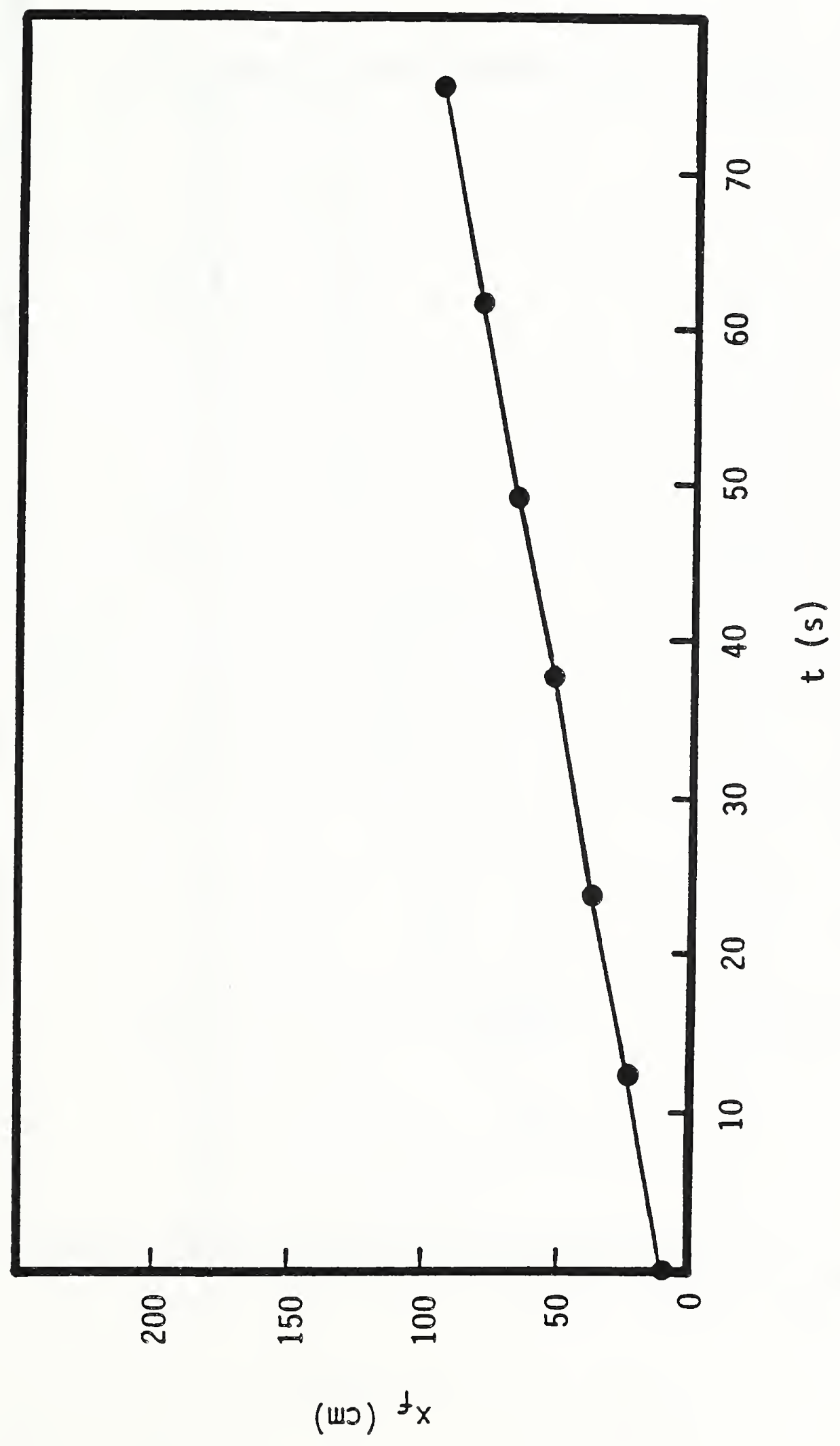

년 出跑 星

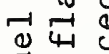
ये 政 吉骂 4 ○。 울 唯 气 당 ง 1 (1) तो - H 을 펌 0 \& प्रे क $\sum_{1}$ on 串 ชำ (1) मु 4 巳 ฮั L $m$ 。 ज $N$ 강 运 प. $x^{4} 3$ है $5 \approx$ 出 嵒

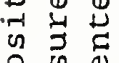
○ ज 山岂 ¿ 我 0 पू थ (1) 0 it 00 许每 Е 일 


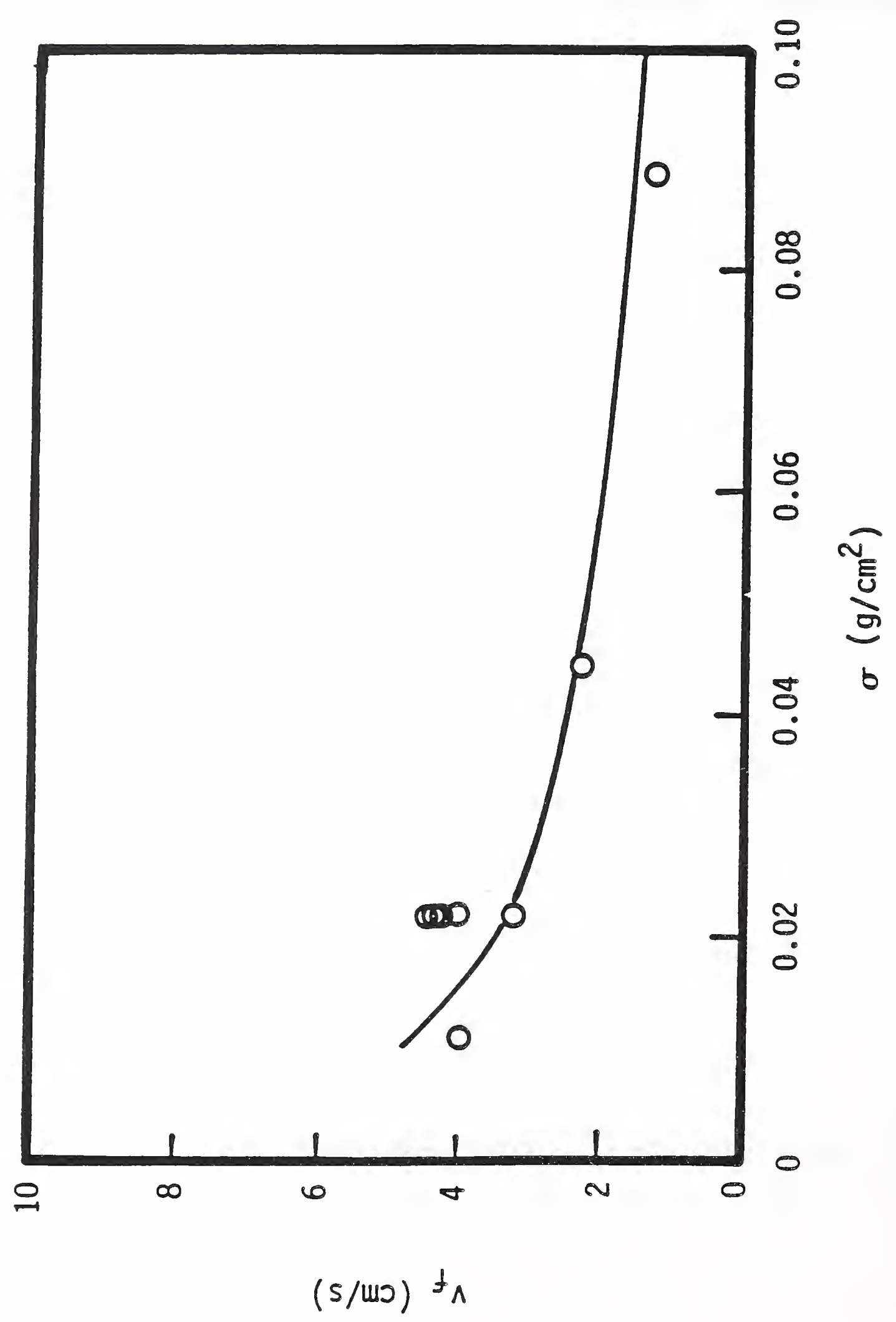

है ह

8

-

$\therefore \circ$

- 뭉

¿

D

릴

.

崩。

0 :

$\overbrace{}^{0} \stackrel{0}{0}$

Tु

䒿

$-0$

品

$4>^{4}$

0

เి

त

艺:

4 os

os

(2)

$>$ 出

वे

号

急

$\rightarrow$ in

김 
000

(2) 0 
model for fire spread based on the experimental findings. Taken together, this effort has produced a significant improvement in the understanding of fire spread in this type of fuel matrix.

The theoretical effort has produced some insights into fire spread mechanisms. Initially, these authors believed that fire spread rate could be understood in terms of convective plume dynamics [120-122]. Experimental findings were not in agreement with this model and the development of a new model based on radiation from overhead flames was proposed [123]. When the new model was formulated it included heat transfer mechanism by both radiation and convection [124]. Experimental findings are found to be consistent with theory only when the principal heat transfer mechanism is assumed to be convection.

In a very recent publication, Nelson and Adkins [125] have utilized dimensional analysis to derive three nondimensional variables which describe the rate of flame spread in terms of fuel consumption, ambient wind velocity, and flame residence time. The resulting expression adequately correlates data for the wide ranges of fuel type and energy release rate characteristic of wildland fires.

\subsubsection{Fire Properties in an Amblent Wind}

The development of wind tunnels for fire studies has resulted in many fire properties being measured as a function of wind velocity. Two of the most widely recorded are flame length and flame bending angle. Here the flame length is defined as the distance from the center of the burning region of the fuel bed to the end of the visible flame and the flame bending angle is the angle between the flame direction and the direction normal to the fuel surface. 
The earliest reports of flame length measurements in a wind tunnel are three short reports from the Fire Research Station, Borehamwood, United Kingdom $[114,126,127]$. Initial results from burning wood cribs indicated flame lengths decreased slightly as the wind velocity was increased [114,126]. It was suggested that nondimensional flame lengths should be proportional to two dimensionless groups; nondimensionalized mass burning rate, $\dot{\mathrm{m}}^{2} /\left(\mathrm{g} \rho^{2} \mathrm{D}^{5}\right)$ (note that this is the same form used for flame length in the absence of wind) and a modified Froude number, $\mathrm{U}_{\circ}^{2} / \mathrm{gD}$, which is characteristic of the ratio of inertial force on the flames due the wind and the buoyant forces generated by the fire. In $[114,126]$ it was shown that such an expression does correlate results for a line fire with the nondimensional mass burning rate suitably modified. The result is

$$
\mathrm{L} / \mathrm{D}=\mathrm{K}\left(\dot{\mathrm{m}}^{\prime \prime 2} / \mathrm{g} \rho_{\mathrm{O}}^{2} \mathrm{D}\right)^{0.43}\left(\mathrm{U}_{\mathrm{o}}^{2} / \mathrm{gD}\right)^{-0.11}
$$

where $\dot{\mathrm{m}}^{\prime}$ is the mass burning rate per unit length and $\mathrm{K}$ is a constant. Figure 18 taken from [127] shows the degree of correlation obtained. These results also appear in [103] where it is suggested that the decrease in flame length with increasing wind velocity is the result of more efficient plume entrainment.

Rios [117] also reported measurements of flame lengths for burning in wood cribs. This author shows that when flame lengths are plotted on a log$\log$ scale as $L / D$ versus $\dot{m}^{\prime \prime} / \rho_{\circ}(\mathrm{gD})^{\frac{1}{2}}$, a straight line with a slope of 0.74 is found. This exponent for $\dot{\mathrm{m}} " / \rho_{\mathrm{o}}(\mathrm{gD})^{\frac{1}{2}}$ can be compared with values of 0.61 reported by Thomas [103] for the no-wind condition and 0.86 for flames in the wind. Note that Rios [117] did not include a modified Froude number in his correlation. Rios also showed that the mass burning rate per unit area 


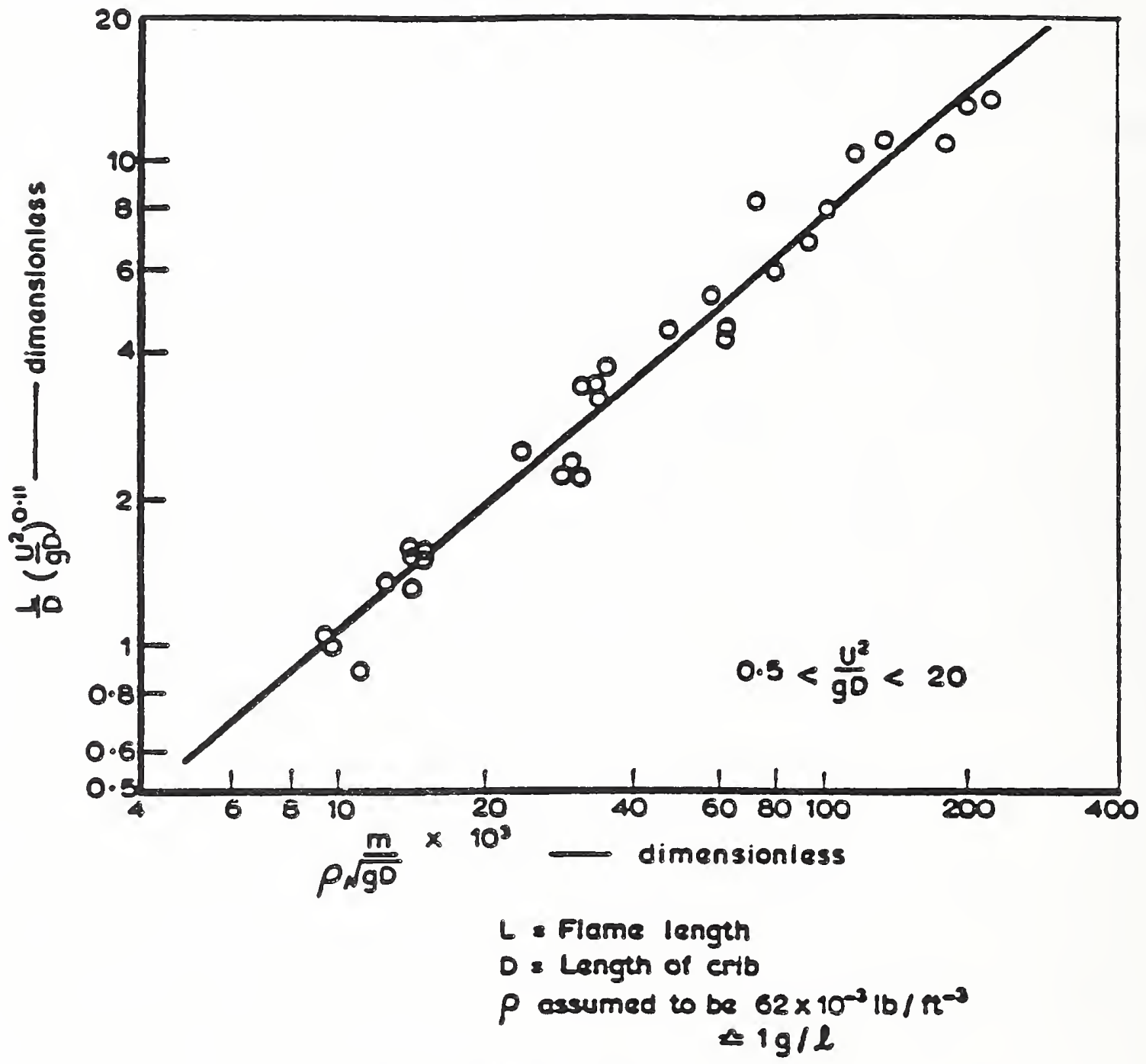

(a) FLAME LENGTH

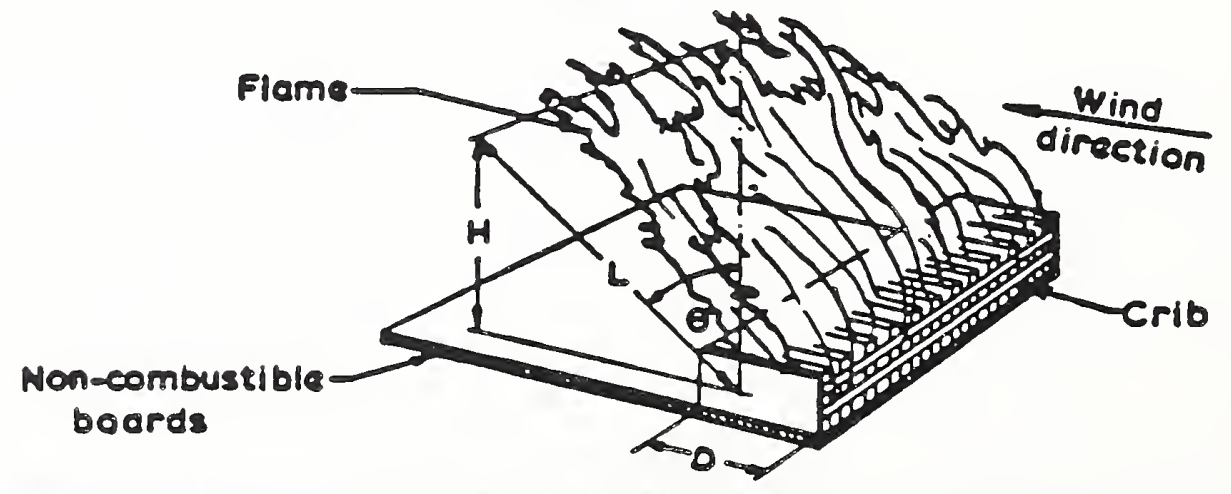

DIAGRAMMATIC SKETCH OF EXPERIMENTS TO REPRESENT BURNING ZONE

Figure 18. Effect of wind speed and burning rate on flames. Figure reproduced from [127]. 
decreased as a function of the depth of the flaming zone. This allowed the flame length to be correlated as a function of the width of the flaming zone.

For fire spread through pine needles, Anderson and Rothermel found that a similar expression to that suggested by Thomas $[103,114,127]$ for the windaided case provided a correlation of their flame length data, but that the exponent for the nondimensionalized mass burning rate was $\approx 0.97[87,88]$. Note that this exponent is larger than those reported by Thomas [103] (0.86) or Rios [117] (0.74).

In his dissertation work, Fang [111] developed a theoretical analysis which predicted that the nondimensional flame length for line fires should be a function of $\left(U_{0} / g D\right)^{-\frac{1}{4}}$ and $\dot{\mathrm{m}}^{\prime \prime} / \rho_{\mathrm{o}}(\mathrm{gD})^{\frac{1}{2}}$. Data plotted on a $\log -\log$ plot for the pine needle fires of Rothermel and Anderson [88] and the wood crib fires of Rios [117] fell around a straight line having a slope of unity.

Nelson and Adkins [112] correlated their flame length data in terms of fire intensity, I. Two methods were utilized for determining fire intensity. The first was Bryam's formulation [128] which gives the fire intensity as $I=$ $\Delta H w R$, where $\Delta H$ is the convective heat release and $w$ is the fuel loading. Results are corrected for a nominal 20\% radiation loss [112]. The second form is derived from the sensible heat released by the fire into the wind tunnel. Bryam's fire intensity gave estimates which were normally lower than the latter method of calculation. Flame lengths were found to be proportional to $I^{\frac{1}{2}}$ as predicted by buoyant plume theory.

Measurements of flame lengths as functions of wind velocity have also been reported for pool fires. Welker and Sliepcevich [129-131] found that flame lengths from pools of various alcohols and alkane pool fires were independent of wind velocity. 
Putnam [132] reported similar measurements for natural gas fires. His measurements are reported as the flame height and horizontal extension of the flames, normalized by the flame length in the absence of wind, as a function of wind velocity. As expected, the flame heights decreased and the flame extensions increased as the wind velocities were increased. The findings indicate that the nondimensionalized flame height is proportional to $\left(\mathrm{U}_{0} / \mathrm{gL}^{*}\right)^{-\frac{3}{*}}$ and the flame extension to $\left(\mathrm{U}_{0} / \mathrm{gL}^{*}\right)^{1 / 6}$ where $\mathrm{L}^{*}$ is the flame length in the absence of wind.

Measurements of the flame angle as a function of wind velocity have also received a great deal of attention. For fine fuels, Anderson and Rothermel [87,88], Fang [111] and Nelson and Adkins [112] have reported such measurements. Measurements for burning wood cribs can be found in Byram et al. [94] and Rios [117]. Very few measurements are available for porous fuel beds with the exception of some as-yet unpublished work at TRW [124] .

Many different correlations have been utilized to treat flame angle measurements. Thomas [116] attempted to correlate the data of Byram et al. [94] by plotting a nondimensional wind speed, $\mathrm{U}_{\mathrm{o}} /\left(\mathrm{gm} / \rho_{\mathrm{a}}\right)^{1 / 3}$, against the cosine of the flame angle, $\phi$. Anderson and Rothermel [86,87] argued that the tangent of the flame angle should be proportional to the ratio of the energy rates per unit area for the flame and wind tunnel airstream which can be expressed as $\mathrm{qU}_{\circ} / \mathrm{E}_{\mathrm{r}}$, where $\mathrm{q}$ is the dynamic pressure due to the ambient wind and $E_{r}$ is the area energy release rate for the fire. A straight line resulted for a $\log -\log$ plot of $\tan \phi$ versus $\mathrm{qU}_{\mathrm{o}} / \mathrm{E}_{\mathrm{r}}$. Nelson and Adkins [112] correlated their measurements by plotting tan $\phi$ versus a Froude number, defined as $\mathrm{Fr}=$ $\mathrm{U}_{0}^{2} / \mathrm{gH}$ for flame height $\mathrm{H}$, on a $\log -\log$ plot. The resulting straight line has a slope of 0.29 . 
The most significant work on modeling the angle of spreading fires in the presence of wind is that of Fang [111]. He has developed a model for a turbulent fire in a crosswind which predicts that the flame angle should be expressible as a function of the Froude number based on the flame depth, D,

$$
\tan \phi / \cos \phi=C_{D}\left(U_{o}^{2} / g D\right)
$$

$C_{D}=C_{F} / 2\left(1-\rho_{0} / \rho_{a}\right)$, where $C_{F}$ is the flame drag coefficient. This expression is very similar to ones developed earlier by Welker and Sliepcevich [129,130,133] following the work of Pipken and Sliepcevich [134] and derived independently by Hamada [135]. Fang [111] showed that his experimental results for three different fuel types were well correlated when $\tan \phi / \cos \phi$ was plotted against $\mathrm{U}_{0}^{2} / \mathrm{gD}$ and that the proportionality constant was 1.54 . Figure 19 shows the correlation. He argued that this result implies that the flame drag coefficient is nearly constant for his fuel beds and the range of $U_{\text {o }}$ investigated.

Welker and Sliepcevichs' [130,133] studies of flame bending angles for liquid pool fires also indicated that the flame drag coefficient appearing in the flame angle correlation is nearly independent of wind speed. These authors did identify a dependence of $C_{D}$ on fuel density.

Rios [117] has reported a similar analysis of flame angle for his measurements on wood crib fires in a wind tunnel. The flame drag coefficients determined from the measurements were plotted as a function of the product of Reynolds and Froude numbers. Whereas the flame drag coefficients for the fine fuel beds of Fang [111] and the pool fires of Welker and Sliepcevich [130,133] were found to be nearly independent of ambient wind velocity, a strong dependence on this parameter was identified by Rios. He [117] speculated that this dependence might be the result of the variation in the depth of the 


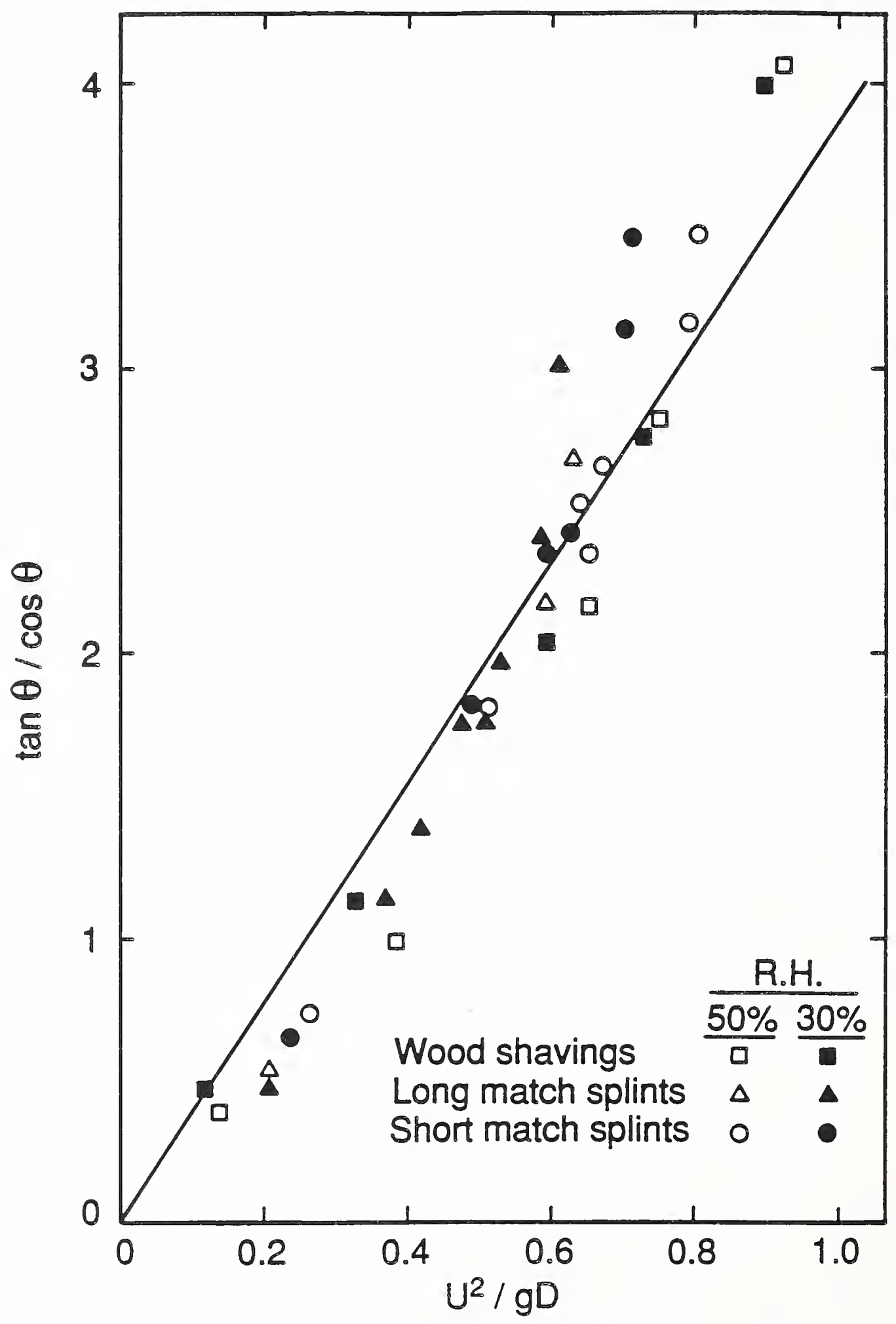

Figure 19. Relationship between flame bending angle and Froude number. Figure redrawn with permission of author from [111]. 
flaming zone which was observed to change as a function of wind velocity. The constant drag coefficient found by Fang [111] for fine fuels suggests that flame depth may not be the determining factor.

Many properties of fires propagating with an ambient wind in addition to spread rates, flame lengths, and flame bending angles have been reported. Results are available for flame widths, mass loss rates, fire intensities, completeness of fuel combustion, plume and fuel bed temperatures, and plume and fuel bed radiation. Space does not permit a review of all of these properties. Interested readers are referred to references in this section for further details.

\subsection{Comments on Theorles for Propagating Wind-Blown Fires}

It was mentioned in Section 8.1 that a detailed theory for wind-aided fire spread has proven very difficult to develop. Perhaps the most widely used model of fire spread is that of Rothermel [24] who utilized experiments in the laboratory and the field in conjunction with a simple energy conservation formulation to generate a mathematical model for predicting fire spread rate. Rothermel based his model on the theoretical analysis of Frandsen [136] who considered the conservation of energy at the fuel front between burning and nonburning fuel. In his analysis Frandsen assumed that the heat transfer occurred by radiation through the fuel bed, but Rothermel [24] utilized a more general approach in which the propagating heat flux was assumed to be a function of the reaction intensity. The effects of ambient wind and slope were incorporated by the use of coefficients to modify the propagating heat flux. Note that no mechanisms for the necessary heat transfer are assumed. Experimental results were utilized to generate the various inputs required for the model [24]. The final product was a mathematical 
prescription which accurately calculated fire spread rates for fuel beds of excelsior, wood cribs constructed from $6.4 \mathrm{~mm}$ sticks, and wood cribs of $12.6 \mathrm{~mm}$ square sticks as a function of packing ratio. A correlation of experiments on fire spread in the presence of wind allowed a general expression for the coefficients for wind and slope to be formulated. A prescription for the application of the model to field situations was provided [24]. When this model was utilized as a submodel for fire spread in a forest, the predicted and actual burning rates and area consumed were in excellent agreement [25].

Fang [111] has analyzed wind-aided fire spread behavior utilizing a more complete formulation of energy balance which considers heat transfer by radiation and convection from the fuel bed and overhead flames as well as convective heat losses. The final expression contains four constants which are related to radiation transfer and convection. These constants were determined by trial and error and apparently have not been utilized in an attempt to estimate the contributions of the various possible heat transfer modes. Agreement between calculated and experimental fire spread rates was quite good.

Pagni and Peterson [137] have developed a mathematical model for fire spread through porous fuel beds. The model assumes a one-dimensional, homogeneous fuel bed and considers heat transfer due to flame and burningember radiation, wind-driven convection to the fuel surface and through the fuel bed, turbulent diffusion of flame eddies, and gas-phase conduction. Calculations were performed for a range of wind velocities, and good agreement was obtained for comparisons with the experimental data of Rothermel and Anderson [88]. 
These authors conclude [137] that radiative transfer from overhead flames dominates the heat transfer process at low ambient wind velocities, but that convection becomes dominant as the wind velocity is increased. For the highest wind velocities considered, flame radiation is calculated to contribute only about $20 \%$ of the total heating required for flame propagation.

Fendell [124] has generated a model for fire spread behavior which yields predictions for fire spread velocities as a function of ambient wind velocity and fuel mass per unit area. The model predicts that the fire spread velocity will be proportional to $U_{\circ} / \sigma$ raised to a power with the exponent dependent on the mechanism responsible for heat transfer. Analysis of available data indicates that convection is the principal heat transfer mechanism.

Models which have been developed to explain plume behavior in a cross wind provide an instructive lesson as to the difficulties faced in developing theoretical fire models and how experimental data can be utilized to aid in choices between models. Assumptions which have been made concerning the effects of a cross wind on a buoyant plume can be classified into two types. The first assumes that the plume acts as if it were a physical object and the wind forces on the plume result from dynamic pressure forces. The second assumes that all of the wind which strikes the fire plume is entrained and that the entrainment is therefore dependent on wind velocity.

Experimental support for the treatment of the a plume as an object is found in the Flambeau fire results. Countryman [6] describes how these large fires "served as a block to the ambient wind, and the flow around the fire was much as the flow moving around a solid object." As is typical for flow past solid objects, vortices form in the lee regions. The incorporation of flame drag coefficients into expressions for flame bending angle $[111,117,129,130,133-135]$ involves the implicit assumption that the flame 
behaves as a solid body. The success of these models in correlating experimental results for flame bending angle provides support for this type of analysis.

Models utilizing the assumption that air entrainment into plumes is proportional to ambient wind velocity have been developed by Albini [138] and Carxier, Fende11, and coworkers [120-122]. These models lead to specific predictions concerning fire intensity [138], flame angles [138], and rates of fire spread [120-122]. Comparisons [112,123] have shown that predictions based on this model of plume behavior fail to predict the experimentallyobserved dependencies of these properties on wind velocity. This result strongly suggests that the assumption that entrainment into buoyant plumes is proportional to $U_{0}$ is inappropriate.

This is a case where a combination of theoretical and experimental analysis has allowed a choice to be made between two very different physical processes which are proposed to describe a complicated physical behavior. The success of the approach demonstrates the importance of synergetic efforts involving experimental and theoretical research.

\subsection{Final Comments on Fire Behavior}

As has been shown, a large number of experiments and theoretical treatments have been developed for fire spread through various fuel matrices formed from individual fuel elements. All of the findings reported are consistent with the assertion of Chandler [85] (see Section 8.1) that overhead flame radiation plays a relatively minor role in the heat transfer responsible for fire spread and that convection is generally the most important mechanism. It is important to note that the fuel beds which have been discussed are relatively small and do not generate flames as large as those expected from a 
building. This suggests that flame radiation might possibly dominate fire spread between buildings as has often been suggested. At the same time, no systematic investigations of the relative importance of convection and thermal radiation as a function of flame size were identified and it is impossible to predict for what size fire, if any, where radiation might be expected to dominate.

\section{FIREBRANDS AND FIRE SPREAD}

During large wildland and urban fires it is often observed that pieces of solid fuels which are burning can be lifted by the buoyant plume of a fire and deposited at large distances from the fire. The locations where firebrands are most likely to fall are on the leeward side of the fire. It is well known that firebrands can result in "spotting" of wildland fires at significant distances from a fire front and do contribute significantly to the fire spread rate and the ability of fires to jump firebreaks. Albini [139] provides an indication of the distances involved when he notes that fires of "intermediate" fire severity can ignite spot fires at distances of 1.6 to 3.2 $\mathrm{km}$. He also notes that spotting distances as large as $16 \mathrm{~km}$ are possible for running crown fires or when fire whirls are generated. Berlad and Lee [140] cite examples of fire brand transport over ranges on the order of $16-30 \mathrm{~km}$.

These authors propose that these firebrands are transported by large vortices shed by a convective column in a crosswind. The review by Lee [141] provides a good description of how firebrands can cause fire spotting and increase fire spread rates.

The contribution of firebrands to urban fire behavior is much less well characterized, but is generally regarded as being very important during periods of high ambient winds when conflagrations are most likely to occur. 
Descriptions in the paper by Lee and Granito [8] suggest how critical the role of firebrands may be in urban fire spread. Firebrands resulted in the ignition of fires in other towns and across large bodies of water. The importance of fire spread by firebrands is indicated by its inclusion as one of the areas requiring investigation in the report by the Committee on Fire Research of the National Academy of Sciences [16].

Every discussion of propagating large fires mentions the possibility that firebrands may be very important in determining fire spread rates. This is true of the models for urban fire spread discussed in Section 7.3. However, Weisbecker and Lee [21] observed that only the IITRI model [43] incorporated a firebrand fire spread model and that this model was "based upon empirical functions derived from inadequately documented data."

There have been some experiments and theoretical efforts designed to characterize firebrand formation, properties, transport, and fire-starting capabilities. The most relevant dealing with firebrand properties are the studies of Tarifa and coworkers $[142,143]$. These authors reported measurements of aerodynamic drag and mass of firebrands as functions of time and relative wind velocity. The experiments were performed in various wind tunnels. The important conclusion was reached that firebrands always fly or fall at their final terminal velocity. The terminal velocity decreases continuously as the firebrand burns. Measurements investigated the role of initial size and shape of the firebrand on the terminal velocity and burning time. Using their findings it is possible to calculate the maximum spotting distance for firebrands released at a specified height in a crosswind. The authors noted the requirement to characterize the convection column in order to be able to predict the initial height achieved by firebrands. 
Waterman has reported experimental studies of firebrand generation by various types of roofing constructions when subjected to a building fire [53], and Waterman and Takata have investigated the capability of various types of firebrands to ignite different flammable materials [54]. Several conclusions were reached concerning firebrand production [53]. Firebrands are formed by materials which have lost their volatiles and are in a state of glowing combustion. By far, the worst type of roofing material is wood shingles. The greatest determinant of firebrand production was the buildup of internal pressure below the room due to ambient wind or the presence of a large fire. The ignition studies [54] showed that the largest brands $(>2.5 \mathrm{~cm}$ ) are the most dangerous. Weathered wood and wood shingles are extremely susceptible to brands, but exterior hosts of sound wood are not. Materials such as cardboard, paper, canvas, cotton padding, and fabrics are susceptible to firebrand ignition. Of these, the interior materials will be most numerous and capable of igniting spot fires. Due to the importance of interior fuels, blast-damaged areas would be highly prone to firebrand fire spread.

Vodvarka $[55,56]$ has summarized the results of studies designed to investigate firebrand production by fires in full-scale structures. Firebrands were detected by lying plastic sheets on the ground at various locations and distances from the structures and noting the sizes of holes burned through the plastic by firebrands. Brands were classified by size and distance from the fire. The largest firebrands tended to fall at distances within a few tens of meters of the structures. One fire [56], designated 68-2, burned very rapidly and developed fire whirls when the roof caved in. After the fire many firebrands, with one having an area of $225 \mathrm{~cm}^{2}$, were found $800 \mathrm{~m}$ from the building. 
In [56] results of observations by experts at accidental fires are discussed. In general, the firebrand distances and dangers were considerably larger in the accidental fires than suggested by the test burns. In one fire in a large factory, several roofs of adjacent buildings were ignited, despite the efforts of fire fighters, including one at a distance of $130 \mathrm{~m}$ and grass fires were ignited at distances up to $240 \mathrm{~m}$. In [55] some experiments in higher ambient winds are reported. As expected, the number of firebrands at larger distances increases with wind speed.

It is clear why modeling fire spread as a result of firebrands is so difficult. It is necessary to incorporate a large number of parameters for which very little experimental information is available. For instance, it is necessary to know the number and distribution of firebrands generated by the fire, the heights to which these firebrands are lofted by the fire, the behavior of the firebrands after they leave the fire plume and begin to fall to earth under the influence of an ambient wind which is expected to vary in velocity as a function of height, the probability that a firebrand will survive until it reaches the ground, and the probability that a firebrand of a given size will contact and ignite fuels capable of creating a spot fire.

No attempt has been made to model this extremely complex problem, but models have been developed which attempt to estimate the maximum spotting distance possible for given fire conditions. The most ambitious of these efforts is that of Albini [139] who developed such a model for the situation where a single tree or small group of trees "torches out". His overall model was formed by combining submodels for A) flame structure, B) the buoyant plume above a steady fire, C) firebrand burning rate, D) lofting of firebrands by a plume, E) surface winds over rough terrain, and F) firebrand trajectories. Several factors are not treated by the model. These include the probability 
of trees burning, availability of optimum firebrand material, probability of spot fire ignition, and the number of spot fires. Note that the nature of the fire for firebrand generation is an input parameter. Albini has extended his analysis to isolated fires [144] and wind-driven surface fires [145]. Morris [146] has incorporated these models in a simple hand-held calculator program which can be utilized by field personnel to estimate maximum spotting distances for tactical fire-fighting purposes.

As will be discussed in the following section, fire whirls are often observed during large fires. These fire whirls are characterized by high upward velocities and are therefore capable of lifting larger firebrands to greater heights than a "normal" fire plume. Muraszew and Fedele [147] have considered the increases in spotting distance which can be expected if fire whirl activity occurs. These authors claim that an ordinary thermal plume can only transport small particles $\approx 150 \mathrm{~m}$ from a fire. Utilizing data for upward velocities from an earlier investigation of fire whirl [148], trajectories of a flat plate simulating a firebrand were calculated for fire whirls having heights of 610,910 , and $1220 \mathrm{~m}$. For these conditions, the maximum possible distances of firebrand travel were in the range of 1.5 to $3.4 \mathrm{~km}$ for an imposed wind velocity of $9.1 \mathrm{~m} / \mathrm{s}$. These findings imply that the generation of fire whirls probably has a very important effect on the rate of fire spread. Lee and Hellman $[149,150]$ have reported similar analyses of firebrand behavior. Berlad and Lee [140] suggest that vortices which shed from a large fire and are carried downstream by the ambient wind may actually transport firebrands over even longer distances.

It should be clear from the discussion of this section that it is likely that firebrands play an important role in determining the spreading rate of large fires in the urban environment. At the present time, it is nearly 
impossible to estimate the contribution of this fire-spread mechanism quantitatively.

\section{FIRE WHIRLS}

In this section the development and characteristics of fire whirls are reviewed. Discussion is limited to localized fire whirls. Fires in which the entire convection plume is rotating were discussed in Section 7.4.1. There are numerous observations of fire whirls in large fires, and several different types of fire whirls have been described. A particularly vivid description of the formation and behavior of a fire whirl in a brush fire can be found in the report of Lohneiss [142].

Soma and Saito [33] have described three different types of fire whirl. One type is the tornado-like fire whirl which descends from the leeward side of a strong fire plume in a mild crosswind. This kind of fire whirl was observed by Dessens [77]. Soma and Saito [33] provide another example by showing a strong fire whirl formed near a burning ship. A second type of fire whirl developed during the deadly Tokyo fire of 1923. This fire whirl was responsible for the deaths of 38,000 people. The whirl formed in an open area with no fuel to support combustion, but which was surrounded on three sides by a mass fire. An ambient wind of $4-5 \mathrm{~m} / \mathrm{s}$ blew across the fire area in the direction of the open area. The third type of fire whirl discussed by Soma and Saito [33] is the Hamburg type of firestorm. A list of many large fires is provided in which fire whirls are believed to have occurred and the type of whirl is assigned.

Emori and Saito [32] have described a violent fire whirl which formed on the side of a valley during a forest fire. The resulting increase in fire 
spread rate and burning intensity resulted in injuries to a large number of fire fighters.

As discussed in the last section, Berlad and Lee [140] have suggested that fire whirls propagating downstream from a large fire may be responsible for fire spotting at distances greater than $10 \mathrm{~km}$.

Countryman includes a discussion of fire whirls in his paper on mass fires and fire behavior [6]. These fire whirls are observed to occur near the edges and next to intensely burning fires. Whirls as large as $400 \mathrm{~m}$ across and a kilometer into the atmosphere have been observed. Wind velocities large enough to uproot trees and destroy building have been documented. Countryman claims that fire whirls contribute greatly to fire spread because of their ability to pick up and scatter burning fuels (firebrands). Some factors which appear to favor fire whirl formation are an unstable atmosphere, vortical motion in the ambient atmosphere, and fire on the lee side of a range.

Fire whirls were observed in every test burn carried out during the Flambeau fire tests [79]. A description by observers [152] of one of these fires provides a vivid account of the behavior of these fire whirls. "By far the most impressive phenomenon observed was the violent fire whirls occurring between 21 and 40 minutes after ignition. These whirls were an estimated 5 to $10 \mathrm{ft."} \mathrm{(1.5} \mathrm{to} 3.0 \mathrm{~m})$ "in diameter at the base and could develop into a narrow luminous column $2000 \mathrm{ft."} \mathrm{(600} \mathrm{m)} \mathrm{"} \mathrm{in} \mathrm{height} \mathrm{within} 2$ seconds. Their violence was also attested to by a sound most akin to that of a jet plane which occurred simultaneously with their development. The luminosity of these whirl columns suggests that combustion was still going on."

Countryman [79] summarizes the fire whirl activity found in the Flambeau series. Fires whirls tend to form on the lee side of these fires. He notes that this is the position of strong vortex activity due to fire blocking 
effects on the ambient wind. Often two fire whirls, of opposite rotation, were observed. Figure 20, taken from Berl's review [153], shows the formation of this type of fire whirl. Also included in the figure is a schematic representation of the fire whirl generated in the Dessens study [77]. Fire whirls are more likely for fires where the convection column is leaning due to the presence of ambient wind.

Countryman [79] notes that fire whirls in the urban environment may be very hazardous. This increased danger not only results from increased fire spread rates, but also as a result of the transport of noxious gases and the depletion of oxygen. He also notes that the formation mechanisms of fire whirls are not well characterized, but seem to be dependent on the presence of ambient vorticity.

Palmer [154] has noted that the high-energy fires which generate the vertical vortices shown in Figure 20 can also produce counterrotating horizontal vortices in the presence of a strong wind which propagate in front of the fire. Such vortices are not well-characterized, but it seems clear that they should be capable of transporting flames, hot gases, and firebrands, and therefore have the potential to greatly accelerate fire spread rates.

In one of his full-scale experiments on firebrand formation, Vodvarka [56] observed fire whirl formation during the intense burning of an individual house. These fire whirls may have been responsible for the long-range firebrand transport which was noted for this particular test.

Fire whirls are obviously a common occurrence in large fires. It is interesting to find that fire whirls are often observed during small-scale fire testing as we11. A few examples of these experiments are mentioned here. The physical modeling work of Emmons and Ying [58] and Byram and Martin [59] on the role of ambient vorticity in firestorm formation has already been 


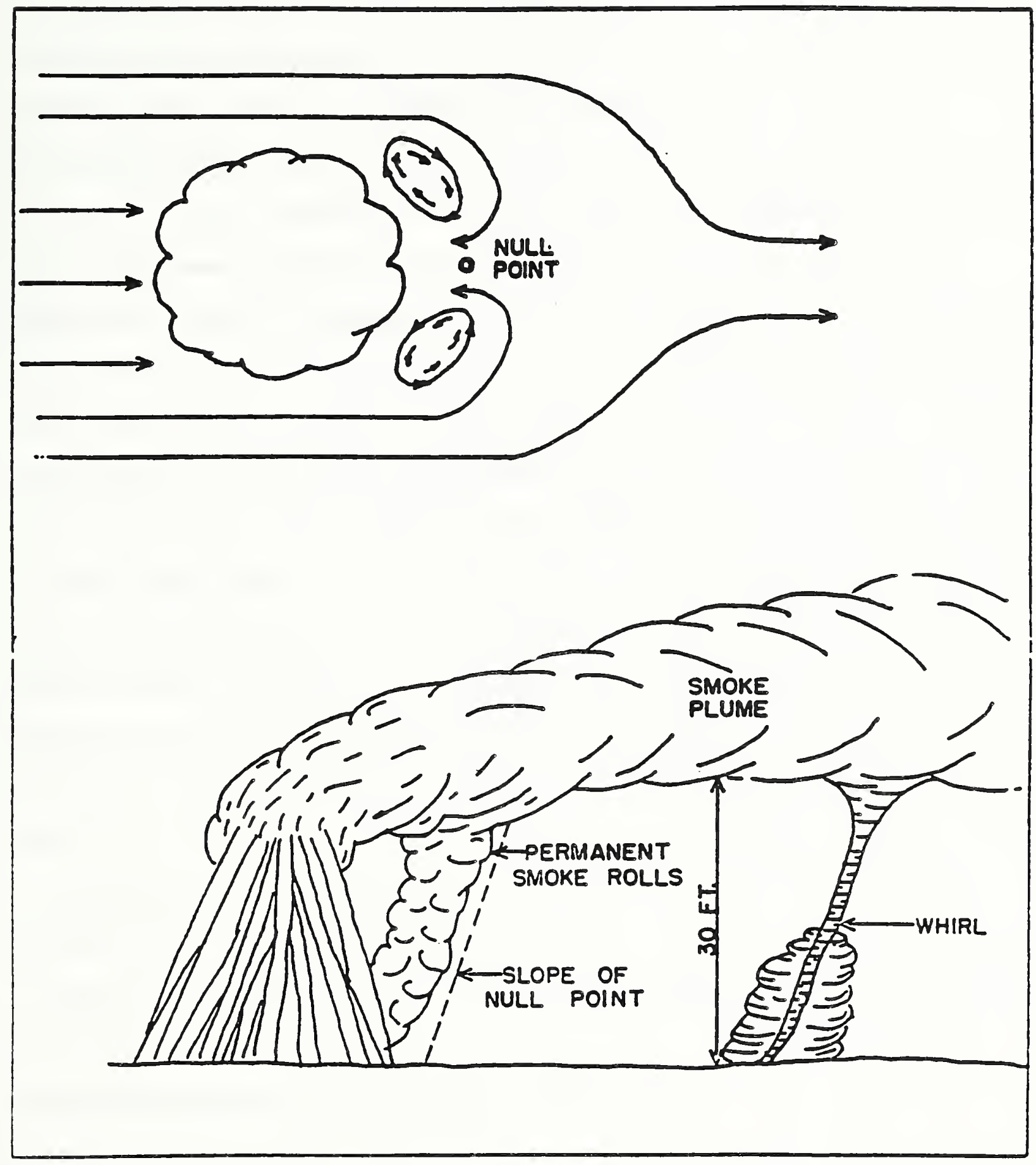

Figure 20. Schematic diagram of fire whirl development behind a bonfire. The whirls are reported to be formed when one of the "smoke rolls" breaks off from near a null-point in back of the wood structure. Figure reproduced from [153]. 
discussed. In a similar experiment for a line fire, Lee and Garris [155] observed the formation of multiple fire whirls in the presence of an imposed ambient vorticity. Emori and Saito [32] and Soma and Saito [33] have modeled the development of fire whirls observed in large fires with scale models. Fire whirls having the proper characteristics were formed.

Fire whirls are often observed in laboratory fire tests involving multiple fires. In laboratory tests designed to mimic a Flambeau fire, Thomas et al. [156] burned multiple small fires. Persistent fire whirls were often observed. These fire whirls had diameters which were considerably smaller than the fuel bed and attained much higher flame heights than observed for the periods of burning during which whirls did not form. Most fire whirls developed as the fires died down and were not usually in the center of the fire bed, but for the largest bed a strong fire whirl was observed over the center. These authors attributed the formation of fire whirls to vorticity in the air flow into the laboratory which was generated by a slight asymmetry. Waterman et al. [12] observed similar fire whirls during laboratory attempts to burn multiple fires.

The effects of a whirlwind on the burning rates of wood cribs has been investigated by Martin et al. [157]. These workers found that the mass loss rates for the cribs increased by 1.4-4.2 times when fire whirls were induced above the burning cribs.

Lee and Otto [158] have investigated the interaction of two small wood crib fires (e.g., for cribs having dimensions of $61 \times 30 \times 10 \mathrm{~cm}^{3}$ ). A slight ambient crosswind of $40 \mathrm{~cm}$ was present. The cribs were oriented facing each other at a distance of half their length and offset longitudinally to each other by half a crib length. When both cribs were ignited a range of burning behaviors and a number of different types of whirls were observed. 
The most conspicuous whirl formed at a position between the burning cribs and dramatically affected their burning behavior. This whirl became strong enough to draw flames through the side of the cribs facing the "street" between the cribs and these flames along with firebrands were entrained into the whirl. Smaller fire whirls were created and moved away from the fire in the lee direction. Both types of whirls were observed to transport firebrands. As the fires began to die, the primary vortex collapsed and a large number of small fire whirls were observed to move away from the fire region, again transporting firebrands. If the fire behaviors observed in this small-scale experiment occur in large fires, it is clear that fire spread and burning rates will be much higher in fires where multiple buildings are on fire than expected based on the burning behavior of individual buildings in the absence of interactions. In his studies of two burning wooden cribs aligned in the direction of flow in a wind tunnel, Rios [117] noted that vortices formed at a position between the two cribs.

Taken together, the above findings indicate that the formation of fire whirls due to the interaction of localized fires is a general phenomenon.

\section{INTERACTIONS OF MULTIPLE FIRES}

There has been a great deal of interest in the merging behavior of flames from individual fuel sources. The principal impetus for this interest has been the attention focused on mass fires which are usually assumed to burn as a single coalesced fire. It is also known that the interaction of flames can change such properties as the fuel consumption rate and flame heights from those observed when the fires burn independently. It is probable that when individual fires are interacting the fire spread rate is modified as well. 
The importance of flame merging to mass fire behavior has taken on new significance since recent efforts to predict wind speeds induced by mass fires have made very different assumptions concerning the nature of fire-plume interactions (see discussion in Section 7.4.2). One approach has considered the individual fires to be entraining air individually, while the second assumes that air is entrained by a single convective fire plume. The calculated behavior depends critically on plume merging characteristics.

Theoretical models for the modifications in flame behavior due to flame interactions are not very well developed, but, fortunately, a large experimental data base is available and the behaviors to be expected are fairly well characterized. A short, but enlightening, general introduction to the effects of flame interaction on the burning behavior of individual fuel sources is provided by Waterman et a1. [12].

For an isolated fire in the absence of wind, entrainment of air occurs equally well from any direction and the fire plume is vertical. However, the plume is highly susceptible to pressure forces. When a second fire is close enough to interact with the first the flow of air is restricted between the plumes and entrainment decreases from these directions. There is a small pressure decrease along the line connecting the fire plumes and they bend toward each other slightly. The change in flame orientation modifies the heat feedback to the fires and hence changes the burning rate. It is also possible for the interacting fires to transfer heat from one to another. As the flames are positioned closer and closer together all of these effects interact until the two fuel beds coalesce and the two fuel beds burn as one. These same types of interactions occur when several fuel beds are considered, but the interactions between the various effects becomes more complicated. 
One of the earliest studies of fire interactions was reported by Putnam and Speich [159]. These workers studied fuel arrays formed by natural gas jets. Conditions were utilized such that the gas fuel flow rates were low enough to generate flames dominated by buoyancy-induced momentum. The use of gaseous fuels eliminated the complication of heat feedback in determining the burning behavior. Measurements of flame lengths were recorded for single fires and for various numbers (maximum of 19 used) of fires with different spacing. Results were presented in terms of dimensionless parameters in which array-flame height/single-flame height, number of jets, source-shape factor, and flame spacing/(fuel-flow rate) $2 / 5$ were deemed the most important.

For a wide range of number of jets, $n$, and spacings, $S$, a collapse of the data was found when $\left\{\left(L / L^{*}\right)-1\right\} /\left(n^{0.4}-1\right)$ was plotted against $S /\left(Q_{0}^{2} / g\right)^{1 / 5}$ where I is the observed flame height of the array and $L^{*}$ is the flame height of an individual flame. A theoretical analysis was performed which was based on three assumptions: 1) entrainment of air into a given jet of the array is partially blocked by the presence of the other jets, 2) total mass flux of air into a given flame at the tip is constant, and 3) the individual flame jets in an array are not bent by their interactions. Predictions of flame length behavior based on these assumptions were in poor agreement with experimental findings. This failure was attributed to a breakdown of condition 3 .

Baldwin et al. [160] considered the interactions of two and four natural gas flames. Their experimental results demonstrate that when two flames are interacting they bend toward each other. A simple theory of these interactions was derived based on the degree of mutual blocking of entrainment and the resulting pressure forces as a result of flame interaction. In general, the experimental and theoretical calculations were not in good agreement. Comparison of predicted flame heights for a large fire in two 
stacks of wood in a lumber yard showed that the analysis did provide order-ofmagnitude flame height estimates.

Welker and Sliepcevich [129] and Huffman, Welker and Sliepcevich [161] have investigated the interactions of multiple liquid pool fires. In a preliminary report [129] measurements were reported for circular (10.6 cm diameter) and square pools $(7.6 \mathrm{~cm}$ sides). Nine circular burners were arranged with a single burner in the center surrounded by eight equally-spaced burners at a distance $\mathrm{S}$. Nine square burners were place in three equallyspaced rows of separation $S$. The pools were filled and ignited simultaneously and allowed to burn to depletion. Rims were above the table surface and therefore subject to heating. The table was weighed and the burning rate could be monitored by the mass loss rate of fuel. Tests were made with a variety of liquid fuels. Radiation intensities were recorded at a constant distance from the edges of the fires.

Measurements of burning rate were plotted as a function of $S$ for both burner configurations. Except for methanol, the same general behavior was observed for all of the fuels. As $S$ was decreased the burning rate increased significantly (up to a factor of 3) until a critical separation distance was attained. Further decreases in $\mathrm{S}$ resulted in lower burning rates. Measurements of flame radiation intensity showed similar behaviors.

This group of workers then performed a considerably more sophisticated experiment using circular pool fires of 5.1, 10.2, and $15.2 \mathrm{~cm}$ diameter [161]. Circular patterns of nine and thirteen pools were arranged as shown in Figure 21 which is taken from their report. The rims of the pools were flush with a flat surface, and a constant-level fuel-feed system was used to maintain a constant fuel level. Fuel burning rates were obtained by measuring fuel- 


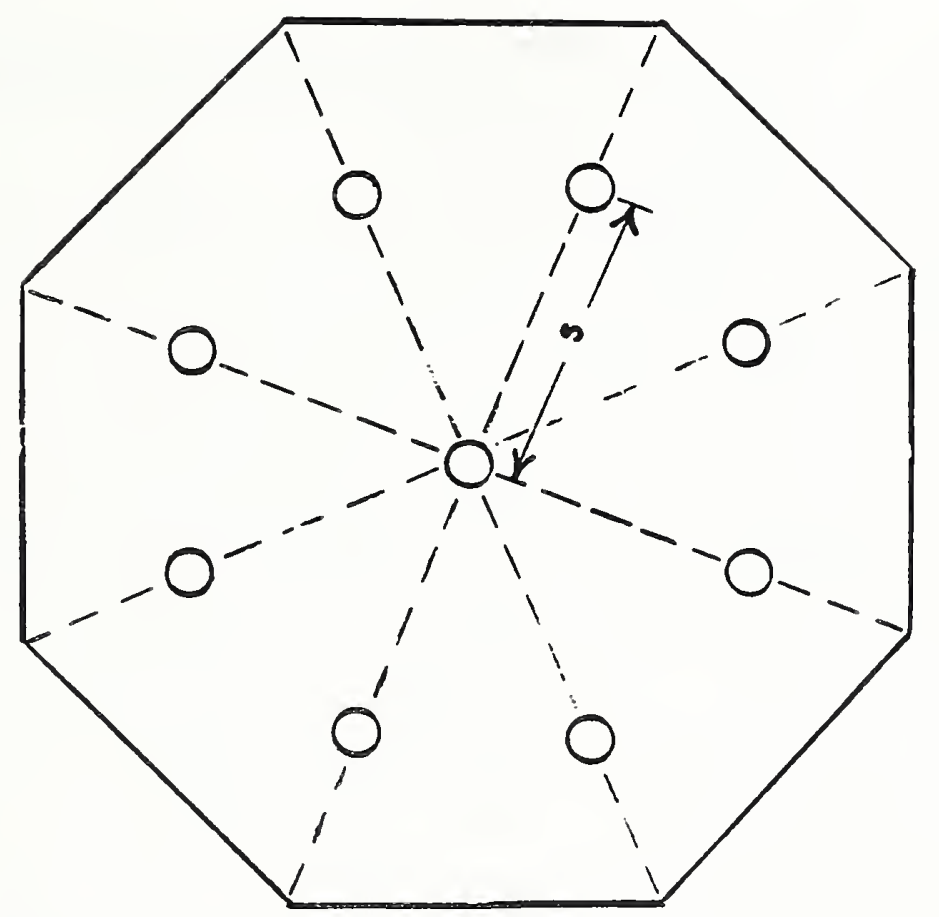

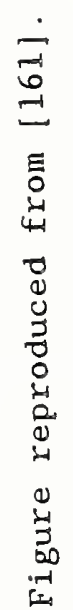
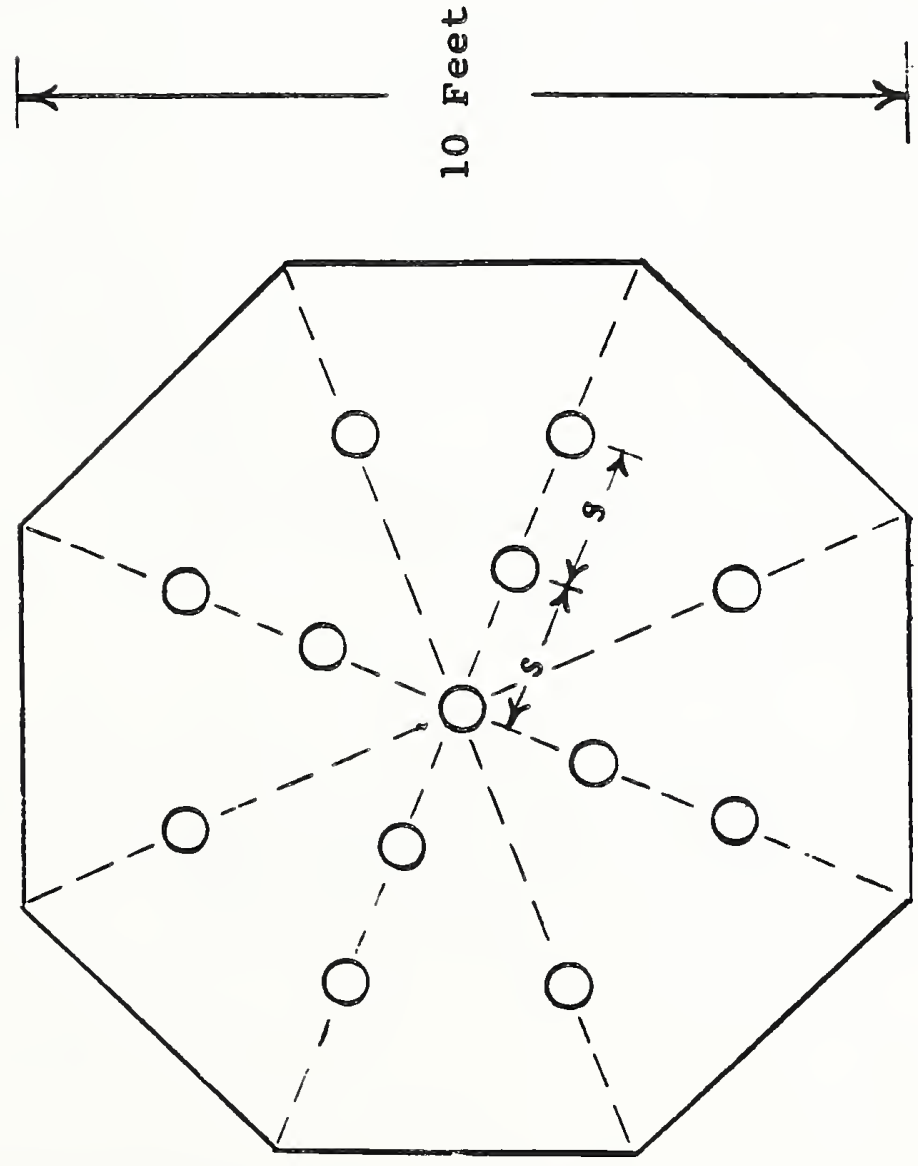

 
rates. Independent measurement systems were employed for each type of pool position. A variety of fuels were employed.

Figure 22 shows an example of results for a nine-pool pattern. Some very interesting effects are evident. At large distances the burning rate for the central pool is decreased from that for an individual burner by interaction with the flames of the outside pools while the outside pools actually consume fuel at a slightly increased rate. As $S$ is decreased, pool fires of both burner types have increased burning rates, but the central pool fire achieves a much higher rate. The center burner reaches a maximum burning rate at $S / D \approx$ 2.8 and then begins to fall off while the burning rates for the outer pool fires continue to rise.

The burning rate behaviors in Figure 22 indicate how complicated flame interactions are. This complicated behavior is the result of variations in radiative heating due to changes in flame angles and mutual heating by pool fires, and air blockage effects which occur as the pools are brought close together. This air blockage effect can become large enough that a layer of vaporized, but unburned, fuel forms above and around the central pool. This unburned fuel results from vaporization of fuel for which insufficient air is available for combustion. The maximum enhancement of burning rate and the nondimensional location, $S / D$, where the maximum occurs vary with fuel. An empirical analysis [161] showed that the data could be collapsed in terms of the dimensionless variables shown in Figure $23 . \mathrm{m}_{\mathrm{p}} / \mathrm{m}_{\mathrm{a}}$ is the ratio of the burning rate at the onset of flame merging divided by the burning rate for a single fire, $\rho_{g} / \rho_{a}$ is the ratio of the fuel density at its boiling point and the ambient density, and $\Delta \mathrm{H}_{c} / \Delta \mathrm{H}_{\mathrm{v}}$ is the ratio of heat of combustion to heat of vaporization for the fuel. 


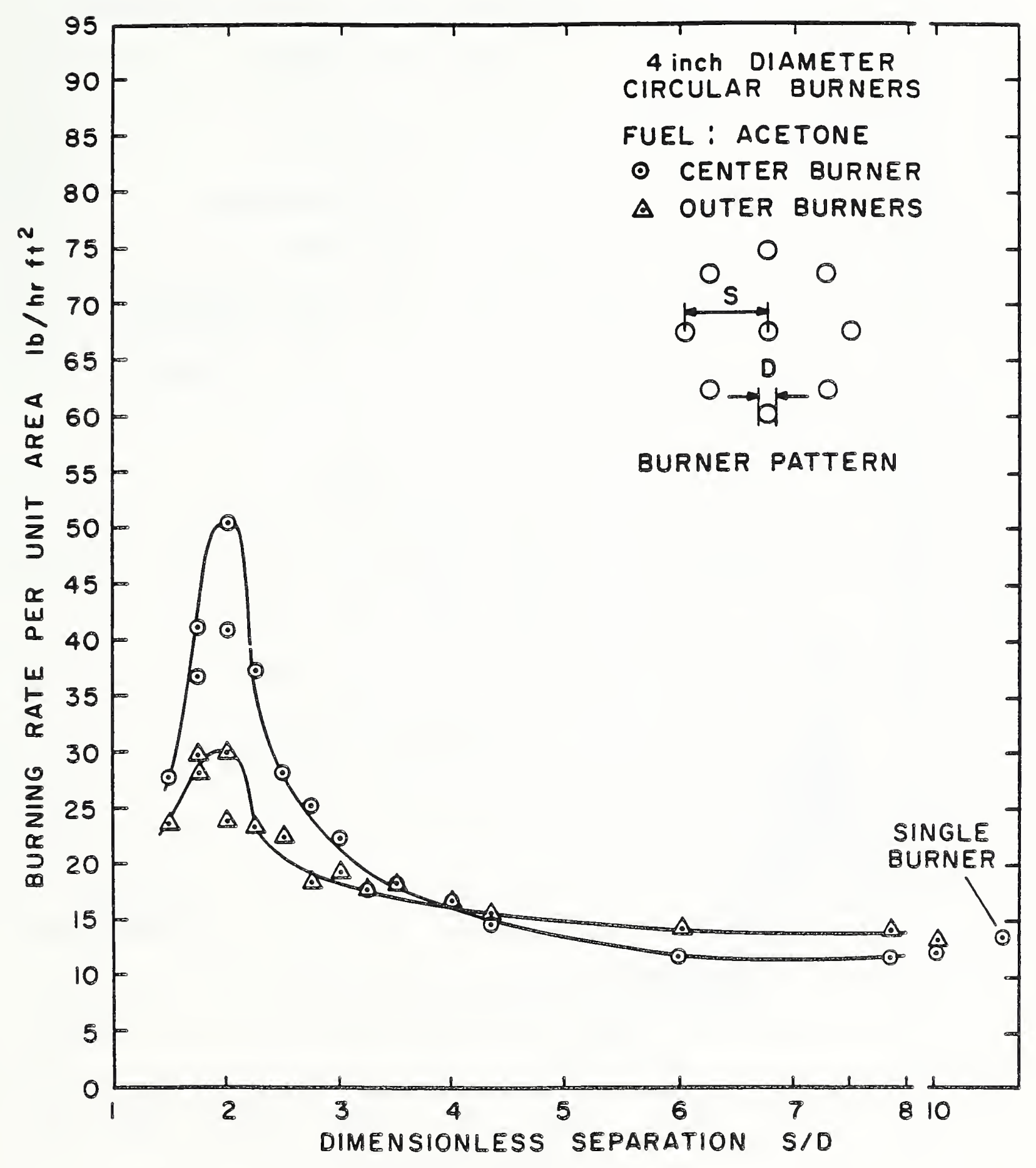

Figure 22. Burning rates of interacting 6 -inch n-hexane fires. Figure reproduced from [161]. 


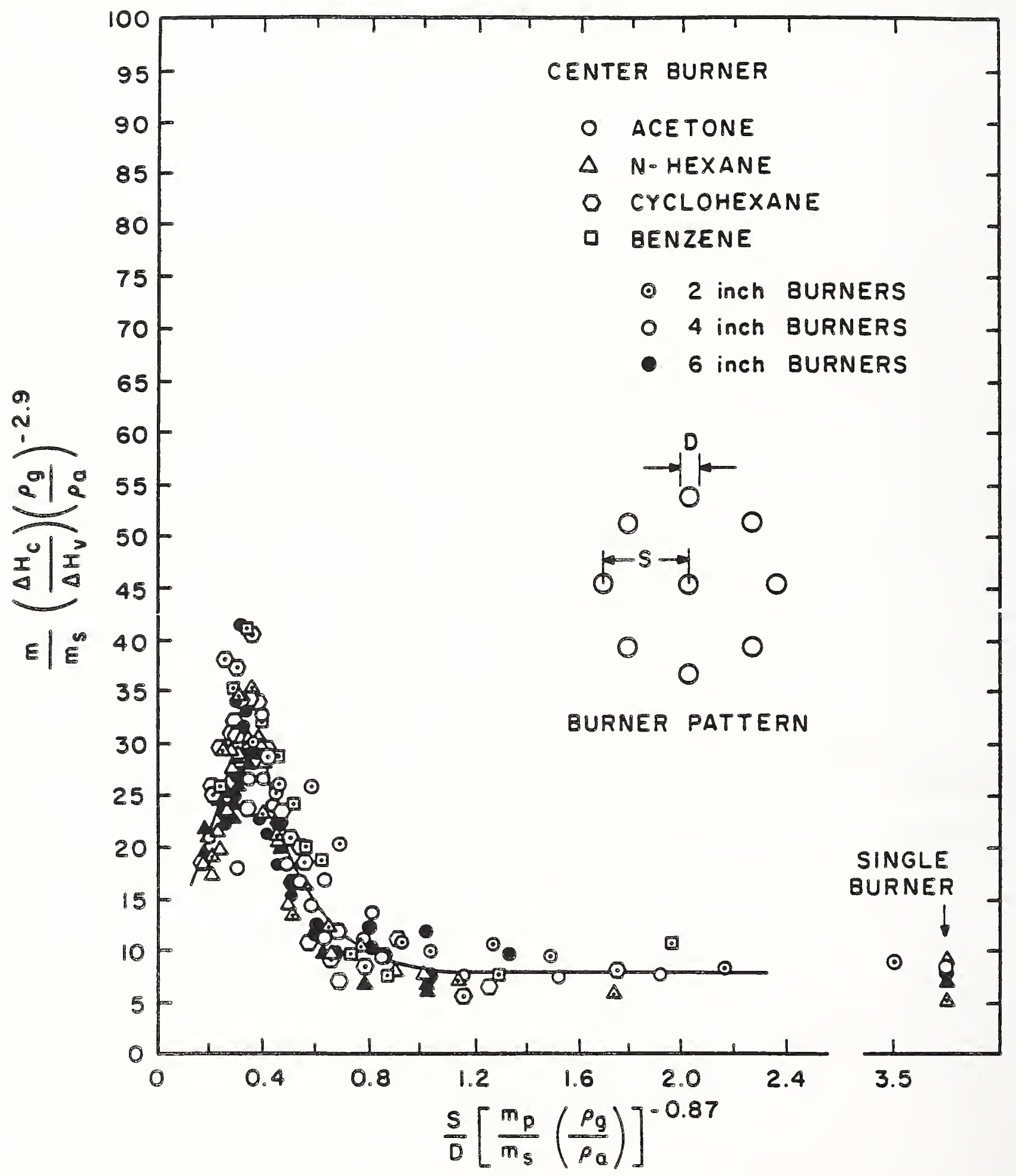

Figure 23. Correlation of center burning rates for all fuels. Figure reproduced from [161]. 
Waterman et al. [12] investigated flame interactions for considerably larger fires. Experiments were reported for up to 36 pool fires having individual pool sizes of $1.5 \mathrm{~m}$ square and for smaller numbers of fires having pool sizes as large as $4.9 \mathrm{~m}$ square. Fuel burning rates were measured. After several such experiments the authors concluded that pool fires were too sensitive to ambient wind effects and decided to investigate wood cribs for which the burning behavior was found to be much less sensitive to ambient winds.

A total of sixty-three experiments were performed using a variety of wood crib sizes, total numbers of cribs, and spacing. Experimental measurements included mass burning rate, temperatures above the center of the fuel bed, radiation levels, air velocity measurements, and photographic records.

Figure 24, which is taken from their report [12], shows examples of the results for different types of cribs plotted as functions of dimensionless crib separation. As the separation distance is decreased, the burning rate first increases rapidly, reaches a maximum, and then begins to decrease. The rapid decrease in burning rate observed when the separation distance is increased beyond that required for a maximum is attributed to the loss of coalescence of the flames [12]. The decreased burning rates observed when the separation is decreased further results from the limited air which can penetrate the inside regions of the fire. Note in the figure that it is possible for the interacting fires to have a lower burning rate than when the fires are independent.

A correlation of the data in terms of the burning rate of a single crib and the nondimensionalized crib separation distance allowed the separation distances for maximum burning to be correlated. Other attempts to correlate 


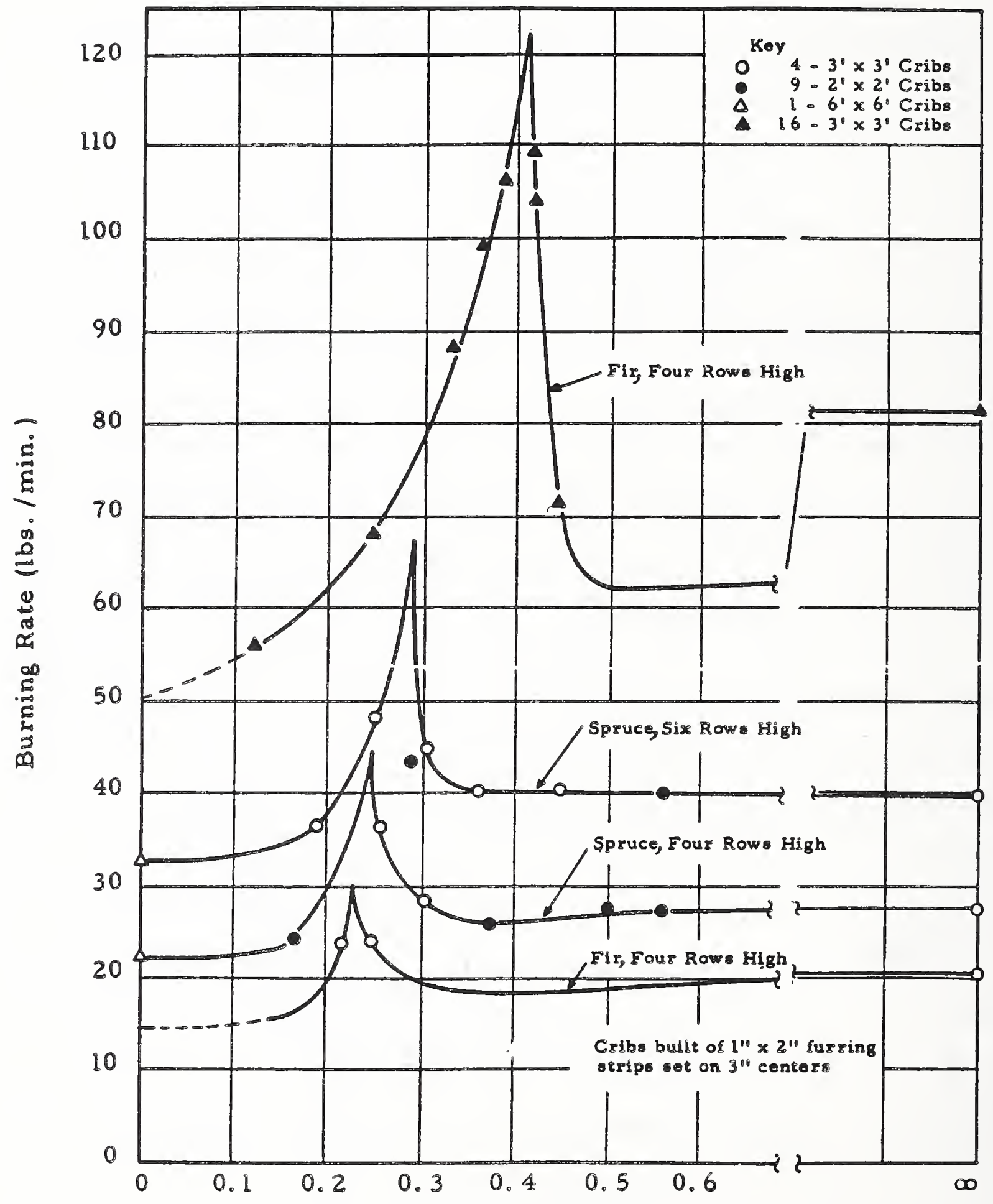

Distance Between Cribs/Width of One Crib

Figure 24. Burning rate as a function of the distance between cribs. Figure reproduced from [12]. 
the data were not successful. Flame length measurements for the coalesced fires were in reasonable agreement with Thomas' correlation [103].

The results discussed thus far only describe the flame interaction expected in the absence of wind. Only one study [117,118] has been identified which considers the effects of an ambient wind on interacting fires. Rios investigated the behavior of two burning wood cribs in a wind tunnel. The only configuration investigated was one where the first crib was located downstream from the second. The cribs were constructed from five layers of $1.9 \mathrm{~cm}$ square sticks with $1.9 \mathrm{~cm}$ spacing. The width of the fuel bed was 91 $\mathrm{cm}$. The sides were partially blocked to insure a constant fire spread rate across the width of the fuel bed.

Rios utilized an ingenious fuel-feed mechanism which allowed the spreading crib fires to be maintained at two independent positions in the wind tunnel. In this way it was possible to measure the flame spread rate for both fires. Other measurements reported are flame lengths and bending angles from photographs and temperature measurements utilizing a thermocouple rake.

The temperature measurements indicated that for lower wind velocities the ceiling of the tunnel was heated by impingement of the fire plume. At higher wind velocities this did not occur as the bent plume did not reach the ceiling. Reference is made to significant radiative heating of objects near the wall of the tunnel due to the fires [117].

Flame heights observed during the experiments were nearly independent of wind velocity for both fires. This was true despite the fact that flame lengths and bending angles were highly dependent on this parameter. It was possible to correlate the lengths of both upstream and downstream fires in the manner suggested by Thomas [103] where L/D was plotted against $\dot{\mathrm{m}}^{\prime \prime} /\left\{\rho_{\mathrm{a}}(\mathrm{gD})^{\frac{1}{2}}\right\}$. 
The exponent for the latter term was 0.74. It was also found that the flame length depended on the depth of the flaming zone to the 0.36 power.

Data for the dependence of the fire spreading rate were reported by plotting the depth of the flame zones for an individual fire and for the two interacting fires as functions of wind velocity. The spacing between the two fires was varied from 0.61 to $1.5 \mathrm{~m}$. At low wind velocities the spread rate of the upstream fire was enhanced by the presence of the downstream fire while the downstream fire spread at a slower rate than a single fire. For higher wind velocities $(>\approx 0.6 \mathrm{~m} / \mathrm{s})$ the rate of spread for both fires was considerably reduced from that observed for a single fire. The spread rate for the upstream fire was higher than for the one located downstream.

The flame bending angles for the upstream and downstream fires were measured as a function of flame separation. The findings are summarized in Figure 25 [117] where it can be seen that a correlation of the results is obtained when the ratio of bending angles is plotted in terms of a modified Froude number based on the separation of the fires.

The experiments discussed above indicate that interaction effects of fires burning on individual fuel beds can significantly modify burning rates and flame lengths. It is considered very likely that, as observed by Rios [117, 118], that flame interactions can also modify fire spread rates significantly. Such effects have not been treated theoretically.

\section{ROLE OF TURBULENT BOUNDARY LAYER IN FIRE SPREAD RATE AND BEHAVIOR}

Ambient winds in the atmosphere form a turbulent boundary layer along the Earth's surface which is characterized by increasing wind velocities as a function of height and significant velocity fluctuations [162]. The nature of the boundary layer is highly sensitive to the type of surface the wind is 


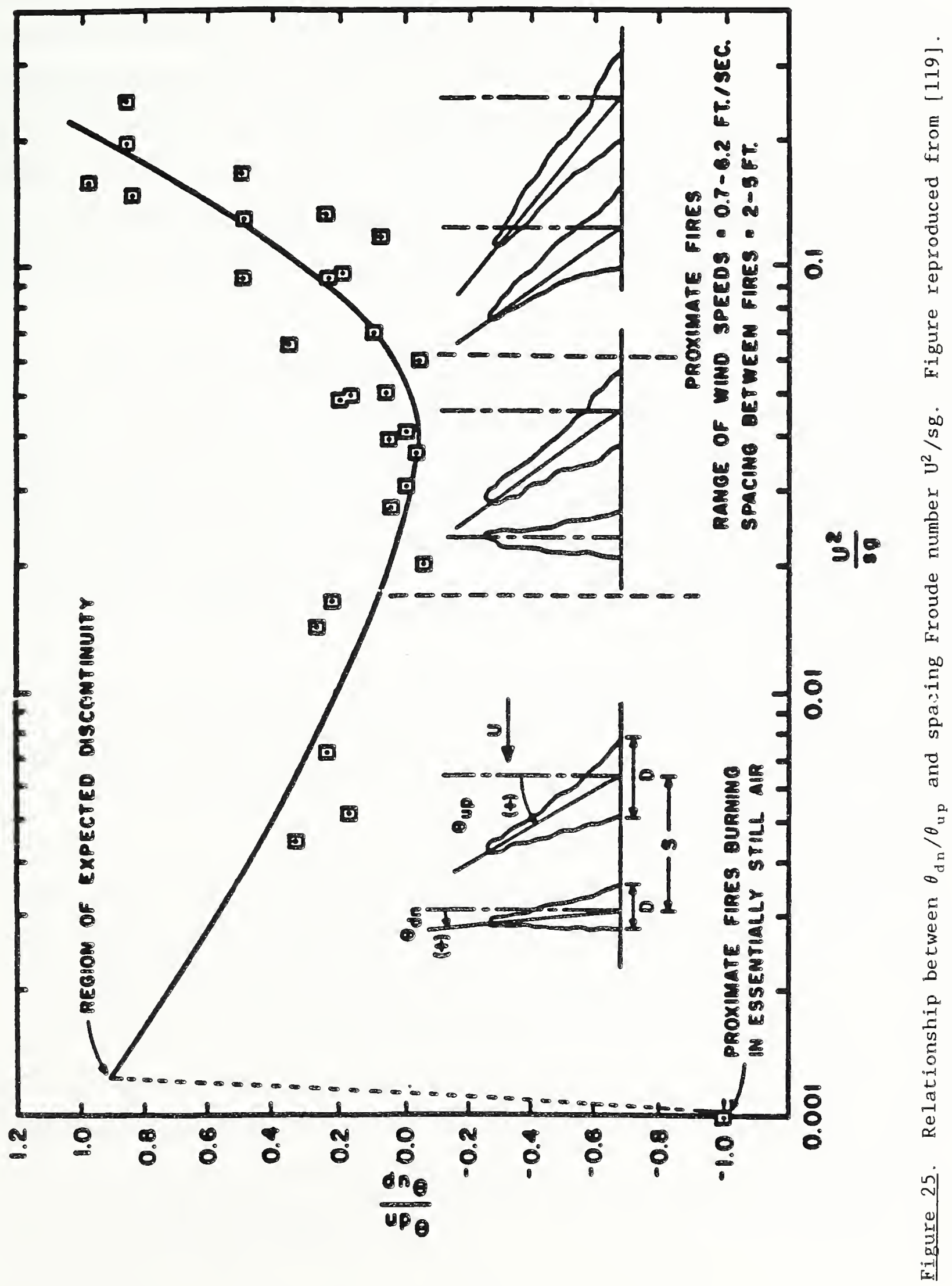


passing over. There has been very little consideration of whether the presence of turbulent fluctuations in the atmospheric boundary layer (ABL) affects fire spread rates or fire behavior. In one of the few discussions of whether or not atmospheric turbulence is important, Byram [179] has written "Probably, atmospheric turbulence can be neglected if $\pi_{6}^{\prime}=u / w$ is small. This would be the case for high-intensity fires and light winds." $u$ is the rootmean-square of the wind velocity fluctuations and $w$ is the updraft velocity of the convection column.

Emori and Saito [32] have incorporated turbulent fluctuations into a physical-model investigation of fire whirl development in the presence of a cross wind. One study [163] has been identified which has physically modeled the behavior of a fire plume from a large-area fire in a wind tunnel ABL. The major conclusion of this investigation is that the velocity and temperature behavior above a large-area fire can be simulated in the absence of rotation effects.

Albini [164] has developed a model of the response of a free-burning fire to wind fluctuations. This model is highly "speculative" [164], but it does predict that fire intensities and spread rates will be modified by the presence of wind velocity fluctuations.

Some qualitative ideas concexning turbulence effects on fire spread rates and fire behavior can be derived from observations made in wind tunnels. Wind tunnels which have been designed for fire studies all attempt to generate uniform velocity profiles with low tuxbulence fluctuations. In their early wind tunnel investigation of fire spread in wood cribs, Byram et al. [94] found that "in the laminar flow of the test section, the flames had a smooth 'unnatural' appearance." For this reason, a $5.1 \mathrm{~cm}$ barrier was placed across the tunnel upstxeam of the fuel bed. This barrier tripped formation of a 
turbulent boundary layer and "introduced enough turbulence to give the flames a normal appearance." Time-averaged velocity measurements were reported which showed that a turbulent boundary layer $0.4 \mathrm{~m}$ deep was created.

During early fire spread rate measurements as a function of wind velocity, Anderson and Rothermel [87,88] found that fire spread over the first half of the fuel bed occurred at rates anywhere from two to seven times higher than over the last half. This behavior was eventually traced to the formation of a rolling vortex over the first half of the fuel bed which was detected by smoke visualization and hot-wire anemometry. This observation suggests that turbulent fluctuations can dramatically alter fire spread rates. In order to overcome the problem of the rolling vortex, these researchers adopted the same solution as Byram et al. [94]. They installed a trip screen that "induced a turbulent boundary layer which was surprisingly uniform over the entire length of the fuel bed." [88] Fire spread rates became uniform over most of the fuel bed length.

Other workers (e.g., $[111,120]$ ) have made fire spread measurements in steady winds having low turbulence levels.

Even though qualitative experiments and preliminary analysis suggest that turbulence in wind flows can significantly affect fire spread rates and flame behaviors, there are no systematic studies available and it is impossible to predict what effects the existence of the $A B L$ has on fire spread in the urban environment. This conclusion means that the results of studies of wind effects on fire spread and behavior for which the flow field is steady or of a different form than the ABL cannot be utilized with complete confidence for predicting fire behavior in a real-world situation. Fire spread experiments performed in a steady flow and in a simulated ABL would allow the effects of turbulence to be characterized. 
13. IS IT NECESSARY TO BE ABLE TO PREDICT FIRE SPREAD ACCURATELY FOLIOWING A NUCLEAR DETONATION, AND IS AN IMPROVED UNDERSTANDING OF WIND-AIDED FIRE SPREAD REQUIRED?

One of the primary purposes of this investigation is to characterize the current understanding of fire spread following a nuclear attack and to provide a qualitative description of the uncertainties which are introduced by a lack of understanding of wind-aided fire spread. The discussion in earlier sections forms a solid foundation for such an assessment.

Clearly, our understanding of the fire environment following a nuclear explosion in or over an urban environment is poor. The uncertainties are emphasized repeatedly in the vast published literature associated with the subject. For this reason, a very general, but plausible, scenario for fire behavior following a nuclear explosion is developed for discussion purposes.

\subsection{A Plausible Scenario for Fire Behavior Following A Nuclear Attack}

Initiation Period ( 0 to 20 minutes)

In Section 7.3 a very idealized description of the environment surrounding ground zero immediately after the dissipation of the fireball and blast wave was provided. For convenience this description is repeated here:

1) A central core which is totally destroyed,

2) A severely blast-damaged ring in which an extremely high number of ignitions have occurred, and the fuel bed is a continuous, inhomogeneous mixture of combustible and incombustible materials.

3) A blast-damaged ring in which an extremely high number of ignitions have occurred, and for which the fuel is localized spatially as highly-damaged buildings and piles of debris.

4) A ring of lightly-damaged buildings where a high density of ignitions has occurred, and

5) An outer ring which is relatively intact and meets existing fire codes where the number of fire starts falls off with increasing distance from ground zero. 
Figure 26 is a pictorial representation of this idealized view. These conditions would be likely to occur for an air burst of greater than 1 Mt during relatively clear atmospheric conditions. No distance scale is defined, but a total radius on the order of tens of kilometers is likely. Of course, the local details would vary subject to innumerable factors, and the above description must be considered a gross oversimplification which is provided for general discussion purposes only.

In the period, lasting for roughly twenty minutes, immediately following the detonation a substantial fraction of the original ignitions begin to grow into fires. In ring 2, fire spread across the nearly continuous fuel bed is initiated. Further out from ground zero in rings 3 and 4, fire development would occur in individual piles of debris or damaged structures. Due to the damage, these fires will develop much faster than normally occurs in buildings. Isolated fires will grow in buildings located in ring 5 at a slower rate.

During the initiation period any ambient winds present are expected to modify fire development and spread. Since developing fires in buildings are relatively insensitive to ambient winds, the largest effect of wind is on rings 2 and 3 where ambient winds contribute to the rapid spread of fires across the continuous fuel bed and individual piles of debris. Ambient winds will substantially increase the fire spread rate and lead to more rapid coalescence of the individual fires.

\section{Period of Rapid Fire Growth (20 Minutes to 60 Minutes)}

After approximately 20 minutes a large fraction of the area in ring 2 will be burning due to the large number of ignitions and fire spread. In the same period the fires in rings 3 and 4 will have grown to the point where the fires are large enough to result in fire spread to adjacent unignited piles of 


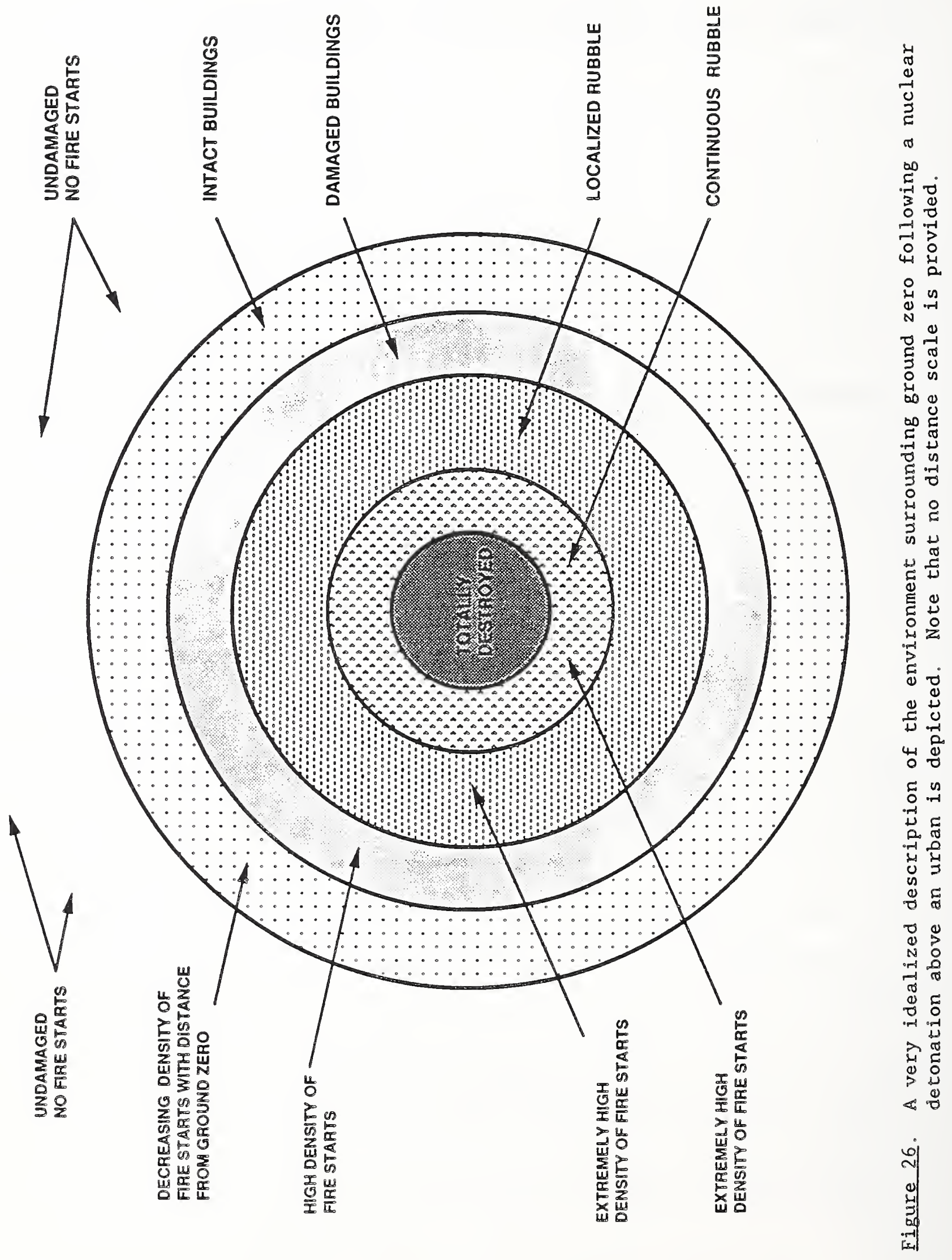


debris and damaged structures. In ring 5 the fires are developing as "normal" structure fires and are approaching flashover at this time.

By this time the fire plumes associated with the numerous fires will have become large enough to affect the behavior of ambient winds. For this reason, fire whirl formation might be expected on the leeward side of the fire area, and these fire whirls are likely to increase fire spread rates within ring 5 and contribute to considerable fire spotting due to brands in downwind positions outside of ring 5. The air requirements of the fires in rings 2 and 3 have grown to the point where a substantial inflow of air from the surroundings is required for combustion. During this period of rapid fire growth the fire-induced winds blowing in toward the center of the fire area begin to increase. Near the end of this development period the fire-induced wind speeds are on the same order or greater than preexisting ambient winds. By the end of this period the entire area of ring 2 is burning. A substantial fraction of the indivdual piles of debris and structures in rings 3 and 4 are fully involved and fire spread to unignited structures occurs in the presence of ambient or fire-induced winds. Fires in structures located in ring 5 have broken through their containments and become capable of fire spread to adjacent buildings. Considerable numbers of fires may be developing downwind (ambient wind) of the initially affected area due to earlier spotting.

\section{Period of Mass Fire Behavior ( 1 hour to several hours)}

After approximately an hour fires have become so numerous and grown to such an extent that mass fire behavior certainly develops. Rapid burning of fuel in rings 2, 3, and 4 occurs and a large percentage of exposed fuel in these areas is consumed. The mass fire behavior generates high winds (perhaps greater than hurricane force) which blow inward toward the fire. Due to the 
strong fire-induced winds, ambient wind behavior is unimportant during this phase of the fire.

Fires which have been ignited in regions 5 and on the leeward side of the original fire-start area begin to spread under the influence of the fireinduced winds. During this period, outward fire spread is nearly impossible due to the inward-blowing winds. However, the isolated fires which have developed in ring 5 and leeward regions act as sources of conflagrations and begin to spread towards the central fire region under the action of high winds. During this pexiod it is highly probable that essentially all structures inside of the maximum initial fire-start distance are ignited despite the fact that the fraction of buildings where fire starts occurred in the outer regions is quite low. If these fires develop rapidly enough, they can augment the existing mass fire conditions and contribute to an even larger and more deadly mass fire. Otherwise, they form a ring of fire around the dying central mass fixe. In either case, it is likely that the entire area which was subject to initial or spotting fire starts is destroyed by fire. This includes the entire area of ring 5 which was relatively undamaged by the initial detonation.

Even though it has not been considered here, it is possible that the winds generated by the mass fire have sufficient velocity to severely damage or perhaps totally flatten standing buildings in region 5 or beyond. If winds of this magnitude do indeed develop they will contribute substantially to the collateral damage resulting from the fire.

\section{Period Following the Mass Fire (Several Hours Onward)}

As the fuel available is consumed, the fixe intensity falls off and the mass fire behavior begins to abate. Eventually, the condition is reached where the fire region consists of numerous gently burning or smoldering areas. 
Fire-induced wind velocities decrease to the point where ambient winds are again of comparable size. It is during this period that fire spread to regions outside of the initial fire area is most likely.

Project Flambeau fires have shown that numerous fire whirls occur during the last stages of large fires. Fire whirls which form following a mass fire of the size described above should be quite strong indeed. In calm conditions these whirls should not present too large of a problem. Transport of firebrands over large distances is unlikely and fire spread will be slow. However, if an ambient wind is present, these fire whirls will be capable of spreading firebrands over a large area downwind of the original fire area and numerous fire starts are expected. The effect will be greatly exacerbated if buildings outside of the initial fire area have been damaged by fire-induced winds .

If ambient winds are sufficiently high, a conflagration certainly will develop. The resulting fire will be of the same type as the accidental, windblown fires which have destroyed urban areas over the centuries, but will be many times largex due to the numerous fire starts. Such a fire can be expected to spread until ambient winds fall off or until it runs out of fuel.

The development of a conflagration following a nuclear detonation is possibly the worst-case scenario. Such a conflagration could spread substantially beyond the initially-affected area and might possibly destroy an entire urban area. In this case the area of collateral damage resulting from a nuclear attack would dwarf the original area subject to the direct blast and fire effects of the burst.

\section{Possible Synergistic Effects of Multiple Nuclear Detonations}

Very little attention has been paid to the effects of multiple nuclear warhead attacks on fire behavior. Reitter et al. [22] consider the 
consequences of multiple-burst attacks to be one of the most important areas of concern in predicting nuclear weapon effects.

Very little information is available to predict the interactions which might occur between two closely spaced, but physically separated, mass fires such as would take place following a simultaneous, multiple-warhead attack on an urban environment. It is impossible to predict whether fire damage would be increased or decreased.

A more definite statement is possible if the mass fires occur at different times (i.e., a second attack takes place several hours after an initial attack). It has been predicted that mass fires will create high winds at large distances from the fire area (see section 7.4.2). If such winds from a later mass fire extend to the vicinity of a dying mass fire, they can overwhelm any ambient winds and initiate a conflagration burning from the region of the initial mass fire towards the currently-burning mass fire. When such an interaction occurs, it is possible that the entire area between the nuclear burst-induced fires which was not initially involved in fire will be consumed. This mechanism could destroy much larger areas than those of two independent detonations. The interaction distance where synergistic effects such as this are possible depends on the "reach" of the winds generated by a mass fire (see the discussion in Section 7.4.2).

\subsection{Comments on the Abslities of Current Models to Predict Urban Fire Spread}

In Section 7.3.2 a summary was provided of deterministic models which have been utilized to predict fire spread in the urban environment. In these models the principal fire spread mechanism is assumed to be flame radiation from individual fires, although the possible importance of firebrands is acknowledged. There are a number of fire effects which have been discussed 
earlier in this report which can substantially alter this picture of urban fire spread.

The first concerns the role of flame radiation in promoting structure to adjacent-structure fire spread. It has been assumed by nearly every worker in this field that radiation is the dominant mechanism for this type of fire spread. However, there is very little direct experimental evidence to support this contention. One example of a test fire was found during literature research in which flame radiation could confidently be assigned as the primary mechanism for fire spread between structures. During a full-scale house burn (denoted 68-2) Vodvarka [165] recorded radiative heat flux measurements on a barn located $11 \mathrm{~m}$ from the house. As a result of the severe fire which developed (fire whirls were observed) the barn spontaneously ignited. Radiant flux levels on the barn were measured and were sufficient to induce ignition. On the other hand, examples of the limited reach of radiation were obtained during the Flambeau fire series [79]. Wooden dowels of $0.64 \mathrm{~cm}$ diameter and $10.2 \mathrm{~cm}$ length were placed at various distances from these large fires. Thermocouples were placed inside the dowels to record the temperature. At a distance of only $1.8 \mathrm{~m}$ the highest temperature observed was $150 \mathrm{C}$ which is well below the ignition temperature. In another test, fuel beds at a distance of $7.6 \mathrm{~m}$ were left unignited at the edge of a large multiple fuel-bed fire. Fire did not spread to these fuel beds despite nearby large flames. Evans and Tracy [152] noted that a plywood NO SMOKING sign $0.6 \mathrm{~m}$ above the ground at a distance of $2.4 \mathrm{~m}$ from a fire edge was not even charred. Countryman [79] feels that convective cooling may be important in preventing higher temperature increases. He notes that convective cooling may not be as important for buildings which have large surfaces, but goes on to say 
"evidence suggests that in urban centers wind and flying firebrands are the key factors in spreading fires."

The literature (see Section 8) reveals that for the types of fire spread (such as porous fuel beds) for which fire spread mechanisms have been more carefully investigated, it is invariably initially believed by researchers that overhead flame radiation is the primary heat transfer mechanism, but experiments reveal that either convection and/or fuel bed radiation are the dominant processes. Furthermore, the dominant heat transfer mechanisms always change in the presence of an ambient wind, with convection becoming more important. As discussed in Section 7.4.2, substantial winds are expected to develop as fire growth occurs following a nuclear detonation. Utilizing thermal radiation to predict fire spread behavior between structures yields rate estimates which must be considered as absolute minimums.

Research discussed in Section 11 suggests that fire behavior is modified when two or more fires are burning in close proximity. Both higher burning rates and fire whirl development have been observed. Whether flame radiation or some other heat transfer process is the dominant mechanism for nearby interstructure fire spread, rates are sure to be increased substantially when fire interactions take place. Such interactions are likely following a nuclear detonation due to the large number of fire starts anticipated. These interactions become more important in the presence of the fire-induced winds which are expected. The models discussed in Section 7.3.2 do not consider fire interaction effects in any form in their analyses.

In Section 9 fire spread by firebrands was discussed. It was shown that even though firebrands are believed to be very important in urban fire spread, the current understanding of the physical processes responsible for fire 
spotting is so poor that no reliable estimates are possible. The uncertainty concerning wind levels in the fire vicinity compounds the problem.

Based on the above discussion, it is the opinion of this author that the mechanisms which are incorporated into existing models for urban fire spread following a nuclear detonation are unlikely to allow accurate or even plausible estimates of fire spread behavior or extent. Perhaps more disconcerting is the fact that the estimates which are provided are very likely to be the absolute minimum spread rates which can be envisioned. All of the possible flame spread mechanisms which are not incorporated into these models lead to increased spreading rates. Fire spread rates and burning intensities are extremely likely to be considerably higher than calculated by these models. This situation is intolerable for those who must develop plans for dealing with the effects of nuclear detonations. If large uncertainties must be tolerated, as they must be for the foreseeable time, it is prudent to try and insure that predictions for fire damage are on the high side and not the absolute minimum which can be conceived.

\subsection{Areas there Improved Understanding of Physical Mechanisms Is Essential for Improved Accuracy of Urban Fire Spread Predictions}

The current understanding of the urban fire behavior which occurs following a nuclear detonation is so incomplete that the only approach to improving fire spread and intensity calculations is fundamental research efforts on the physical mechanisms which have been identified as being, or that might possibly be, important. Using the scenario in Section 13.1 as a guide, it is possible to make a list of many of the various fire behaviors for which our understanding must be improved before predictions of urban fire spread can be attempted which are anything more than highly uncertain guesses. 
In order to describe fire spread behavior it is necessary to know the environment immediately following the detonation and the number and locations of fire starts. These factors obviously depend on fireball and blast effects. There are uncertainties associated with these factors, but the review of the literature suggests that the physical mechanisms are fairly well in hand, and stochastic approaches are valid. Since these factors are not the focus of the present effort, the distribution and number of fire starts as well as the condition of the fuel bed will be assumed as known and described.

Based on the scenario of fire development described in Section 13.1, the areas of fire behavior listed in Table 1 must be better understood in order to predict the development and growth of fire in the urban environment. The list is broken down by the fire periods discussed in Section 13.1.

\subsection{Answers to Questions Posed by the Section Title}

Nuclear weapons can be highly destructive. Based on the experiences of Hiroshima and Nagasaki, a massive nuclear exchange is likely to severely disrupt the societies involved. Due to the potential harm, it is necessary for those responsible for planning the use of nuclear weapons as well as those responsible for developing strategies to deal with the effects of such an attack to have the most reliable estimates of damage which can be generated. This requires that research efforts designed to improve the understanding of nucleax weapon effects proceed with an urgency comparable to that assigned to the improvement of weaponry and defensive measures.

It has been shown that there are gross uncertainties concerning damage in an urban environment which will result from fires following a nuclear detonation, and that estimates provided thus far for such effects are very likely to be low. This situation is clearly incompatible with the needs of 


\section{TABLE 1}

\section{Areas there Fire Research is Required}

\section{Initiation Period}

1. Fire spread in the presence of an ambient wind through continuous fuel beds which are formed from combustible and incombustible materials.

2. Growth of fires from isolated ignition sources in blast-damaged and undamaged buildings.

\section{Period of Rapid Growth}

2 .

3. Mechanisms of fire spread between individual piles of debris and structures in the presence or absence of ambient wind.

4. Localized interactions of nearby fires, and their dependence on wind speed and direction, which lead to increased fire spread rates between nearby structures.

5. Development of large fire whirls due to interactions of wide-area, multiple fire plumes and ambient wind.

6. Mechanisms for the formation, transport, and burning behavior of firebrands and the ignition of structures by firebrands.

7. Development and characterization of winds blowing toward a large-area fire.

\section{Period of Mass Fire Behavior}

$3 ., 4.6 .$, and 7 .

8. Characterization of high winds generated by a mass fire.

9. Behavior, spread, and blow out of fires subject to extremely high winds.

10. Conflagration behavior including the possible formation of vertical and horizontal vortices and their role in generating increased fire spread rates.

Period Following the Mass Fire

$3 ., 4 ., 5,6,7,8 ., 10$.

11. Fire whirl formation as a result of the interaction of a dying mass fire and an ambient wind.

Possible Synergistic Effects of Multiple Nuclear Detonations

3. 4., 6., 8., 9., 10., 11.

12. Interactions of Multiple Mass Fires. 
planners to assess damage levels resulting from the detonation of nuclear devices.

The answer to the question concerning the need for an ability to predict fire spread accurately following a nuclear detonation is a decisive yes. To not provide such a predictive capability is incompatible with a professed need to understand the ramifications of the use of such weapons and for government officials to protect our society to the fullest extent possible.

The second, more specific, question asks whether an improved understanding of wind-aided fire spread is required to achieve the goal of a better predictive capability for urban fire spread. A quick perusal of Table 1 indicates that a large fraction of the areas where additional research is required involves interactions of fire and wind. This is due to the fact that interactions of wind with urban area fires have not received a great deal of research attention. As a result, the role of wind in urban fire spread is poorly characterized. Until this sicuation is remedied, it will remain impossible to estimate accurately the fire damage to be expected from the detonation of a nuclear device. Again, the answer is yes.

\section{POSSIBILITY OF IMPROVING THE UNDERSTANDING OF WIND AIDED URBAN FIRE SPREAD UTILIZING A LABORATORY WIND TUNNEL}

In the last section the conclusion is reached that an improved understanding of fire spread in the urban environment following a nuclear attack is crucial. In order to achieve this goal it is necessary to investigate the many fire-wind interactions listed in Table 1 . It is clear that full-scale or even large-scale tests are not feasible. The dangers and costs involved in burning any substantial area of a city in the presence of strong winds are prohibitive. Analysis of accidental fires has proven virtually useless. An actual test involving a nuclear weapon is out of the 
question. Clearly, other means must be found to provide the fundamental information required.

In this section the question of whether or not significant improvement in our understanding of the physical processes included in Table 1 can be generated by an experimental program utilizing a laboratory wind tunnel is discussed. Before this point can be addressed, it is necessary to review the role of similarity analysis in fire research. This discussion will allow us to more easily consider what can be learned by fire experiments in wind tunnels.

\subsection{Similarity Analysis and Fire Behavior}

A general approach often used in problems of this type where testing on actual large scales is prohibitively expensive or impossible is to model physically the behavior on smaller scales. Perhaps the most widely known example of such modeling is the wind tunnel testing of aircraft [166] which has been extensively employed since the days of the Wright brothers. In recent years, physical modeling studies for civil engineering problems have become widespread $[166,167]$. The effects of simulated atmospheric boundary layer winds on buildings and other structures are routinely investigated [168].

Physical modeling is based on the use of similarity analysis. Similarity between two systems is said to be fulfilled when "the equations which govern them are the same except for the constant coefficients." [169] The similarity condition requires that physical behaviors in two systems be identical when multiplied by suitable scaling constants. Thus the behavior of a small model can be utilized to characterize the behavior of a much larger system if the two are completely similar. 
Similitude is tested by the use of dimensionless variables. Three different methods have been developed to allow the necessary dimensionless variables to be deduced [170]. In the first, the variables which are believed by the researcher to affect the physical behavior of interest are listed. A formal procedure based on the pi theorem then allows dimensionless groups to be derived in terms of these groups. In the second, the mathematical equations describing the behavior of interest are written and then manipulated until the dimensionless variables required to represent the equations in dimensionless form are obtained. Hottel [170] notes that the first procedure "permits variables to be introduced without identification of the physical reason and yields dimensionless groups which may be in a valid but unfamiliar form.", while the second suggests that it is necessary to have complete knowledge of the governing equations. The third approach discussed by Hottel [170] is for the researcher to utilize his "feeling" for the problem as wel1 as his understanding of conservation equations to deduce the form of the necessary dimensionless parameters. In a sense, this approach may be considered as a combination of the more formalized analyses.

The difficulty in the application of similarity analysis to fire problems is that the researcher quickly discovers that "combustion modeling is impossible." [171] Spalding has discussed this problem in his insightful review paper [171]. The problem can be traced to the large number of dimensionless groups for which similarity must be fulfilled. Hottel,provides a list of 120 dimensionless variables and notes that even more variables must be considered in an exhaustive treatment. The forms of the equations do not allow full similarity to be attained.

Fortunately, it has been found that useful information can be obtained for cases where full similarity is not possible. As spalding [171] puts it, 
"though the theory of modeling requires that all the set-up and interpretation rules should be obeyed, experience has shown that flouting some of them does not entirely invalidate the prediction. Thus nearly all currently used combustion models are examples of partial modeling in which only a few of the rules are obeyed." The problem, of course, is to identify which variables are important and to try and estimate the effects of not properly scaling others.

There are numerous examples where partial modeling has been successfully applied to fire situations. The reader is referred to the review papers of Hottel [170], Spalding [171], Heskestad [172], Kanury [173] and Quintiere [174]. Many of the dimensionless correlations (e.g., flame lengths and burning rates) discussed in earlier sections were based on partial similarity analysis.

In some cases the number of parameters which can be properly scaled is increased by making model studies for varying pressures or under conditions of variable gravity. Williams [175-177] provides an excellent discussion of why this is useful. These studies are not discussed in detail because it is believed by this author that such experiments are not financially feasible in wind tunnels.

. There have been a number of studies which have considered the use of similarity analysis for the investigation of mass fires. Most of these have focused on fire storms. Both theoretical treatments [173,175-179] and experiments $[33,58,59,155,156,180]$ have been presented. Very little work has focused on conflagrations or the more general cases where fire spread is taking place. An exception is the recent work of Nelson and Adkins [125] who have reported a dimensionless correlation for wind-driven fire spread in wildlands. The study of Lee and Garris [155] considered the formation of fire whirls along a line fire and might have application to a moving line fire. 
One of the most encouraging developments in the physical modeling of fires is the recent demonstration that small-scale experiments can generate fire whirl activities in the presence of suitably-scaled ambient winds (due to laboratory flows ox within a wind tunnel) which are reminiscent of those observed in mass fires $[32,33,158]$. In Section 10 it was noted that Lee and Otto [158] observed firebrands being transported by fire whirls in smallscale studies. It may be possible to improve our understanding of firebrand transport by fire whirls utilizing scale models. The creation of fire whirls which are qualitatively similar to those observed in mass fires in small systems suggests that the necessary dimensionless groups are scaled properly. It should be possible to learn a great deal concerning fire whirl activity fxom carefully designed small-scale experiments. One might hope that horizontal vortices of the type mentioned by Palmer [154] (see Section 10) might be generated and investigated in a wind tunnel.

\subsection{Similaxty Analysis and Fire Spread}

One of the properties of fire which cannot be scaled correctly is thermal radiation. The basis for this was discussed in section 8.1 where it was noted that the importance of thermal radiation increases with increasing flame size. For this reason, it is impossible to utilize similarity analysis to analyze fire spread unless it can be established that either thermal radiation is unimportant or completely dominates the heat transfer process in both smallscale and full-scale systems.

In order to deduce the heat transfer mechanisms responsible for fire spread it is necessary to perform experiments at a variety of scales. As noted in Section 8.5 , it has not been shown conclusively that wind-aided fire spread between nearby buildings occurs solely by thermal radiation, despite 
the fact that this is the assumption which has been used in models for the process.

\subsection{Problems Where Wind-Tunnel Studies Can Contribute to an Improved Understanding}

\subsubsection{Specific Areas Concerning Wind-Alded Urban Fire Spread}

Table 1 in Section 13.3 lists specific areas where improved understanding is necessary before the fire effects of a nuclear detonation on an urban environment can be predicted with some confidence. The items on this list are considered individually to assess whether experiments in a suitable wind tunnel can provide a better understanding of the process. The conclusions which are reached are based on the literature review and analysis which has been provided.

1. Fire spread in the presence of an ambient wind through continuous fuel beds which are formed from combustible and incombustible materials.

The vast majority of what is currently understood concerning wind-aided fire spread in various types of fuel beds is the result of experiments performed in wind tunnels. Experiments designed to investigate this question are currently being performed in the TRW wind tunnel [124]. It is clear that these experiments are providing new information concerning the behavior of wind-aided fire spread through fuel beds of this type.

These studies have just begun and are utilizing highly idealized fuel configurations. More realistic fuel beds can be utilized to provide additional insights. 
2. Growth of fires from isolated ignition sources in blast-damaged and undamaged buildings.

In general, this is one of the better characterized areas where fire research is required. Wind effects are not expected to be very important in this phase of fire growth unless the winds are quite high and the structure is damaged. This is therefore not a research topic which would profit significantly from wind tunnel experimentation.

3. Mechanisms of fire spread between structures in the presence or absence of ambient wind.

The mechanism of fire spread between adjacent structures is one of the principal factors which must be characterized in order to be able to predict urban fire spread. As has been discussed, there are serious uncertainties concerning the heat transfer processes responsible for fire spread between structures in calm conditions, and very little attention has been given to fire spread in the presence of wind. Experiments in a wind tunnel will allow these important questions to be addressed.

In the last section it was concluded that the particular heat transfer mechanisms responsible for fire spread could not be studied by similarity analysis. In order to gain a better understanding of these mechanisms it would be more profitable to investigate wind-aided fixe spread through a fuel bed which is as similar as possible to one composed of full-scale structures. A change in mechanism from convective to radiative heat transfer can be identified by repeating the experiments for various fuel sizes. In this way, it should be possible to characterize changes in fire spread mechanism both as a function of wind velocicy and scale. This is exactly the information required. 
4. Localized interactions of nearby burning fuel beds and their dependence on wind speed and direction.

The interactions of two or more burning fuel beds in the presence of an ambient wind is very poorly characterized. The only useful experimental knowledge is provided by the experiments of Lee and Otto [158] and Rios $[117,118]$. Even though the vortex activity observed by Lee and Otto [158] was attributed to a slow ambient air flow, no quantification of the effects was possible. Rios $[117,118]$ did observe changes in burning rate when a second propagating wood crib fire was placed downstream from the first, but only one wind orientation was utilized.

The omission of possible fire interaction effects is one of the most serious limitations of fire spread theories designed to predict urban fire spread. Measurements in a wind tunnel similar to those above would help ameliorate this deficiency.

5. Development of large fire whirls due to interactions of wide-area, multiple fire plumes and ambient wind.

The experimental studies of Emori and Saito [32] and Soma and Saito [33] have demonstrated that it is possible to investigate fire whirl development in wind tunnel studies. As pointed out in Section 14.1, it appears as if partial modeling of large fires will allow fire whirl activity to be investigated in small-scale models. The characterization of the conditions necessary for fire whirl formation and their behavior would represent a major breakthrough for improving the understanding of not only urban fire spread, but also mass fire in general.

6. Mechanism for the formation, transport, and burning behavior of firebrands and the ignition of structures by firebrands.

This is an area where wind tunnel studies can have little impact. The behavior of firebrands (i.e., mass loss and burn out) have been investigated 
in wind tunnels $[142,143]$. It is also possible to generate firebrands in small-scale model fires [158]. Some information concerning firebrand behavior can be derived from such studies. However, it is highly likely that these studies will suffer from questions concerning proper scaling. For this reason, wind tunnel testing will not be able to completely eliminate uncertainties concerning fire spread by brands.

\section{Development and characterization of winds flowing toward a large fire.}

This is a research question that might profitably be investigated in a wind tunnel. There are several potential problems. Many uncertainties exist concerning the role of fire interactions in inducing wind flows (see the discussion in Section 7.4.2). One of these uncertainties concerns whether it is appropriate to consider the numerous fires as simply a uniform heat source, or whether it is necessary to treat the fire plumes individually. It would be very difficult to investigate this problem within the confines of a wind tunnel.

Even if one considers a uniform heat source, difficulties are encountered in that the air flows which are induced by the fire or heat source will be of very low velocity. These may be difficult to characterize experimentally. Of course, it would be of interest to consider the interaction of a developing "mass fire" (i.e., one where inward wind flows are on the same order as ambient wind) and the ambient wind field. If the small wind flows generated by a feasible heat source in a wind tunnel can be characterized, the effects of an ambient flow of roughly the same order could be studied. Again the vexy low velocities to be expected would present experimental measurement difficulties. 
8. Characterization of high winds generated by a mass fire.

The winds which have been predicted for large area, multiple-source fires are much larger than expected for any "ordinary" ambient winds. This is an area of considerable theoretical research activity (see Section 7.4.2). With the possible exception of studies designed to investigate the formation of a large, single rotating fire plume $[33,58,59]$, it is unlikely that experiments within a wind tunnel will provide insight into this behavior.

9. Behavior, spread, and blow out of fires subject to extremely high winds.

No studies were identified during the literature review which had investigated the blow out behavior of burning solids by high wind despite the fact that blow out of turbulent jet diffusion flames of gaseous jets is of great current theoxetical and experimental interest [181]. In the literature dealing with wind-aided fire spread it is often mentioned that spread rates should eventually begin to decrease at high wind velocities and that blow out is expected at still higher velocities. No validated experimental measurements have been reported which allow a prediction for the velocities where such effects occur.

Given the high wind velocities expected in the vicinity of a mass fire, the blow out behavior of solid-fueled fires is potentially of great importance and might determine whether a conflagration is possible in the "Period Following the Mass Fire" discussed in Section 13.1. Wind tunnel investigations of this question are therefore warranted.

There are several experimental difficulties which may limit the effectiveness of this type of study. As will be seen in Section 15.3 there is a high price to be paid in construction costs and fan requirements to produce a wind tunnel capable of high wind velocities. Based on previous wind tunnel investigations, the wind velocities required to blow out reasonably-sized 
fires must be on the order of tens of meters per second. Blow out of smaller fires can probably be investigated at the wind velocities which can be generated in wind tunnels, but problems with incomplete scaling will once again result in large uncertainties in the extension of the findings to full scale.

10. Conflagration behavior including the possible formation of vertical and horizontal vortices and their role in generating increased fire spread rates.

This research problem is similar to number 5 discussed above. The reason it has been listed separately is that the types of vortical behavior which are considered are much more poorly characterized than normal fire whirls. Their existence is based primarily on anecdotal evidence.

As has been discussed in Section 14.1, it is possible that these behaviors can be treated utilizing standard partial scaling approaches. If so, it should be possible to generate both strong vertical and horizontal vortices and characterize their behavior within a wind tunnel. Success in this area would be a significant contribution to the understanding of a fire spread mechanism which is believed to contribute substantially to the extremely high fire spread rate associated with conflagration behavior.

11. Fire whirl formation as a result of the interaction of a dying mass fire and an ambient wind.

This type of fire whirl formation could be the principal mechanism which initiates a conflagration-type of fire spread at the end of the "fire storm" phase of burning. As pointed out eaxlier, such a conflagration has the potential to greatly amplify the destructiveness of the fire effects of a nuclear detonation. As already discussed in numbers 5 and 10 above, previous experiments have suggested that wind tunnel experiments can provide an improved understanding of this type of behavior. 
12. Interactions of Multiple Mass Fires.

This type of fire behavior will be very dependent on the winds which are generated by mass fires. As already discussed in number 8 above, wind tunnel investigations are unlikely to contribute to an improved understanding of this aspect of mass fires. On the other hand, wind-aided fire spread will be very important when a nearby dying mass fire and a fully-involved mass fire exist concurrently. The wind tunnel investigation is expected to provide important information concerning the fire spread rates and behaviors which can be expected.

\subsubsection{Role of Turbulence in Wind-Aided Fire Spread}

It was noted in Section 12 that very little information is available concerning the effects of the atmospheric boundary layex on fire spread and other fire properties (e.g., fire whirls). It is conceivable that such effects could be quite large.

Since the 1960 s there have been rapid gains in the development of wind tunnels which can simulate the atmospheric boundary layer (see Section 16.2). A wind tunnel which is designed to provide either uniform velocity or ABL flows is certainly feasible and would allow the effects of turbulence on fire spread rate and fire behavior to be assessed.

\subsubsection{Additional Research Question Which Are Difficule to Investigate In Wind Tunnels}

There are several research questions concerning mass fires which are extremely difficult to investigate in wind tunnels. Some were discussed above. Others arise due to limitations of wind tunnel experiments. The two most important deal with effects which may be very important in the earth's atmosphere, but which are very difficult to study in wind tunnels. 
Much speculation has focused on the role of atmospheric stability in contributing to fire storm formation. Atmospheric stability refers to whether or not the temperature distribution aids, is neutral, or hinders the upward movement of a heated plume. It is often stated [57] that an unstable atmosphere (a condition where plume growth is enhanced) contributes to fire storm formation. It would obviously be useful to investigate this question experimentally. Unfortunately, it is very difficult to model atmospheric boundary layers in wind tunnels which are not neutral [182]. It will be assumed that any wind tunnels designed for fire research will not incorporate a capability for investigating the effects of stable or unstable atmospheres.

The second atmospheric effect which cannot be investigated in wind tunnels is the interaction of fluid flows and the angular momentum resulting from the rotation of the earth. As discussed by Cermak [183], this interaction is characterized by a dimensionless group known as the Rossby number, $R O=U_{g} / f z_{0}$, where $U_{g}$ is the wind velocity at the geostrophic wind height, $f$ is the Coriolis parameter, and $z_{0}$ is the roughness length at the surface. The Rossby number is proportional to the ratio of inertial and Coriolis forces. Rossby number scales linearly with dimension [183], so that the corresponding Ro for a wind tunnel will be quite small compared to a large-scale object such as a building or mass fire.

The inability to scale Rossby number may not be a serious drawback. It is generally conceded that Coriolis forces play a minimal role in fire behavior. As discussed in Section 7.4.2, the vorticity due to the Coriolis effect is too small to be significantly concentrated in mass fires during the time frame characteristic for the burning of these fires. 


\subsection{Projected Role of Wind Tunnels in Improving the Understanding of Urban Fire Spread Following a Nuclear Attack}

It has been shown that our predictive capabilities for fire damage in an urban environment following a nuclear detonation are inexact and are very likely to underestimate the damage. An improved predictive capability will require a coordinated effort between workers concerned with aspects of the problem which can be properly scaled and therefore investigated on smaller scales and appropriate theoretical analysis for other aspects which cannot be scaled adequately and are therefore impossible to characterize experimentally. The knowledge base must be accumulated systematically over an extended period of time and continuously evaluated in such a manner that suitable models and theories are developed concurrently. Note that this description parallels the approaches taken by researchers who are interested in wildland and structural fires (see the discussion in Section 5).

In this section the areas for which fire studies in wind tunnels can contribute to a fuller understanding of the mechanisms of spread and behaviors of fires in the urban environment have been described. It has become clear that careful studies of fire behaviors in a wind tunnel will contribute an extensive data base for improving the understanding of the physical processes which are responsible. At the same time, aspects of the problem which are not amenable to this type of investigation have also been mentioned.

The potential seriousness of the fire problem following the use of nuclear weapons dictates that our capabilities for modeling urban fire damage be improved. Wind tunnel tests designed to investigate the aspects of the problem discussed above must be performed to provide the fundamental underpinnings for these new models. The lack of such investigations is a 
major contributing cause to the large uncertainties associated with past attempts to deal with this problem.

The conclusion of this section is that sultable wind tunnel experiments are an absolute necessity in order to improve the understanding of fire spread following a nuclear attack in the urban environment.

\section{ANALYSIS OF THE NEED FOR A NEW WIND TUNNEL FACILITY TO INVESTIGATE WIND EFFECIS ON FIRE SPREAD AND FLAME BEHAVIOR}

It has been concluded that predictions of fire spread in urban environments must be improved to enable more realistic estimates of fire damage resulting from a nuclear detonation. A large number of the research areas where improved information is required can be investigated utilizing smaller-scale experiments in wind tunnels. In this section, the question of whethex or not a new wind tunnel facility is requixed for these fire studies will be addressed.

To aid in this evaluation, currently existing facilities for investigating fire behavior will be reviewed and their characteristics briefly described. Additional factors which need to be considered, but which have received scant attention, will then be discussed. The desired characteristics for a wind tunnel facility designed especially for investigations of the fire problems listed in Section 14 will then be enumerated. A comparison of the capabilities of currently-existing facilities with these characteristics allows an assessment to be made of whether or not a new wind tunnel facility is required. 


\subsection{Currently Existing Wind Tunnel Facilities for Investigating Wind-Aided Fire Spread and Wind-Fire Interactions}

Before discussing specific facilities which have been constructed for investigation of fires in an imposed wind it is necessary to define a few general terms used to describe wind tunnels. A good introduction to wind tunnels is provided by Pope and Harper [166]. Marshall [184] has provided an updated account in his report on the preliminary design of a boundary layer wind tunnel facility. Useful information is also available in detailed reports concerning wind tunnels utilized for fire studies $[111,120,130,185,186]$.

There are two basic types of wind tunnels. These are known as open- or closed-circuit depending on whethex the flow through the test section of the wind tunnel makes a single pass though the tunnel and exits to the surroundings or is recirculated and passed repeatedly through the test section. Open-circuit wind tunnels can be either enclosed within a building or open to the atmosphere. Due to the need to remove products of combustion, all fire tunnels thus far constructed have utilized open-circuit designs which exhaust to the atmosphere.

Wind tunnels are known as forced-draft when a fan pushes air through the test section and as induced-draft when a fan pulls air through the test section. Induced-draft systems are often favored since the large spatial and temporal velocity fluctuations introduced by the fan exit the system, and it is considerably easier to generate uniform, low-turbulence flow at the input side of the test section. A decided disadvantage of induced-draft systems for fire studies is that the fan is subjected to the heat and combustion products which pass over and through the fan as they exit the system. 
When a forced-draft system is employed it is often necessary to utilize many flow conditioning devices such as honeycombs and screens which introduce significant pressure drops. As a result, more power is required to drive the fan and produce comparable velocities in a forced-draft system. Both inducedand forced-draft wind tunnels have been developed for fire studies.

The test section of a wind tunnel is the position where experiments take place. Test sections can be either open or enclosed. In open test sections the flow exits the tunnel into ambient surroundings (either a large room or the atmosphere) and is not constrained by tunnel walls. Such test sections are generally short since the flow field deteriorates over short distances. Enclosed test sections can take a variety of shapes, but all wind tunnels utilized for fire studies have either square or rectangular cross sections with constant areas along their test section lengths. Some specialized wind tunnels employ cross-sectional areas which increase as a function of downstream distance (see discussion in Section 16.2).

All wind tunnels attempt to introduce uniform, well-characterized velocity profiles at the entrance of the test section. Generally, the turbulent fluctuations are minimized as well. Note that controlled turbulence may then be introduced if a turbulent flow is required. For low-velocity wind tunnels, a continuously increasing velocity in the flow channel immediately upstream of the test section provides a means for generating, with more or less success, the desired uniform flow. The increasing velocity is created by the use of a flow contraction (see [184] for design details). Area reductions of nine ox more are required to obtain highly uniform flows with low turbulence. Screens and honeycomb (flow straightening devices) are often inserted into the flow upstream of the test section to provide additional smoothing. 
Interestingly, many designers of wind tunnels for fire studies have chosen not to include a contraction section in their designs. Complete reliance is placed on flow straighteners to provide uniform flow. Welker [130] indicates that the tunnel designed by Milburn [185] was the first lowspeed wind tunnel engineered without a contraction.

Important considerations in the design of wind tunnels are the types of fans to be used and the power needed to generate the required flows. Electric motors are usually utilized to drive the fan. Both the volume of gas flow and pressure drops in the system increase as the velocity is increased. Work is required to accelerate the air and overcome the pressure drops. For this reason, the maximum power which is required to drive the fan is a strong function of the maximum velocity which must be achieved in the test section. Pope and Harper [166], Marshall [184], and Milburn [185] describe how the power requirements of a wind tunnel can be estimated.

Wind tunnels utilized for fire studies are open to the atmosphere. Many fire behaviors are dependent on ambient conditions such as temperature or relative humidity. Unless provisions are included for conditioning the outside air, the ambient conditions within the test section of an open wind tunnel are determined entirely by outdoor meterological conditions. For this reason, some of the wind tunnels constructed for fire investigations have provided temperature and relative humidity control of the air drawn through the test section from the outside.

Many wind tunnel facilities have been utilized for combustion studies. It is believed that during the course of this investigation most, if not all, of these facilities have been identified. It has been possible to characterize some in much better detail than others. Table 2 is a list of these wind tunnels, references where they are discussed, and several of their 


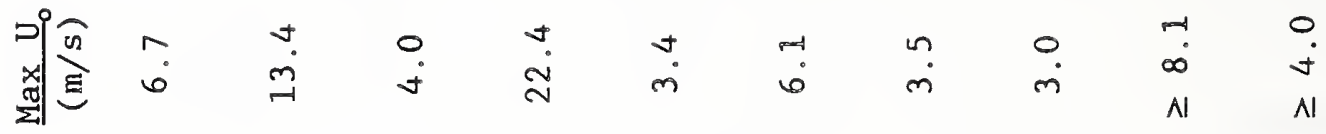

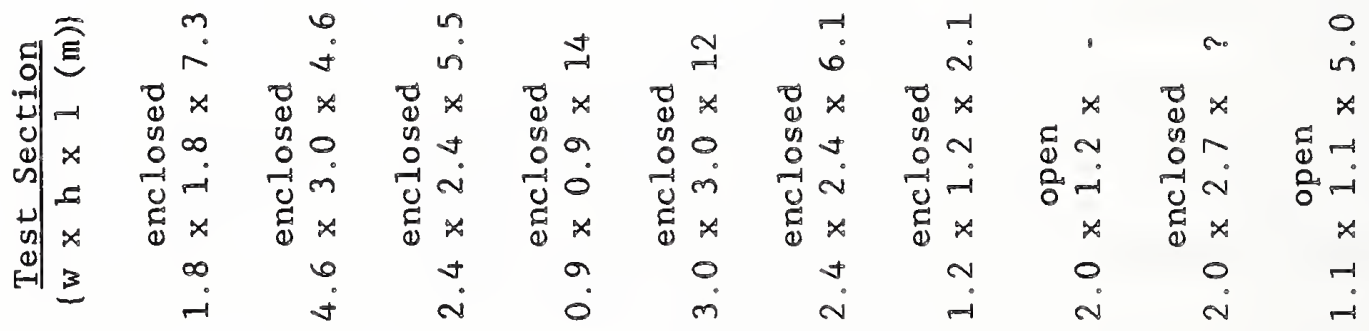

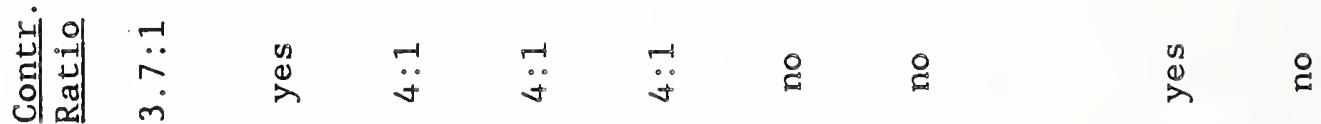

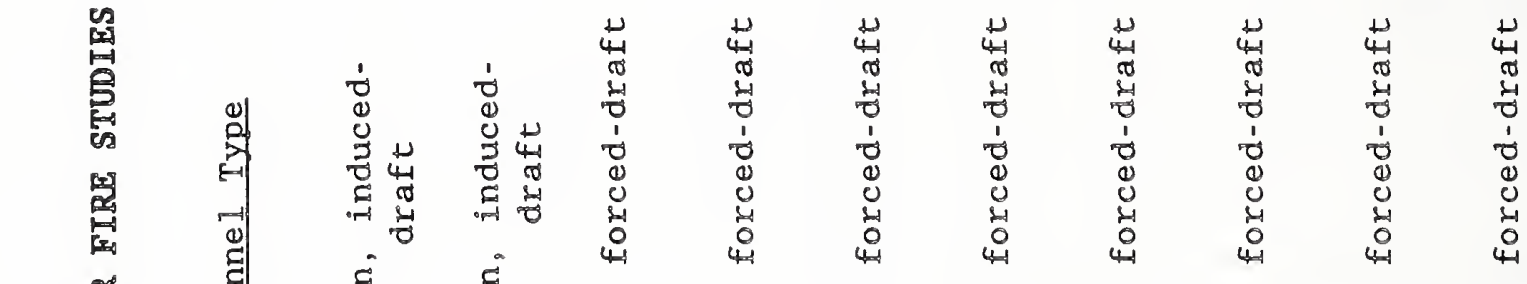

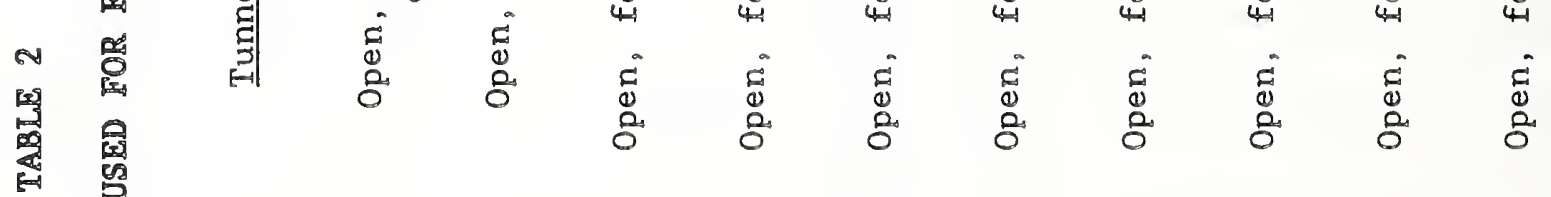

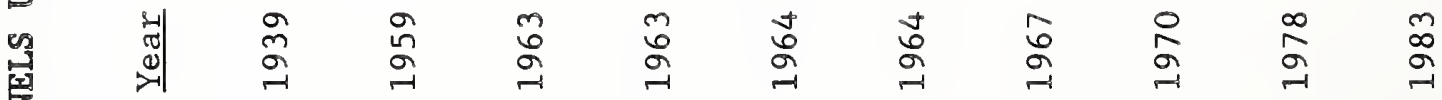

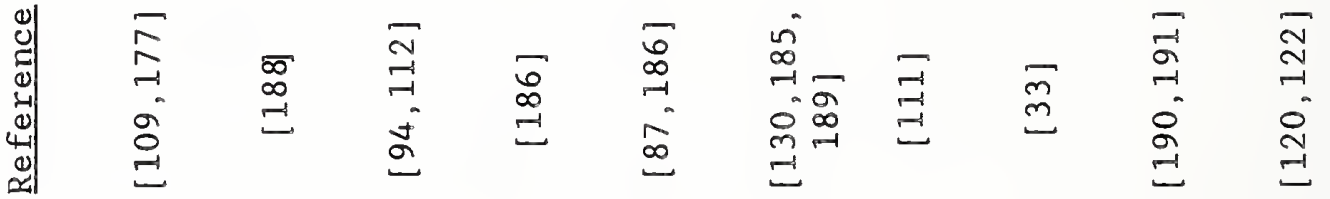

i⿱山⿸\zh14𠃋

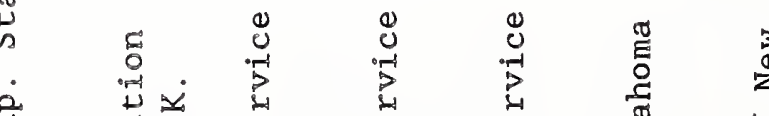

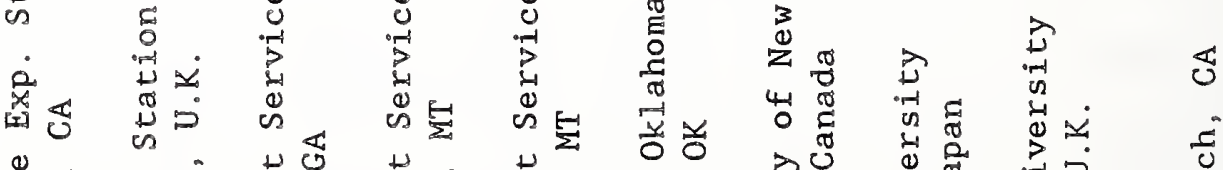

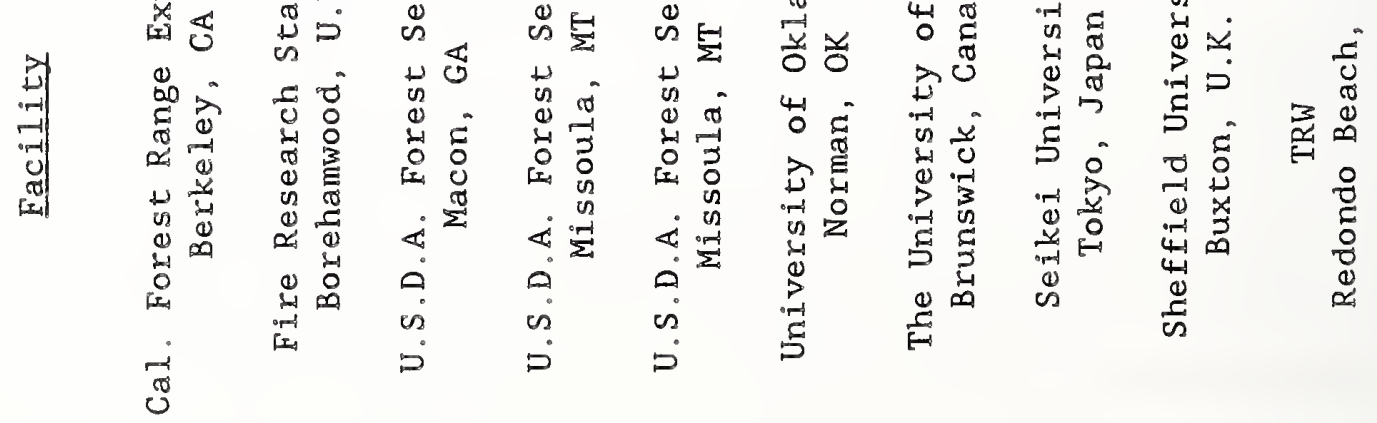

\#1

$N$

m

$\checkmark$

in 6

$r$

$\infty$

or 


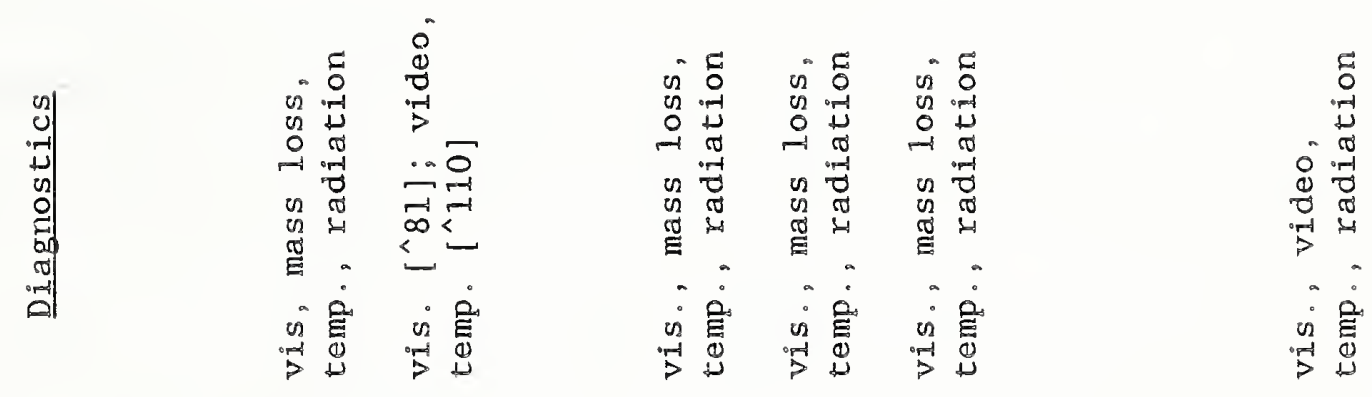

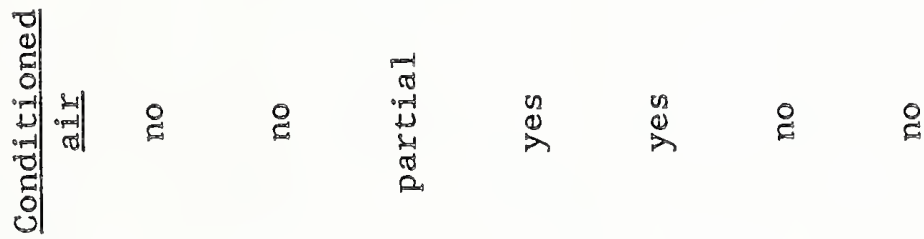

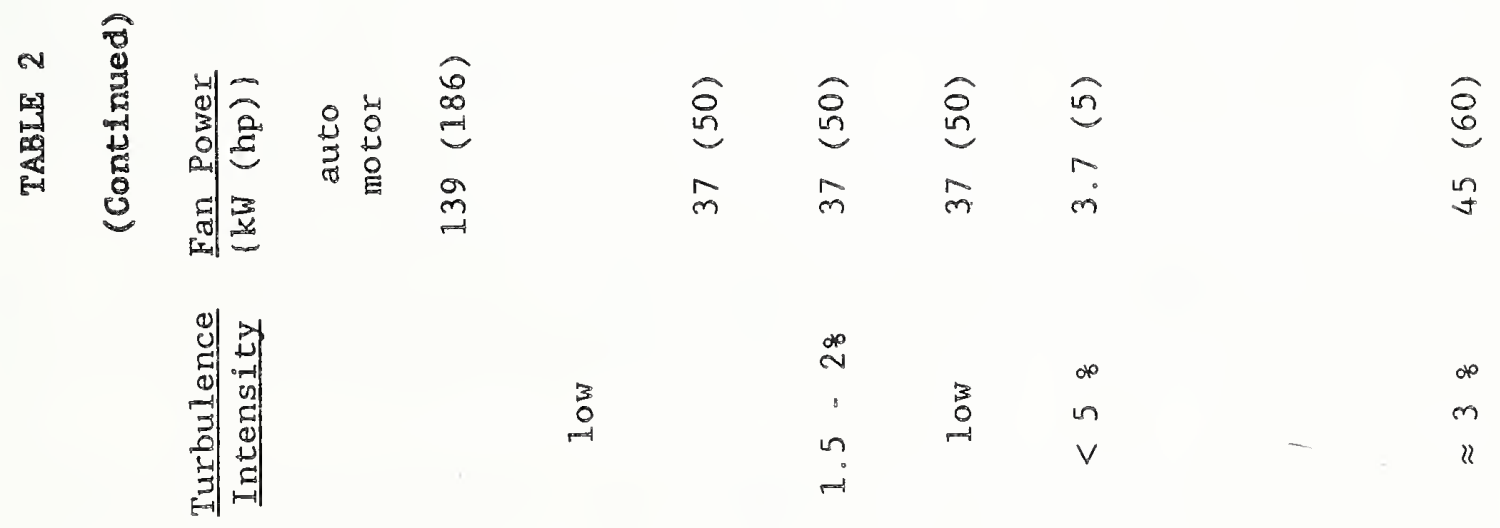

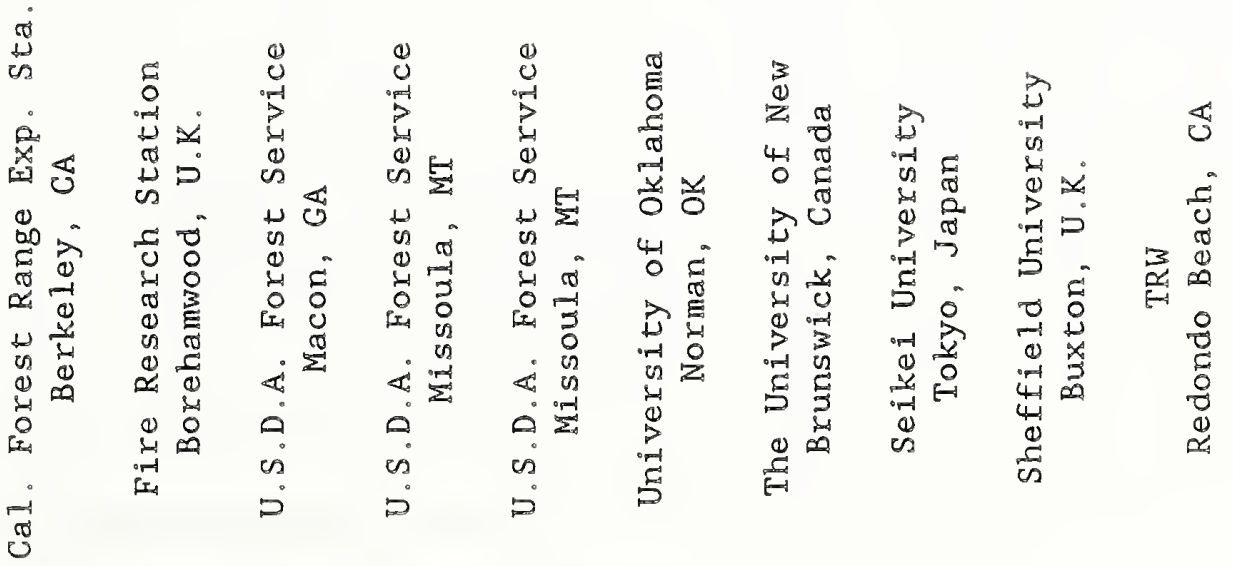

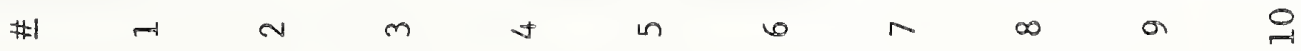


important characteristics. Blanks indicate that the relevant information was not available.

Characteristics reported include the year the tunnel was placed in operation, the tunnel type and whether it uses forced-or induced-flow, the entrance area contraction ratio if one is used, the test section measurements and whether it is open or enclosed, the maximum velocity in the test section, the turbulence intensity (defined as the root-mean-square of the turbulent fluctuations divided by the average velocity), the power required to drive the fan for the maximum velocity, whether or not conditioned air is used, and the diagnostics which have been employed to make measurements in fire experiments. The following abbreviations are used for diagnostics. "vis." stands for visible and refers to measurements made by eye or photography, "video" means flame behaviors are recorded on video tape, "mass loss" refers to measurements of the fuel mass loss rate, "temp." refers to temperature measurements which are usually recorded by thermocouples, and "radiation" means measurements of thermal radiation generated by the fires. In some cases the indicated diagnostics have been incorporated into the experiments later than the references cited.

The wind tunnels which have been used for fire studies vary in the way the test sections are confined. Most flame spread measurements have been made within enclosed test sections. This is primarily due to the fact that the flow distance for which the flow is uniform is longer than for an open test section. The flow is also less sensitive to fluctuations. Fire studies in open test sections have been performed primarily in Japan. Some measurements have been reported in English for the Seikei University wind tunnel included in Table 2. It is interesting that similar measurements of the effects of wind on fires have also been made for wind tunnels with open test sections as 
large as five meters square $[192,193]$. Burning behaviors of automobiles and the ignition of live trees located near a fire subject to a cross wind have been studied.

Researchers at TRW $[120,122]$ have used an interesting combination of enclosed and open test sections to investigate fire spread. Their wind tunnel has been designed to have a movable ceiling which is advanced at the same rate as a fire moving with the wind. In this way it is possible to have the fire plume rise relatively freely in a large hood while maintaining the wind profile nearly constant at the location of the fire. It should be noted that the principal reason for utilizing this configuration was a theoretical analysis $[120,122]$ which suggested that the plume dynamics would determine fire spread rate. This has not turned out to be the case [123], and in fact, the fire spread rate is little affected by the presence or absence of the tunnel roof [124].

The only existing wind tunnel listed in Table 2 which utilized an induced flow is at the Fire Research Station facility in Borehamwood, Herts, UK. Water cooling was provided for the fan. No definitive tests have been reported, but it appears likely that the fire response to an induced flow will differ from that of a forced flow (more similar to natural winds) due to differences in pressure distributions in the two cases.

Figures 27 to 30 show schematics for five of the wind tunnels which have been utilized for fire studies. These figures should be consulted during the following discussion of the important characteristics for each facility.

\section{U.S.D.A. Forest Service: Missoula, MT}

This elaborate facility is quite versatile and has a range of fire research capabilities. It can be seen in Figure 27 that ourside air which is drawn in by the blower is conditioned before being forced into the large 


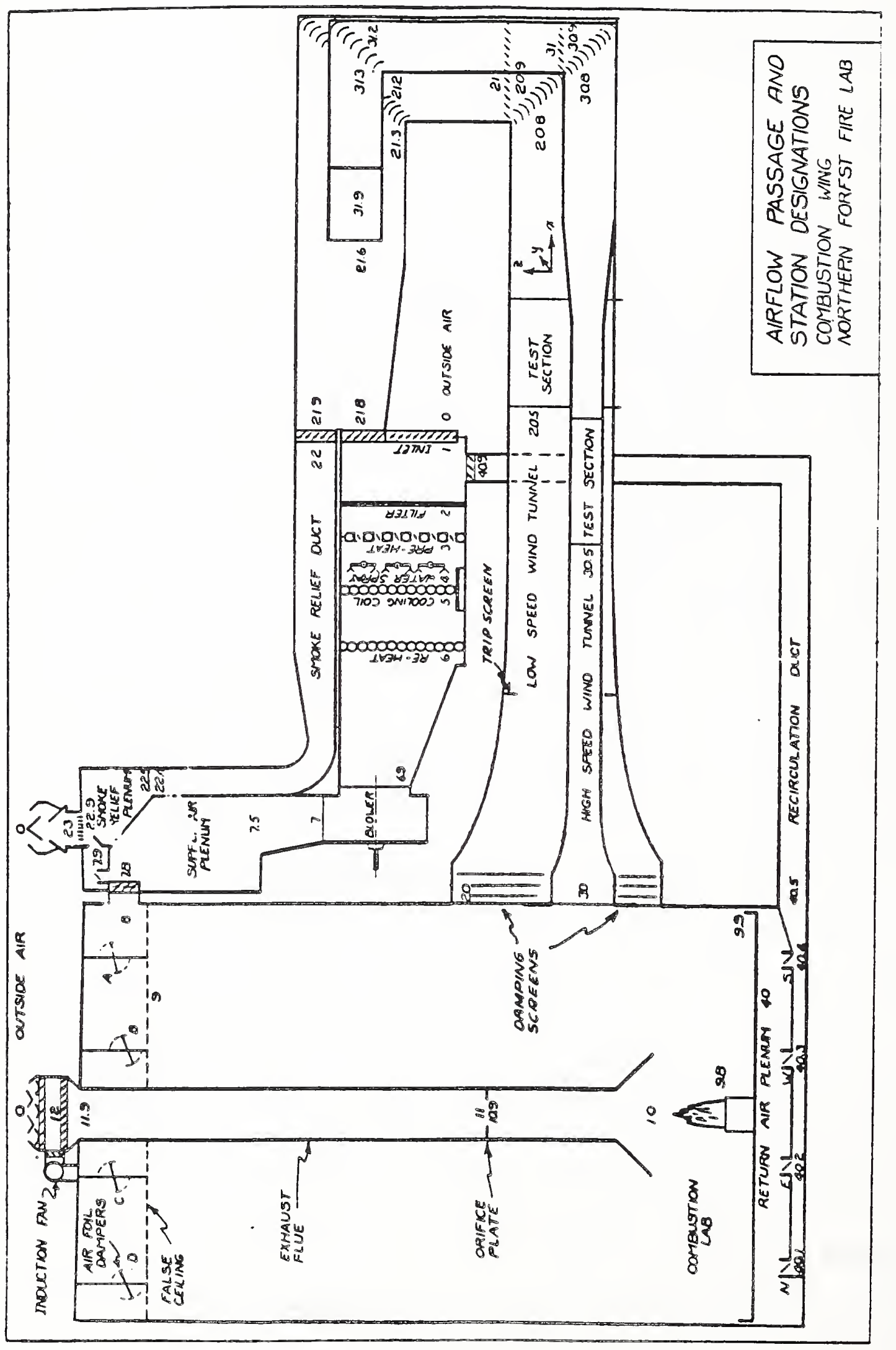

E

尔

$\Sigma$

.

$\nabla$

$\stackrel{\Phi}{\Perp}$

บั

0

$\rightarrow \infty$

i

क

$\sim$ E

is

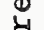

0 .

$\therefore 3$

$\varangle$

$\therefore$

लं

D

Ð

낭

4 प्य

点

융

-4.

올일

完

ช 4

㟔

4

0 u

0

is

린

Uै

$4 \%$

จे 


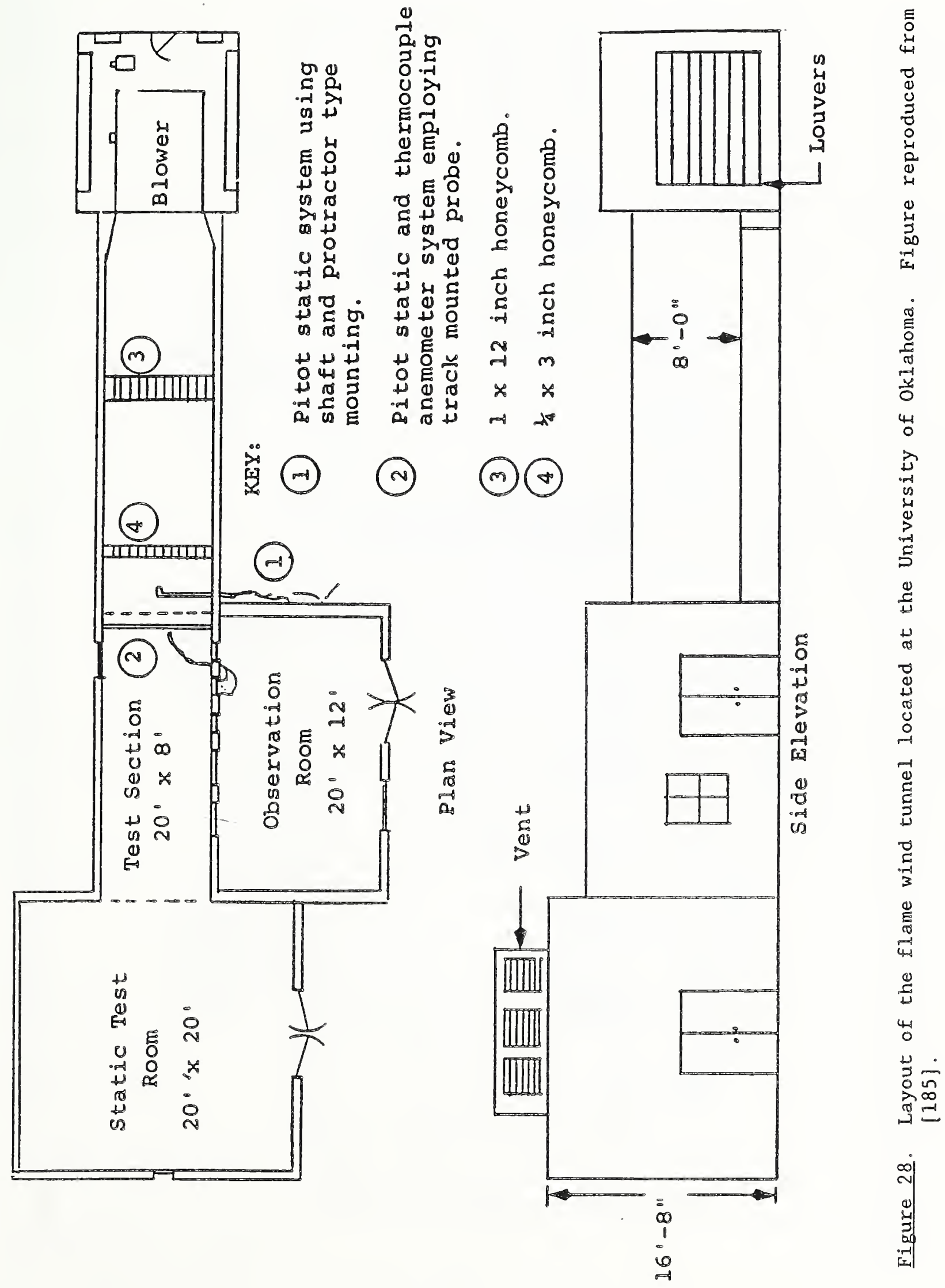




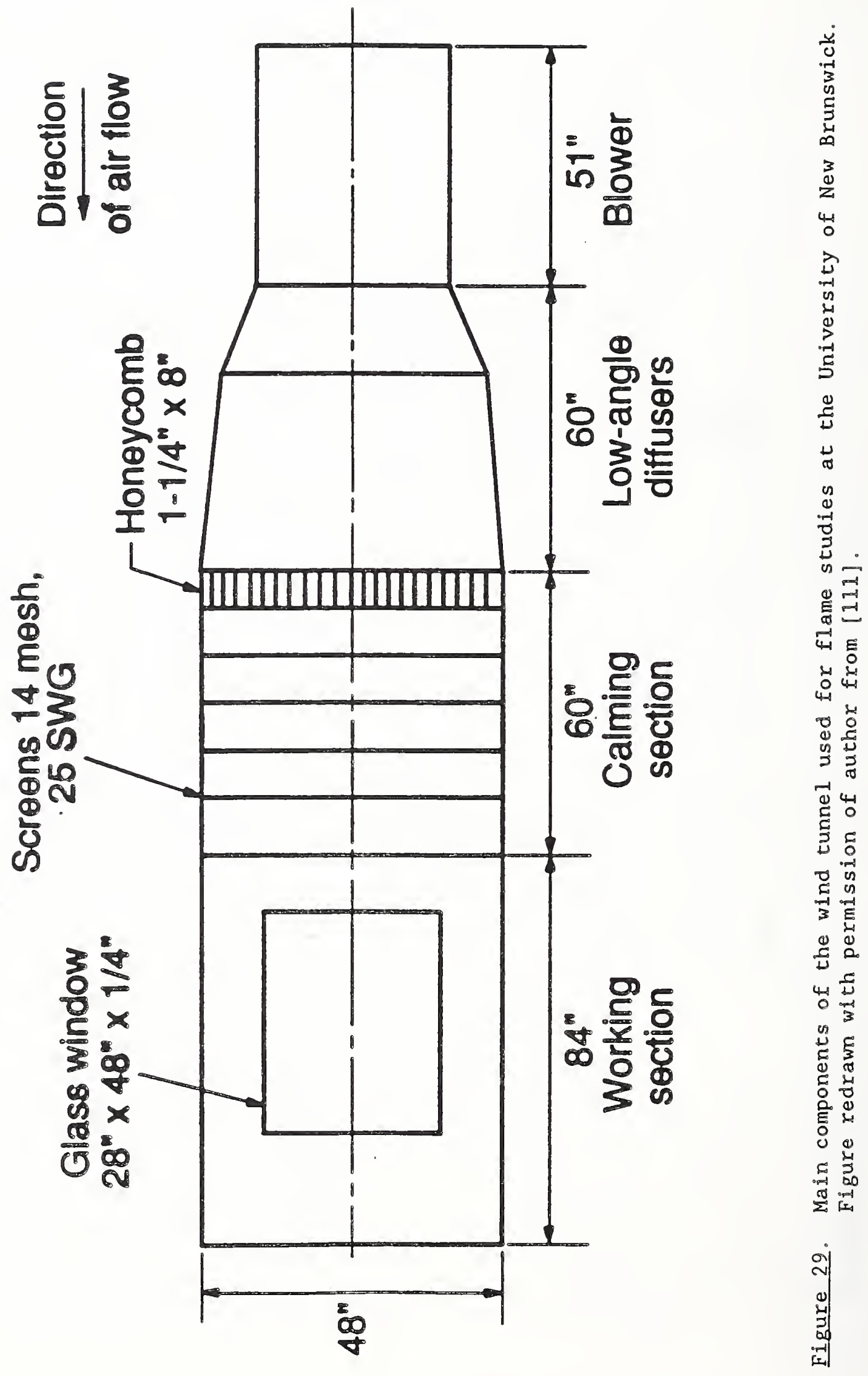




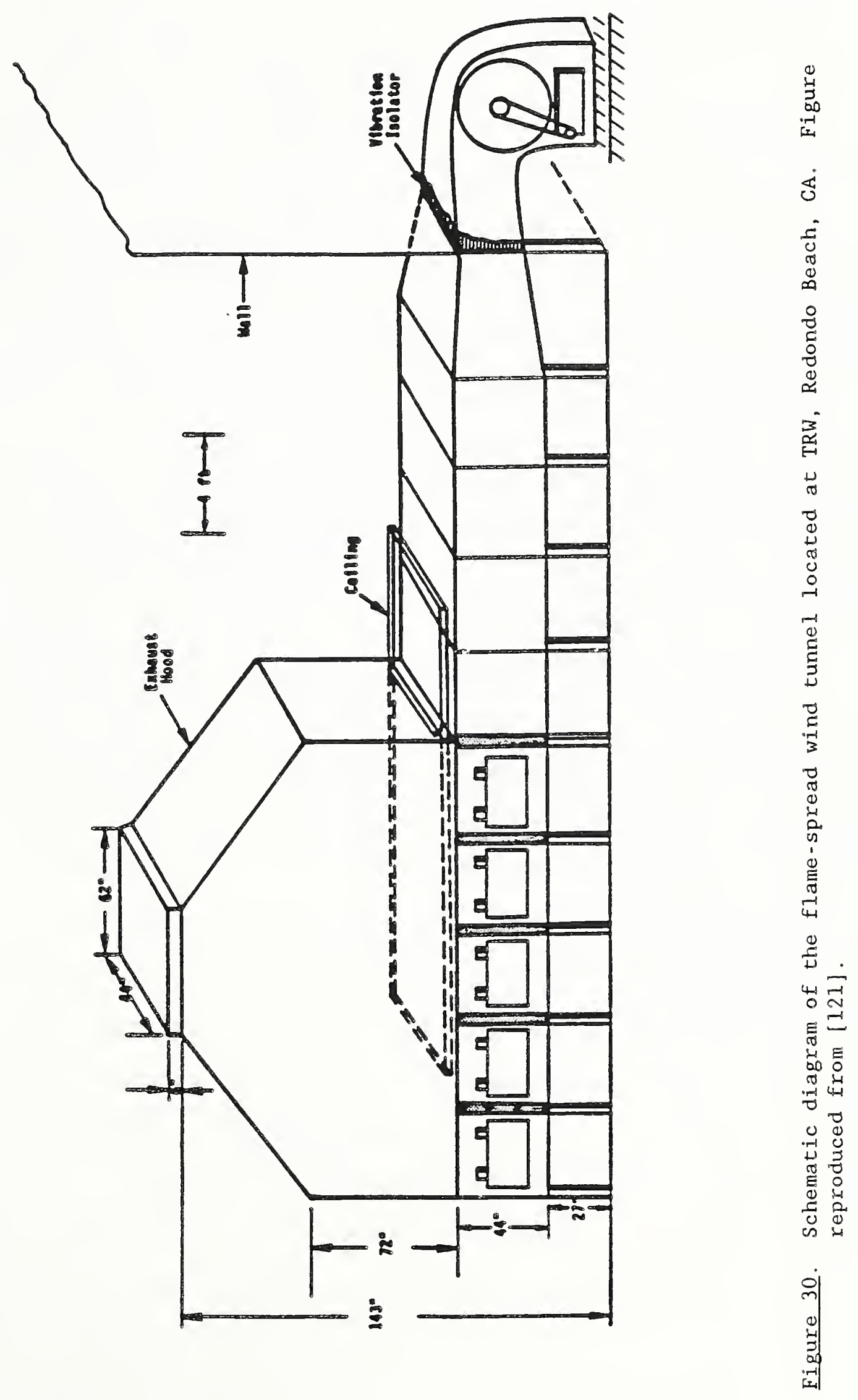


volume denoted as the combustion $\mathrm{lab}$. Here the air can take either of three exit paths. If static fire experiments are of interest, a slow flow is used in the combustion laboratory. Combustion products are collected in a large hood and expelled from the building. The height of the hood is adjustable.

Openings in the side walls of the combustion laboratory provide access to two wind tunnels ( 1 isted as numbers 4 and 5 in Table 2). Note that 4:1 area contractions connect the entrances of the wind tunnels to the test sections. When the dampers are opened, air flows from the combustion laboratory and through the test sections of the tunnels. This air can either be passed through the conditioning unit and fan again (recirculation mode) or routed to the smoke relief plenum where it is released to the atmosphere (single-pass mode). When the tunnels are utilized for fire studies the facility is operated in the single-pass mode.

The smaller tunnel (\# 4) is used primarily for instrument calibrations, but measurements of firebrand behavior have also been made here. The larger tunnel (\#5) has been utilized for investigations of fire spread behavior in fine fuels. Many of the findings of experiments performed in this tunnel have already been discussed.

In June, 1988 the author of this report had an opportunity to visit this facility and observe a test burn. The following comments are based upon this visit and conversations with members of the staff. The facility is in outstanding shape. It has been well maintained since its construction, and the instrumentation utilized for measurements has been upgraded. Considering the number of fires which have been burned in this facility, it is remarkably clean. Apparently, no active cleaning is required. This author was surprised to learn that the rolling vortex which was observed in the test section of the 
large tunnel was the result of asymmetry in the location of the tunnel entrance in the wall of the combustion laboratory [194].

The majority of test measurements on fire spread performed in this facility were completed prior to 1974. After this time, efforts were focused on development of fire spread models based on the experimental findings. The focus of research is now turning from the problem of fire spread through fine fuels (most important for majority of wildland fires) to the ignition of crown fires (responsible for greatest damage). Large numbers of experiments are planned in the wind tunnel to evaluate convective and radiative heat transfer above surface fires to better characterize the conditions required for the development of destructive crown fires.

\section{University of Oklahoma, Norman, $\mathrm{OK}$}

The schematic for this facility is reproduced in Figure 28. Comparison with the diagram in Figure 27 indicates that this facility is considerably simpler than the Forest Service arrangement. This tunnel is denoted as \# 6 in Table 2.

Following a small diffuser which connects the fan to the flow straightener, the dimensions of the system are unchanged until the flow exits the tunnel into the static test room. The locations of flow straightening devices are indicated. Note that there is no provision for preconditioning the air, and the conditions of the air within the wind tunnel will be the same as those in the atmosphere outside of the tunnel.

In contrast to the Forest Service tunnels, the air flow for this test section does not enter from a large volume, but instead exits into a large volume known as the static test room. A room, equipped with louvers for flow velocity control surrounds the fan. This room and static test room ensure that this tunnel is relatively insensitive to outside wind fluctuations. 
Despite the absence of a contraction at the upstream end of the test section, velocity profiles for the tunnel are very uniform.

It is interesting that the University of Oklahoma facility cost roughly 18 of the amount required for the Forest Service facility $(\$ 8,000$ versus $\$ 800,000$ in 1964 dollars). The great difference results from the absence of air conditioning, the simplicity of the design, and different construction methods (the University of Oklahoma researchers did a large fraction of the labor themselves) for tunnel \#6 versus tunnels \#4 and 5 .

This facility was also visited in June, 1988. The following comments are based on observations and discussions with researchers. The simplicity and low construction cost of this wind tunnel are remarkable. Several experiments which have been performed in this facility have been described above. The results of this work have made significant contributions to the understanding of wind effects on burning behavior. In particular, the work of Rios [117] is the only work available on the interactions of two propagating fires in the presence of wind. The approach of using two stationary fuel beds to investigate the interactions of propagating flames is unique.

The buildings which comprise the wind tunnel are somewhat dilapidated. Some repairs would be necessary before this facility could be utilized for long-term studies. The tunnel was last utilized for fire studies in 1975. Since then it has been modified for use in investigations of smoke generation and transport. Instrumentation which is in place is the same as was available when it was constructed. Installation of modern electronic instrumentation would be required before any new experimentation on fire was initiated.

\section{Universicy of New Brunswick, Fredericton, Canada}

As is evident from Table 2 and Figure 29, this wind tunnel is considerably smaller than the two discussed above. Its design is similar to 
the University of Oklahoma facility in that it is a forced-flow, open wind tunnel which utilizes honeycomb and screens for flow smoothing and does not incorporate a contraction. The entire tunnel, including the fan and motor, is housed in a laboratory module. The air flow from the tunnel passes into a hood where it is exhausted by a small fan.

This facility has not been inspected, but conversations with Professor Steward of the Chemical Engineering Department indicate that even though the facility is not in constant use, it is well-maintained and is utilized infrequently.

\section{TRW, Redondo Beach, CA}

The TRW wind tunnel for fire studies has a test section which is roughly the same cross-sectional area and twice the length of that at the University of New Brunswick. Its schematic is shown in Figure 30. This is the most recently constructed of the wind tunnels listed in Table 2.

Figure 30 shows that this facility has a fan that is isolated outside of the laboratory which houses the wind tunnel. It does not utilize a flow contraction, but does have a relatively long flow conditioning section. The unique feature of this tunnel which can be seen in Figure 30 is the movable ceiling which is translated in such a way that a propagating fire in the tunnel is always allowed to expand Exeely into the exhaust hood. Even though the tunnel is able to maintain the flow field at the rear of a spreading fire as if the test section is enclosed, the fire is free to expand as if the test section is open.

A comparison of the maximum flow velocities achievable and the kilowatts required to power the fans for the University of New Brunswick and the TRW wind cunnels indicates that the TRW facility is much less efficient (see Table 2). This is a result of the elaborate flow conditioning and resulting 
pressure drop utilized in the latter case. Figure 31 shows a diagram of the honeycomb and screens used for flow conditioning. The turbulence level in the TRW tunnel is roughly half of that for the University of New Brunswick facility.

Since the completion of the TRW facility in 1983, the instrumentation has been considerably improved [124]. Digital data acquisition is utilized to record multiple temperature and thermal radiation measurements in the fuel bed and in the plume. One potentially serious drawback to the facility is that it does not have the capability to record the mass loss rate of fuel during an experiment. This is not a serious deficiency if the fuel is completely consumed and the spread rate and flame depth can be accurately measured. However, such measurements have proven difficult for other researchers.

\subsection{Other Important Considerations in the Design of Wind Tunnels for Fire Studies}

Very little discussion has been identified in the literature of two potential problems which can seriously affect the validity of measurements of fire behavior made in wind tunnels. These are heating of the wind tunnel walls by the fire and potential modifications of the flow field due to blockage effects associated with the presence of the fire.

Severe heating of the walls of a wind tunnel due to thermal radiation or convection can result in structural damage even when the construction materials are nonflammable. It is usually necessary to provide visual access to the tunnel, and thermal-resistant glass or plastics are particularly susceptible to damage. Instrumentation may also be damaged due to the extreme temperatures. Less severe heating of the walls can present a serious difficulty due to the thermal radiation which results. This thermal radiation will be absorbed by the fuel and may change its burning behavior. Rios [117] 


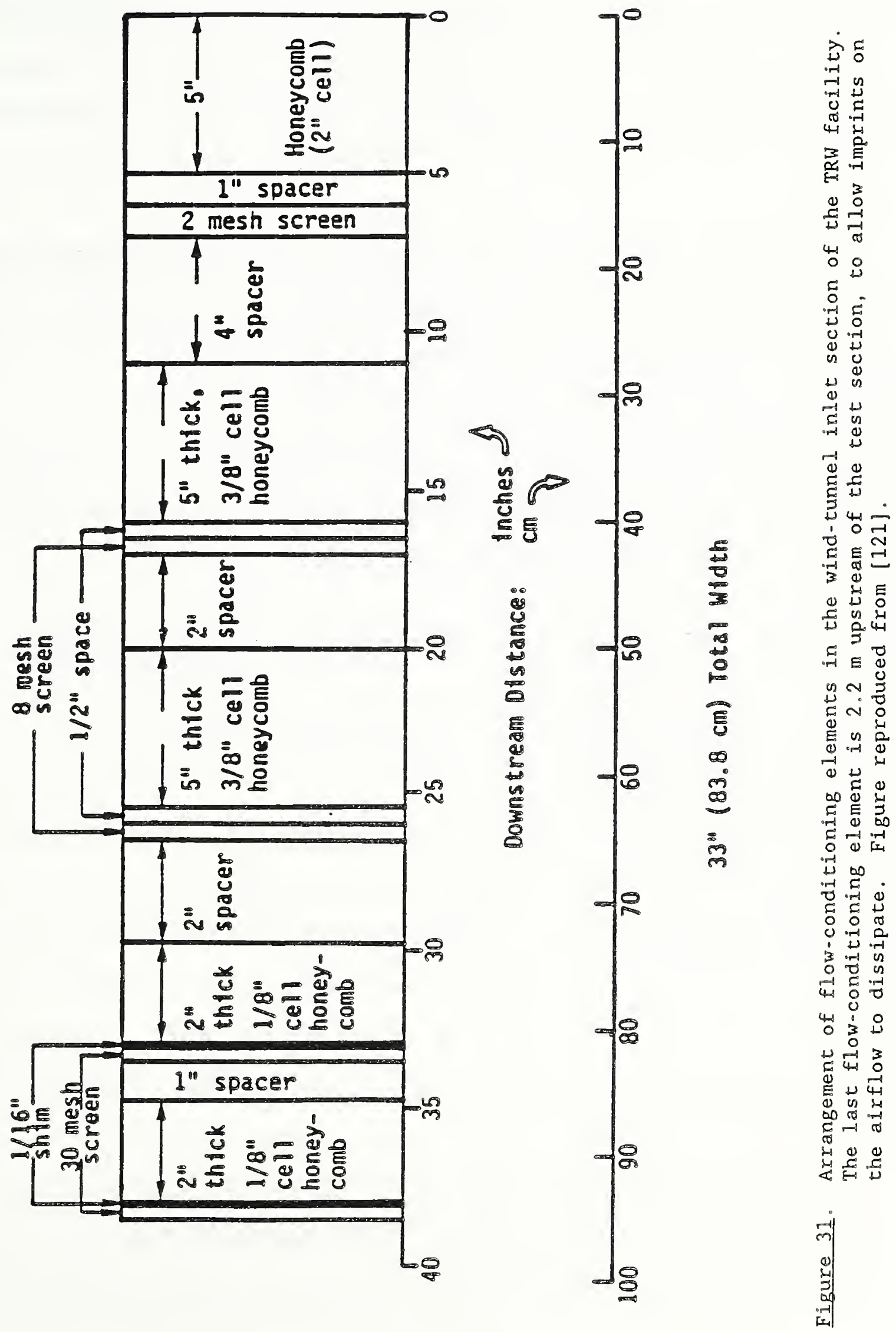


mentions that during his investigation of spreading wood crib fires heated tunnel walls "exerted a pronounced effect on the temperature profiles." Researchers at both wind tunnel facilities visited during the preparation of this report indicated that tunnel wall heating was a serious problem $[194,195]$.

Fire sizes can be estimated from the mass loss rates reported by Rios [117]. The heat release of wood is assumed to be $18 \mathrm{~kJ} / \mathrm{g}$. The largest fire was $\approx 360 \mathrm{~kW}$. Note that this experiment is particularly susceptible to wall heating since the fires are held stationary in the flow. Mass loss measurements reported by Fang [111] indicate the largest fire used in his measurements of fire spread rate was $122 \mathrm{~kW}$. Similarly the data of Nelson and Adkins [112] suggest a maximum heat release rate of $\approx 650 \mathrm{~kW}$.

Fleeter et al. [120] indicate that the TRW wind tunnel facility was designed to be able to handle fires as large as $17 \mathrm{MW}$ for short periods of time. Checks of the fuel beds which have been burned in this facility indicate fuel loadings are low and the power of the fires must lie considerably below this level.

The problem of tunnel wall heating is a heat transfer problem rivaling heat transfer within fires in complexity. For a fire in a wind tunnel it is necessary to know the convective and radiative heat release of the fire as well as the plume behavior and heat transfer properties of the walls. Such a calculation is beyond the scope of the current investigation. However, the effects of wall heating of wind tunnels must be considered in any new designs developed for wind tunnels.

The second problem concerns the effects of the fire on flow patterns within the tunnel. Researchers have known for a long while that the forces on structures are not the same in a confined wind and an open wind [196]. This 
effect arises because the structure (model) in the wind tunnel partially blocks the air flow. In Section 8.4 it was noted that fires can affect wind flow fields much like solid bodies. This suggests that wind tunnel blockage effects must be considered.

It is difficult to estimate the fraction of wind tunnel area which must be blocked before measurable effects occur. Melbourne [196] indicates that measurable differences are observed for blunt bodies having blockage factors as smal1 as 2\%. Aerodynamic modelers [197-199] routinely cite 10\% blockage as the maximum acceptable. Since data for flame bending angles are correlated utilizing flame drag coefficients of order 1 (see Section 8.3.2), significant tunnel blockage effects must be expected when the fuel bed and projected flame area fill more than $10 \%$ of the tunnel cross-sectional area.

\subsection{Desired Capabilities of Wind Tunnel For Investigating Problems of Relevance to Uxban Fire Spread}

In Section 14 the research areas in which wind-tunnel experiments of fire spread and behavior would contribute to the understanding of fire spread in an urban environment have been considexed. Hexe, the ideal properties of a wind tunnel designed to deal with this range of problems will be discussed. The discussion is broken down into various sections dealing with various windtunnel attributes.

\section{Wind Tunnel Size}

The old adage, "the bigger the better", applies for this wind tunnel property. In order to determine if thermal radiation dominates over convection as the heat transfer mechanism responsible for fire spread between structures requires measurements over a wide range of size scales. In the last section it was observed that only relatively small fixes can be 
investigated in currently existing wind tunnels designed for fire studies. The largest estimate of fire size utilized was $\approx 0.65 \mathrm{MW}$. A typical value of energy release for a fully-involved burning house is on the order of tens of megawatts.

Larger wind tunnels can handle higher heat loads. This is due to the fact that flow volumes of air increase with tunnel size as do the surface areas of the tunnel walls. Due to these increases, the energy generated by a fire can be more easily dissipated and the associated temperature rises are smaller.

In the last section it was pointed out that tunnel blockage effects might seriously affect measurements when the projected areas of the flame and fuel bed exceed ten percent of the cross-sectional area of the wind tunnel. For a given fire size, the effects of tunnel blockage will be less for a larger tunne1.

The sizes of fuel beds which can be investigated in fire spread experiments are limited by tunnel size. It has often been noted that fuel bed widths are not wide enough to allow a true one-dimensional fire front to develop (e.g., [120]).

The burning time of fuels increases with thickness. As the burning time increases the length of fuel bed which is burning for a spreading fire also grows. Eventually, a point is reached where the entire length of the fuel bed (limited by wind tunnel length) is burning and it becomes impossible to study fire spread. For this reason, experiments in wind tunnels have been limited to very thin fuels. Longer test sections would allow thicker fuels to be investigated.

In Section 14 it was noted that one of the areas where wind tunnel tests can contribute to an improved understanding of large fires concerns the 
development and characteristics of fire whirls. Observations and characterization of fire whirls becomes easier as the scale of the model is increased. Scale increases require a larger wind tunnel facility.

Clearly, the larger a wind tunnel, the more suitable it is for fire studies. Limitations on size therefore becomes the determining factor. As in nearly all cases like this, the primary limitation is cost. Nearly every cost associated with the construction of a wind tunnel increases with size at faster than a linear rate. For instance, doubling the dimensions of the test section of a proposed tunnel quadruples the volume of aix flow required if the maximum wind velocity is to remain constant. The cost of motors to power fans also increases quite rapidly as the motors become larger. Associated power and installation requirements add additional cost. For a doubling of tunnel size in three dimensions the tunnel surface area increases by a factor of four. As the tunnel becomes larger, the structural requirements are also increased which adds additional costs. It is clear that in the absence of infinite financing, a balance must be struck between size and cost.

\section{Maximum Wind Velocities}

The wind velocities utilized for studies of fire behavior in past wind tunnel investigations have generally been quite modest. Table 2 shows that values below $8 \mathrm{~m} / \mathrm{s}$ are typical. As the discussion in Section 8 indicates, the wind velocity required to significantly modify fire behavior depends on the heat release rate of the fire. This relationship is implicit in the use of the modified Froude number, $U_{0}^{2} / g D$, to correlate experimental findings. If larger heat release rate fires are to be investigated, higher wind velocities will be required.

As discussed in Section 14.3.1 the blow out of solid-fueled fires by wind may play an important role in the fire behavior following a nuclear 
detonation. Very little is known concerning the scaling behavior of this fire property. On small scales we know that matches and candles are easily extinguished by wind and we also know that urban and wildland fires continue to burn at wind velocities as high as tens of meters per second. It is important to determine the parameters responsible for this scaling behavior. Blow out can be investigated in a tunnel if wind velocities are sufficiently high. Therefore, a wind tunnel designed for investigations of nuclear detonation-induced fires should have the capability of generating quite high wind velocities.

As is true for wind tunnel size, the increases in cost for generating higher wind speeds is much greater than linear in velocity. The power required to generate a given wind velocity depends on $U_{0}$ raised to roughly the third power [184,185]. Therefore, a tunnel designed to generate maximum velocities twice as high as another identical tunnel will require a motor capable of providing eight times the power.

\section{Type of Test Section}

Both types of wind tunnel test sections, open and enclosed, have been utilized for fire investigations. Advantages of the enclosed test sections are that they can be longer and are not very sensitive to ambient conditions outside of the tunnel. Disadvantages are that plumes generated by a fire are not free to rise indefinitely and modifications of fire behavior due to tunnel blockage are a real possibility.

Open test sections allow larger fires to be investigated since the fire heat release is not contained within the tunnel, but is released into the open or the large enclosure surrounding the tunnel mouth. However the shorter lengths of the test section required by the use of open test sections means that fire spread measurements, or even measurements in the fire plume 
downstream of the fire are subject to errors. The plume rising from a fire in the potential core region of the flow from the tunnel can rise uninterrupted from the fire, but the hot gases will be subject to a strong wind shear as they move beyond the region of uniform flow.

The above discussion suggests that there will be many factors which determine whether an experiment should be carried out in an open or enclosed wind-tunnel test section. These factors include the size of fire to be investigated, nature of the property to be measured $(e \cdot g$. , fire spread rate or flame bending angle), and cross-sectional area and length of the test section.

Clearly, the most versatile wind tunnel would allow experiments to be performed in either an open or enclosed test section. An added advantage of such an arrangement is that experiments can be repeated for both conditions, and, by comparison of experimental findings, an assessment made of the dependence of the results on the test-section type. As Professor Sherwood has pointed out [198], such a comparison would provide an indication of how well experiments are reproducing the effects of an ambient wind field. Both enclosed and open test sections are subject to perturbations, but these perturbations are different for the two types. Agreement between experiments repeated in both types of test section implies that these perturbations are small and that the results are indicative of the behavior expected in an ambient wind field.

\section{Velocity Profiles and Turbulence Properties}

Up to now, wind tunnels designed for fire research have attempted to provide the most uniform velocity profiles possible at the tunnel entrance. Turbulence levels are generally maintained as low as possible. There has been little consistency in how these velocity profiles and turbulence levels have been modified within the tunnel for fire measurements. 
Some workers have attempted to maintain uniform, low-turbulence flows throughout the test section. It should be noted that this is difficult since turbulent boundary layers grow along the fuel surface as the flow passes over. This is particularly crucial in fire spread measurements where the flow distance between the tunnel entrance and the rear of the propagating fire is a function of time.

Other workers have "tripped" the formation of a boundary layer utilizing short screens placed near the floox of the tunnel. This means that flames near the surface are subject to a turbulent boundary layer, but that the flow above the boundary layer will be roughly uniform and have low turbulence. Still others have used grids or screens placed across the entire tunnel to create turbulent flow throughout the tunnel cross section.

It is difficult to decide which flow conditions to use for fire tests. As pointed out in Section 12, such fire properties as wind-aided spread rate may be very sensitive to the nature of the velocity profile and its turbulence properties. The choice of the wind velocity field must depend on the goals of a particular experiment. A uniform, low-turbulence flow is the simplest profile, and this type of flow is most amenable to theoretical treatment. On the other hand, the goal of most experiments is to improve the understanding of atmospheric winds on fire behavior. The atmospheric boundary layer is highly turbulent with turbulent intensities near the surface of $\approx 30 \%$. In order to model real-world conditions, an ABL flow is superior.

The ideal wind tunnel should be capable of investigating fire behavior in both uniform, low-turbulence flow and/or within a turbulent boundary layer. Since the primary goal is to understand wind effects, the boundary layer flow should model as closely as possible the atmospheric boundary layer (see discussion in Section 12). As was true when considering what type of test 
section should be employed, having the capability for producing both flow behaviors will allow experimental findings to be obtained for each. Comparison of the results will permit the effects of velocity profile shape and turbulence level on fire behavior to be assessed.

\subsection{Requirement for Development of a New Wind Tunnel Facility}

Existing wind tunnels designed for fire research investigations are listed in Table 2. Presumably, these or similar wind tunnel facilities would be available for performing the types of research studies described in Section 14. The question is, "Can a single or combination of existing facilities provide the measurement capabilities of the ideal wind tunnel outlined in the last section?" The answer is definitely not. The reasoning behind this conclusion follows.

Consider the properties listed in the last section. It has been pointed out that the maximum fire sizes (in terms of power) which can be burned in existing wind tunnels vary from roughly 0.1 to $0.65 \mathrm{MW}$. One of the most important goals of a wind tunnel research program designed to improve the understanding of urban fire spread is the assessment of the heat transfer mechanisms responsible for flame spread between near-lying buildings. As noted, this requires that the heat transfer behaviors of a range of different fires be assessed in the presence of wind in order to ascertain if a change occurs from primarily convective to radiative transfer as the scale increases. It is significant that all such studies utilizing existing facilities have found that convective heat transfer dominates. Measurements are required on larger fires.

Most fire-spread experiments thus far have been made for very thin fuels or wood cribs. Longer fuel beds of thicker fuels having higher heat release 
rates should be investigated. Existing wind tunnels are not capable of handling the additional heat release rates and longer fuel beds which are required.

The maximum wind velocities of existing wind tunnels are sufficient to allow investigations of the fire problems for which they were designed (e.g., fire spread through thin forest fuels or organized beds of thin fuels). However, with the possible exceptions of the facilities at Borehamwood (Table 2. \#2) or the small tunnel at Missoula (\#4), maximum wind velocities for existing tunnels are too low to allow larger fires or fire blow out behavior to be investigated. It should be noted that the Borehamwood facility is an induced-flow tunnel and may not accurately reproduce the behavior of fires in the open (see Section 15.1), and the small tunnel at Missoula has not been employed for fire spread investigations [186].

None of the currently existing wind tunnels have well-characterized velocity profiles or turbulence levels in the presence of fire and a fuel bed. This results partly from a lack of suitable instrumentation for such measurements and partly from a disregard of the potential importance of velocity profiles and turbulence intensity on fire spread and properties. No experimental efforts have been made to characterize the role of variations in wind profile or turbulence level. The lengths of the fire tunnels which are currently available are all too short to allow the development of a simulated atmospheric boundary layer even if the enhancing techniques described in the following section are utilized.

No single facility has been used to make and compare wind tunnel measurements with open and enclosed test sections. In fact, this is an experimental verification of wind tunnel modeling of fire behavior which remains to be performed. The wind tunnel facility at the University of 
Oklahoma is designed in such a way (i.e., it has a static test chamber located at the exit for the tunnel) that it might possibly be used for both types of measurements [185]. Unfortunately, the ratio of the widths of the cross section for the test chamber to the tunnel is only $2.5: 1$. This is probably too low to prevent pressure fluctuations, associated with air flow into the chamber from the test section, which interfere with the wind field (see discussion in the following section). Some measurements of this type might be made at two different tunnels (e.g., the University of Oklahoma and Seikei University) and compared, but it would certainly be more reliable for researchers at a single location to perform experiments utilizing the same techniques and instrumentation.

The above discussion shows that while existing wind tunnel facilities have made major contributions to the understanding of wind-aided fire spread and fire behavior, they are not suitable for dealing with the wide range of questions raised by consideration of the urban fire-spread problem. Experiments which can improve the understanding of the role of velocity profiles and turbulence on burning characteristics in a wind are feasible, but cannot be carried out in existing facilities. The same is true with regard to testing whether or not measurements in wind tunnels are influenced by the measurement technique itself. Professor Sherwood of Aerolab [198] has provided an interesting observation on the latter point. He notes that findings within a wind tunnel must be "above reproach", since many conclusions in the past have been based on effects associated with wind tunnel testing and not the physics associated with a free wind.

It is not surprising that currently-existing wind tunnel facilities for fire research are not well-suited for dealing with the problems associated with urban fire spread. Most were designed and built during the period from 
1959 to 1967. Designing these tunnels was complicated by the lack of a rudimentary understanding of the effects to be expected. The development of low-speed wind tunnels in the decades since the 1940 s had proceeded at a very slow pace. No modern examples of low-speed wind tunnels existed to serve as guides. It is a tribute to these early researchers that despite these difficulties their work has contributed to a greatly improved understanding of wind-aided fire spread and wind-fire interactions, and that many of the wind tunnels they designed and built are still in use today.

The single facility constructed in the 1980s (Table 2, \#10) was designed especially to investigate fire spread through organized structures of fine fuels. Treating this problem is the first step on the road to an improved understanding of the fire spread mechanisms in fuel matrices which are similar to urban environments. Significant progress has been made. However, this facility is relatively small and not designed to handle the wide range of experiments necessary to dramatically improve the understanding of urban fire spread.

Clearly, a new facility is required to deal with the large number of research areas identified in this paper. The discussion in this section has provided rough guidelines for designing a wind tunnel facility in which an experimental program can be carried out which will significantly enhance our understanding of fire spread in an urban environment following a nuclear detonation. In the following section general specifications are given for a facility which, if designed and constructed, will approach closely the ideal wind tunnel facility discussed above. 
16. GENERAL SPECIFICATIONS FOR A WIND TUNNEL FACILITY DESIGNED FOR STUDIES OF
FIRE CHARACTERISTICS RELEVANT TO URBAN FIRE BEHAVIOR

This section provides general specifications for a wind tunnel facility to investigate the problems which are associated with urban fire spread (see discussion in earlier sections). The purpose is not to provide final design drawings or engineering specifications, but to provide specific recommendations concerning the form which the proposed facility should take.

The characteristics of the proposed facility match as closely as possible those for the ideal wind tunnel discussed in Section 15.3. Both existing wind tunnels designed for fire studies (described in Section 15.1) and wind tunnels designed for modeling the atmospheric boundary layer have provided ideas which have been incorporated into the design. Discussions with other researchers have also been invaluable. The result is a unique design which, if engineered and constructed, will provide capabilities for fire research that are not available in existing research facilities.

A Iist of specifications is given in Table 3 and Figure 32 shows rough schematics for the proposed wind tunnel facility in both plan and elevation views. Note that only the wind tunnel components and the test chamber are shown. In a final design, additional areas would be necessary to house research personnel, instrumentation, and other equipment.

The general specifications of the wind tunnel facility will be discussed first. Then each section of the proposed facility will be discussed in greater detail to provide the reasoning for its final form.

\subsection{Overall Tunnel Specifications}

The wind tunnel facility pictured in Figure 32 is an open wind tunnel which has been designed to permit a wide range of experimental investigations 
TABLE 3

\section{RECOMMENDED WIND TUNNEL SPECIFICATIONS}

Type of Tunnel: Open

Type of Flow: Forced

Type of Test Section: Both Open and Closed

Environmental Conditioning of Flow: None

Turbulence Characteristics of Test Section: Low Turbulence or Model

Atmospheric Boundary Layer

Test Section Dimensions:

Width: $6 \mathrm{~m}$

Height: $6 \mathrm{~m}$

Length: $20 \mathrm{~m}$

Area Ratio for Contraction: $2: 1$

Speed Range in Test Section: $0=15 \mathrm{~m} / \mathrm{s}$.

Flow Volume Rate Required For Maximum Velocity: $540 \mathrm{~m}^{3} / \mathrm{s}$

Power Required to Drive Fan: Estimated to be roughly $300 \mathrm{~kW}$

Test Chamber Dimensions:

Width: $24 \mathrm{~m}$

Length: $24 \mathrm{~m}$

Height: $24 \mathrm{~m}$

Ratio of Test Chamber Width to Test Section Width: $4: 1$ 


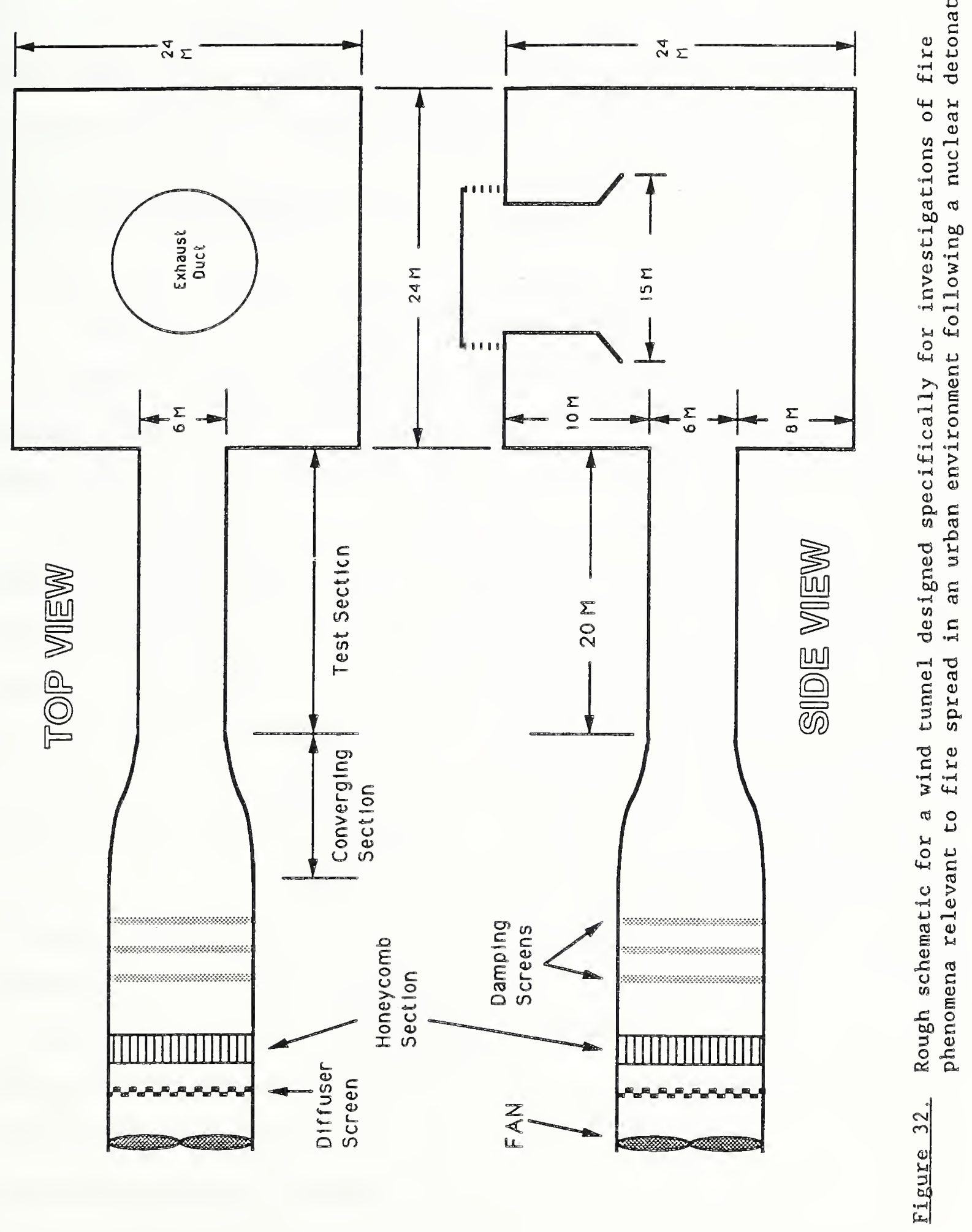


dealing with fire behavior. Experiments can be performed within the enclosed test section or at the mouth of the tunnel in an open test section. The large test chamber also provides a location for static fire experiments. The enclosed test section has been scaled and configured so that experiments can be performed in either a uniform, low-turbulence flow or in a boundary layer conditioned to simulate the atmospheric boundary layer. The flexibility built into the design significantly increases the types of experiments which can be undertaken and provides unique opportunities for validating the applicability of research findings within the tunnel to fire behavior in the atmosphere.

The specifications for the tunnel include a cross-sectional area of $6 \times 6 \mathrm{~m}^{2}$ and a maximum velocity of $15 \mathrm{~m} / \mathrm{s}$ ( $33 \mathrm{mph}$ ) requiring a maximum volume flow rate of $540 \mathrm{~m}^{3} / \mathrm{s}\left(1.14 \times 10^{6} \mathrm{cfm}\right)$. The test section cross-sectional area and maximum velocity axe larger than any existing wind tunnel utilized for fire studies. It is interesting to compare the specifications of the proposed tunnel with those for an existing low-speed wind tunnel. The 9M V/STOL Wind Tunnel of the National Research Council Canada [200] was completed in Ottawa in 1970. This closed tunnel has a $6.1 \times 9.1 \times 22.9 \mathrm{~m}$ test section and can generate velocities as high as $55 \mathrm{~m} / \mathrm{s}$. The motor used to power this cunnel is a $6.7 \mathrm{MW}$ (9000 hp) D.C. electric motor. Compared to this gargantuan facility, the proposed wind tunnel is only of moderate size.

Based on the discussion of Sections 15.2 and 15.3, it should be possible to investigate fires as large as $2 \mathrm{MW}$ in the enclosed test section and perhaps even laxger in the open test section. While such fires are not as large as a fully-involved burning building, they are considerably larger than those which can be studied in existing facilities and will allow tests of scaling of the heat transfer mechanisms responsible for fire spread. The large cross. sectional area also mitigates against tunnel blockage effects. 
The maximum test section velocity of $15 \mathrm{~m} / \mathrm{s}$ is roughly twice that for existing facilities and is consistent with the larger fires which can be burned. It is probably too low to investigate the blow out of moderatelysized fires, but is considered the maximum possible without unreasonable increases in the size of the motor required to power the fan.

\subsection{Enclosed Test Section}

The test section has a square $6 \times 6 \mathrm{~m}^{2}$ cross section and a length of $20 \mathrm{~m}$. The cross-sectional area has been chosen to be roughly four times larger than the largest existing wind tunnel utilized for fire studies. This increase in area will allow larger fires to be investigated than has been possible in the past.

The test section length has been chosen to allow for different experimental conditions. Near the entrance the velocity flow field will be highly uniform and have low turbulence. Experiments requiring a well-defined velocity flow field can be performed at this location. The length of the test section will also allow measurements of flame spread behavior through longer fuel beds than have been possible in existing tunnels. A more important reason for specifying a relatively long test section compared to earlier tunnels is to provide sufficient length for the creation of a model atmospheric boundary layer. When operating in this mode, the fire experiments will be located as close as possible to the test section exit.

During the past three decades experimental capabilities for modeling the $A B L$ have vastly improved. The primary driving force for these improvements has been the desire to physically model a large number of wind effects such as stresses on structures, surface vehicles, dispersion of pollutants, flow patterns in cities and forests, and the blowing of snow. An extensive 
bibliography of such investigations up to 1970 is available [201]. The monograph [167] edited by Reinhold provides more recent examples.

Two general approaches have been adopted to model the ABL. The first [183] utilizes extremely long test sections and allows the boundary layer to develop naturally. The second uses artificial techniques to accelerate the growth of the boundary layer [202]. The latter method has been adopted for the proposed facility since it requires a considerably shorter test section.

Two general classes of augmentation have been utilized which are known as passive and active. In passive augmentation, barriers are placed in the flow field which introduce turbulence and a rough surface is then used to aid the growth of the layer. A typical system would consist of spires followed by small blocks placed on the floor of the wind tunnel [202]. The second class of augmentation is to inject momentum into the tunnel flow (e.g., by the use of multiple small jets $[203,204])$. For the purposes of the proposed wind tunnel, passive augmentation would be most suitable since it is simpler and cheaper to implement. The tunnel is not designed to be the ultimate in $A B L$ simulation facilities, but to investigate fire behavior.

Augmentation does not provide complete modeling of the ABL, but by the judicious choice of augmentation devices the experimenter has a wide range of control over the boundary layers which are created with regard to boundarylayer depth and turbulence intensity. This freedom allows experiments which simulate various boundary-layer behaviors of urban environments from suburban residential tracts to high-rise city centers.

The development of boundary layers presents another problem in wind tunnel experiments. The growth of a boundary layer requires a deceleration of fluid flow near solid surfaces. As a result, fluid near the center of the tunnel is accelerated and a pressure gradient develops along the length of the 
tunnel. This behavior is always a potential source of interference. Even in experiments for which the velocity at the entrance to the tunnel is uniform and has low turbulence intensities, boundary layer growth occurs and introduces pressure gradients. Many wind tunnels designed for the investigation of $\mathrm{ABL}$ problems incorporate increasing cross-sectional areas [200] or adjustable ceilings [184] so that the height of the tunnel can be changed as a function of the downstream distance. In this way it is possible to mitigate against the development of the pressure gradient.

For the proposed wind tunnel for fire studies it is recommended that the possibility of a variable cross section be considered in the engineering of the facility. Since a wide range of conditions and boundary layers are to be utilized, it is probable that a continuously-variable means for altering the cross section would be required. It seems likely, however, that the advantages of such a capability would not outweigh the added cost of the facility.

Visualization of the effects of wind on fire behavior is a very important aspect of any investigation in a wind tunnel. It is necessary that adequate windows be incorporated into the final design. Since experiments are likely to be placed at any position along the enclosed test section, the entire length must be visually accessible. Greatest visual assess is required near either end where experiments requiring uniform flow conditions or an $A B L$ boundary layer are to be located. Of course, windows must be shielded and heat resistant.

Physical assess to the tunnel is another important aspect of the design. The floor of the tunnel should be movable and an area provided underneath for sample preparation and instrument placement. For fire spread measurements, the capability of moving the fuel bed so that the flame front remains fixed in 
space provides real advantages in instrumenting (such as mass loss and temperature measurements) and visualizing fire behavior. This idea was originally used by Fons et al. [92] for fires in still conditions and Rios [117] developed fuel feed systems from below the tunnel floor which allowed wind tunnel investigations of interacting spreading fires. Access from below is imperative for this mode of fire study. Figure 32 shows that there is an area under the test section which can be enclosed and utilized to provide access through the floor of the test section. Experimenters should also have doorways available on the level of the tunnel for easy and fast access to the enclosed test section.

No provision has been included in the design for conditioning the air flowing through the test section. The author believes that a conditioning unit for temperature and humidity sufficient for the large flow volumes involved (up to $540 \mathrm{~m}^{3} / \mathrm{s}$ ) would not be economically feasible, but the question should be considered further during engineering studies. The decision to not include temperature and humidity control probably means that there would be some periods of time during which testing would not be possible due to unsatisfactory outside-weather conditions. The University of Oklahoma and TRW facilities do not condition their air flows and have managed to generate an immense amount of useful experimental information.

No recommendation is made at this time concerning the materials to be utilized for construction of the test section, but it is clear that these materials must be noncombustible and capable of withstanding high temperature loading. Concrete or steel are possible choices. A final choice must await engineering studies for the facility. 


\subsection{Test Chamber}

The large (24 × $24 \times 24 \mathrm{~m})$ test chamber included in the wind tunnel

facility shown in Figure 32 is intended to serve many functions. It acts as a ballast for the enclosed test section and thus isolates the wind tunnel from outside wind fluctuations. It provides a large volume around the exit of the wind tunnel where fire studies can be made in an open test section. It serves as a large chamber where fire experiments can be performed in the absence of wind. This capability is particularly important for comparison with experiments carried out in the presence of a wind. Finally, the test chamber is the area where combustion products (smoke and noxious gases) are collected, treated, and released to the atmosphere.

Similar test chambers are incorporated into existing installations for fire studies in winds. Both the University of Oklahoma (Figure 28) and the Forest Service facility at Missoula (Figure 27) have test chambers even though each is designed to serve a different role with regard to the wind tunnel. The TRW facility (Figure 30) is similar in that it incorporates a hood at the end of the test section, but the hood is not designed to be used for static tests.

The test chamber in the Forest Service facility is pressurized and serves as a plenum region for the wind tunnels. This is a very unusual design. The University of Oklahoma system uses the test chamber in much the same way as the facility proposed here. It serves as a ballast volume for the wind tunnel, a static test cell, and a smoke release point.

It should be pointed out that existing wind tunnels for fire studies as well as the one being proposed here, do not utilize a device known as a diffuser following the test section. The diffuser provides a gradual increase in the cross section of the flow and in this way mitigates the large pressure 
drop which occurs when a confined flow enters a large volume. A reduced pressure drop at the tunnel exit means that a smaller motor is required to drive the flow. The use of diffusers is quite common in aerodynamic wind tunnels. In fact, designers of precision aerodynamic wind tunnels feel that if a diffuser is not included that the term "wind tunnel" should not be used, but that the facility should instead be named a "wind generator" [198,199]. In this report the term wind tunnel is used in the more general sense.

The size of the test chamber is dictated by a desire to have the capability of performing measurements in an open test section. It is necessary to avoid pressure fluctuations which interfere with the flow field. Standard practice $[198,199]$ for open test sections is to have a distance between the tunnel exit and the wall of the enclosure which is at least four times the tunnel's characteristic dimension. For a $6 \mathrm{~m}^{2}$ square exit, a $24 \mathrm{~m}$ distance is required.

As was discussed in Section 15.1, the length of an open test section where experiments are possible is quite short. Only stationary fires or fires which are propagating but are moved to maintain their position in one place are suitable for investigation. This drawback should not be a major limitation on the usefulness of the open test section. Its advantages are that it should be possible to burn larger fires than within the enclosed test section and comparisons with findings within the enclosed test section will allow an analysis of the significance of perturbations introduced by the use of wind tunnels on fire behavior.

The flow fields within the open test section should be similar to those within the tunnel. By the proper placement and use of flow conditioning devices, either uniform, low turbulence or ABL boundary layer flows can be created. 
In Figure 32, the plan view of the proposed facility shows that the exit of the wind tunnel is raised $8 \mathrm{~m}$ from the floor of the test chamber. Not only does this separation reduce the asymmetry of the tunnel exit and possible interference effects on the enclosed test section flow, it provides a work area beneath the open test section where experiments in this section can be arranged. Presumably, a work platform would be placed below the tunnel exit when experiments utilizing the open test section were to be carried out. This platform would be removed when measurements were to be made in the enclosed wind tunnel test section or under static conditions.

The design of the test chamber is greatly complicated by the need to deal with smoke control and removal. Different means have been used for removing combustion products from existing wind tunnel facilities. In several, the forced flow of air along with buoyancy effects simply sweeps the products out. This is the method used in the University of Oklahoma (released from louvers at the top of the test chamber), U.S.D.A. Forest Service, Missoula (released from a chimney at the top of the research building), and TRW (flow out of overhead hood) facilities. The University of New Brunswick workers included a small exhaust fan in their design. The Missoula facility also includes an exhaust fan for use during wind-free experiments in the test chamber.

Due to the large volumes involved and the need to keep the test chamber relatively clear for workers safety and comfort, it is recommended that a small exhaust fan be located at the top to remove smoke and combustion gases. In regard to cleanliness of the test chamber, an inspection of the University of Oklahoma wind tunnel showed that following many years of fire testing there was surprisingly little buildup of soot on the walls of the test chamber. Apparently, the removal of combustion products is quite efficient. The use of an exhaust fan will improve the situation. 
The static test chamber of the Missoula facility has a large hood (see Figure 27) which can be lowered and raised depending on the nature of the experiment. It would be very useful to have a similar arrangement in the test chamber of the proposed wind tunnel laboratory, but allow for some horizontal movement as well. A $15 \mathrm{~m}$ diameter hood would probably be satisfactory. The hood could then be positioned to remove combustion products most efficiently depending on which type of experiment (enclosed test section, open test section, or static) was being run.

Smoke and combustion products present still another serious problem in the design of the facility. None of the existing facilities incorporate means for eliminating smoke or noxious gases from their flows before release. They are vented directly into the atmosphere. For the larger fires to be burned in the proposed facility, levels of combustion products may well exceed permissible amounts and might present a serious pollution problem. Before a final design for the facility can be completed, this question must be looked into further. It may be necessary to incorporate an afterburner or scrubbers to alleviate the problem.

During periods when the wind tunnel is not in operation or when static experiments are underway it is necessary to provide fresh air to the test chamber. This can be accomplished by a series of ducts surrounding the test chamber floor which can be opened or closed. During periods when the wind tunnel is not in operation air from outside would be drawn through these ducts by the exhaust fan in the ceiling of the test chamber.

\subsection{Fan and Flow Conditioning Section}

Figure 32 shows that this section of the wind tunnel facility consists of a fan, motor, and housing; a settling chamber; and a contraction. This 
section of the wind tunnel facility can be designed in innumerable ways. It has not been the goal of this investigation to provide the required engineering analysis, but to make recommendations and estimates for the components to be included. A possible solution is provided for discussion purposes, but it must be emphasized that the final form for this section of the facility can only be finalized following a detailed engineering and cost analysis. In the final result some of the components shown (e.g, the contraction section) may be eliminated or others (e.g., a diffuser or plenum) may be added.

One of the first questions to be considered is whether or not to include a contraction in the design of the tunnel. As discussed in Section 15.1, existing facilities for fire studies have been designed in both ways. It is important to note, however, that standard low-speed wind tunnel designs do include contractions.

Milburn [185] was the first to design and build a low-speed tunnel without a contraction. Even though Milburn considered designs utilizing contractions, he concluded that they were too costly for the available funding. Measurements reported in [185] and [130] show that the approach adopted of using only flow straightening devices was quite successful. Uniform, low turbulence flows were generated.

During a visit to the University of Oklahoma, the author was able to discuss this point with Professor Ed Blick [197], Milburn's research advisor. Professor Blick indicated that some effort was required to arrange the flow straightening devices so that uniform flow was produced. However, the total effort required only a few weeks. He was quite confident that the same approach could be utilized with comparable results in a larger facility such as the one proposed here. 
The same topic was discussed in conversations with the professional staff of a company which designs and constructs wind tunnels $[198,199]$. They agreed that the tested approach of Milburn [185] would most likely be successful in a wind tunnel of the size proposed here. However, it was their very strong opinion based on extensive experience that the benefits of including a weak contraction were so great that the additional construction cost incurred would be minimal compared to the improvement in flow behavior.

Marshall [205] takes a more balanced view. He feels that both viewpoints have their strong points and that a final choice can only be made based on a complete engineering and cost analysis of the competing designs. For the purposes of this report, a $2: 1$ area contraction (a mild contraction) has been included in the design for the wind tunnel shown in Figure 32.

A single, large fan is shown in Figure 32. Such a fan would be very expensive. Other possibilities must certainly be considered. These include the use of several smaller fans [205].

Flow fluctuations in time and space introduced by the fan are reduced in the settling section of the system. A diffusing screen is included to remove spatial variations in the velocity profile. This is followed by a honeycomb section designed to remove large-scale turbulent fluctuations. Three additional smoothing screens are provided to further reduce turbulence before the flow is contracted into the test section. The contraction will further reduce turbulence levels. A great deal of information concerning the flow straightening capabilities of screens and honeycomb is available (e.g., $[184,185])$ and theix effects can be predicted fairly well.

No explicit methods are available for the design of the length and shape of the diffuser [184]. Marshall [184] provides an excellent discussion which can serve as a starting point. However, the final design will be dependent on 
such factors as fan type. It may be advisable to perform small-scale wind tunnel experiments to determine the most favorable form for this tunnel component.

If experiments are to be run in the open test section in the presence of uniform flow, some flow smoothing capabilities must also be incorporated into the enclosed test section. The arrangement of the screens and honeycombs adopted by Milburn [185] provides a very good starting point.

The first section of the wind tunnel, and the last to be discussed here, is the fan, motor, and housing. The primary reason for leaving a discussion of this section to last is that it is the most difficult to specify without performing the detailed engineering studies which are required before the facility can be constructed.

Marshall [184] has pointed out that standard fans are available for flow volumes up to $136 \mathrm{~m}^{3} / \mathrm{s}$, with special designs being required for higher flow volumes. Since the maximum flow volume for the proposed wind tunnel is $540 \mathrm{~m}^{3} / \mathrm{s}$, a specially-designed fan will certainly be required if a single fan is to be utilized. It is likely that the fan will be of the blade type since such fans provide relatively uniform flows and, by the use of variable speed motors and blade angles, a wide range of flow velocities.

Since the fan section is to be open to the atmosphere, it is necessary to insulate the fan as much as possible from ambient wind fluctuations. The workers at the University of Oklahoma [185] had a great deal of success by locating their fan in a room with louvered windows. This design also provides additional velocity control since the area of the openings into the room can be varied by adjusting the louvers.

The power required for the fan can be estimated if some assumptions are made concerning the final design of the tunnel and the efficiency of the fan. 
The procedure is to calculate the pressure drops through the tunnel at the highest velocity to be utilized. The power required to overcome these losses is equal to the flux of force due to the air flow (Nt/s) times the head loss in meters. Head losses have been estimated using the procedures outlined by Pope and Harper [166], Marshal1 [184], and Milburn [185]. Table 4 lists the pressure drops calculated for various sections of the wind tunnel of Figure 32 for a test section flow velocity of $15 \mathrm{~m} / \mathrm{s}$. For a volume flow of $540 \mathrm{~m}^{3} / \mathrm{s}$ at $20 \mathrm{C}$ the required power is calculated to be $200 \mathrm{~kW}$. Assuming a 708 fan efficiency, a motor rated for $286 \mathrm{~kW}(383 \mathrm{h.p.})$ is required.

Marshall [184] has discussed the various options available for variablespeed motors. He believes [205] that the best choice for a motor in the type of facility described here is either a d.c. powered, voltage-regulated or a frequency-regulated $a . c$. induction motor. Both of these types of motor are widely employed for large wind tunnels.

\subsection{Other Considerations}

Thus far, no consideration has been given to cost in the analysis of the wind tunnel which has been recommended for construction. The goal was simply to identify the nature of the problems to be solved and provide the best solution. There can be little doubt that the design and construction costs would run to several millions of dollars. A better estimate would require some preliminary engineering design work for the facility.

Additional costs would be incurred due to the need to instrument the facility. Since this facility would be state-of-the-art it would only make sense to utilize state-of-the-art instrumentation. In particular, data acquisition and analysis with large numbers of input channels would be required. 
TABLE 4

ESTIMATED PRESSURE DROPS THROUGH SECTIONS OF THE PROPOSED WIND TUNNEL

Tunnel Component

Fan

Settling Chamber:

Diffusing screen Honeycomb

Smoothing screens

Duct

Contraction

Test Section

Discharge to Test Chamber

Flow in Test Chamber

Discharge from Test Chamber

TOTAL:
Pressure Loss (Pascals)

94

10

91

1

5

4

135

1

30

371
Percent of Total Loss

25

3

25

0.2

1

1

36

0.2

8 
Conclusions reached during the course of this study are that instrumentation for fire research has not advanced rapidly since the 1960s, and that the new measurement techniques which have been developed have not been incorporated into experimental systems for fire spread studies. Some effort would be necessary to insure that the most modern, dependable, and accurate instrumentation is obtained or developed for measurements of velocity, mass loss rate, thermal radiation, temperature, and chemical composition.

A multi-year research program will be necessary to complete the experiments which are required to dramatically improve the current understanding of urban fire spread. A long-term commitment of support for personnel, operating expenses, and maintenance is imperative.

\section{FINAI COMMENTS}

This report has provided a detailed assessment of the role of fire in the destructiveness of nuclear attacks within an urban environment and current abilities to predict these effects. The unsettling conclusions have been reached that current estimates of fire damage, while indicating significant damage as a result of fire, are most likely low, and the knowledge base utilized for these estimates is so incomplete that reliable estimates are not possible.

The research areas necessary for improving predictive capabilities were listed and it was shown that many could be profitably investigated using scale-model studies in a properly-designed wind tunnel facility. Current Eacilities available for fire research studies were reviewed and the conclusion reached that none have the necessary characteristics to allow extensive experimental investigations of the problems relevant to urban fire 
spread. Specific recommendations for a new wind tunnel facility designed especially to deal with these problems have been provided.

In making the decision on whether to proceed with the construction of a new wind tunnel facility planners should keep in mind the following points.

1. The need for an improved understanding of urban fire spread as it relates to nuclear weapon effects is overwhelming.

2. At the present time, predictive capabilities for estimating fire damage in an urban environment following a nuclear attack are very limited and uncertain.

3. Wind tunnel experiments will not provide all of the required information, but will offer the opportunity to improve substantially the understanding of the problem.

4. Most existing wind tunnels were designed decades ago and are not wellsuited for the required experimentation.

5. Some progress can be and is being made in existing facilities, but substantial improvements in understanding require a new facility and a sustained commitment for support. 


\section{ACKNOWLEDGMENTS}

This work was supported by the Defense Nuclear Agency under Contract IACRO 88-890. The project monitor was Dr. Mark D. Flohr.

A large number of researchers have provided information which has been incorporated into this report. This manuscript would not have been possible without their efforts. Some of these people may not be mentioned here, but the author wishes to express his sincere thanks to everyone who has made a contribution.

Three site visits were made during the preparation of this report. Professor Cedomir Sliepcevich of the Flame Dynamics Laboratory of the University of Oklahoma acted as the host for the author's visit to Norman. Thanks to him a great deal was learned about wind tunnel construction in general and the University of Oklahoma facility in particular. He also arranged for meetings with several members of the faculcy including Professor Ed Blick of the Petroleum and Geological Engineering Department. Professor Blick's student, Richard Milburn, designed the University of Oklahoma facility, and Professor Blick's comments were most useful. Professor Sub Gollahalli of the Aerospace, Mechanical, and Nuclear Engineering Department was also present and discussed instrumentation difficulties. Professor Sliepcevich's assistant, Ms Billy Ann Brown, was very conscientious in providing copies of theses and making the arrangements for the visit.

Mr. Richard C. Rothermel, project leader, acted as host for the facility visit at the Intermountain Fire Sciences Laboratory in Missoula, Montana. He arranged for a most interesting laboratory tour and for conversations with many of the staff members. Conversations with Dr. Darold Ward and Ralph Nelson were particularly relevant. Mr. Rothermel was also kind enough to 
rearrange the planned schedule so that the author was able to witness a test burn in their large wind tunnel facility.

The third site visit was to the Aerolab facilities in Laurel, Maryland. Professors A. Wiley Sherwood and C. M. Chen, owner and chief engineer, respectively, took an afternoon from their busy schedules to meet with the author and show their facilities. Their comments concerning wind tunnel construction were most helpful.

Additional discussions were held with Stan Martin of Stan Martin and Associates and Frank Fendell of TRW. Both of these researchexs have worked in the fire spread area for many years and their insightful comments proved to be most useful in the preparation of this report.

Professor Kozo Saito of the University of Kentucky and Dr. Takashi Kashiwagi of the Center for Fire Research, NIST provided information concerning the facilities available in Japan for wind-aided fire spread investigations.

Dr. Jin Bao Fang of the Center for Building Technology, NIST was kind enough to provide a copy of his thesis fxom the University of New Brunswick. Another member of this center, Dr. Richard Marshall, had recently completed a design study for a low-speed wind tunnel. The final report describing his study along with personal discussions with Dr. Marshall contributed a great deal to the proposed design for the wind tunnel which is included in this report.

Drs. George Mulholland, Howard Baum, and James Quintiere of the Center for Fire Research, NIST are acknowledged for providing the impetus for this work and for their careful reading of this manuscript. Nelson Bryner of the Center for Fire Research prepared Figures 26 and 32 and aided in the calculations of the flow properties for the proposed wind tunnel. 
[1] Glasstone, S. and Dolan, P. J., The Effects of Nuclear Weapons, 3rd ed., United States Department of Defense, 1977.

[2] von Hippe1, F. N., Levi, B. G., Postol, T. A., and Daugherty, W. H., "Civilian Casualties from Counterforce Attacks," Scientific American 259 (September, 1988) 36-42.

[3] Committee on the Atmospheric Effects of Nuclear Explosions, The Effects on the Atmosphere of a Major Nuclear Exchange, National Academy Press, Washington, 1985.

[4] Groce, D. E. and McKay, M. W., "Historical Fires Bibliography," Science Applications, Inc., Topical Report SAI-133-82-038-LJ, February, 1982.

[5] Reitter, T. A., McCallan, D. B., and Kang, S-W., "Literature Survey of Blast and Fire Effects of Nuclear Weapons on Urban Areas," Lawrence Livermore National Laboratory Report UCRL-53340, June, 1982.

[6] Countryman, C. M., "Mass Fires and Fire Behavior," U. S. Forest Service Report PSW-19, 1964.

[7] Brode, H. L., Sma11, R. D., Thomas, F. J., Larson, D. A., and Speicher, S. J., "Large-Scale Urban Fires," in "Fire, Airblast, and Underground Effects From Nuclear Explosions--Some Current Progress," (Brode, H. L. et al.) Defense Nuclear Agency Report DNA 5741T, January, 1981.

[8] Lee, S. L. and Granito, A. R., "Research Analysis--Conflagration Fire Behavior, The 1973 Chelsea, Massachusetts Fire," Fire Command! 41 (1974) $12-14$.

[9] Baldwin, R., "Firestorm, Its Size and Importance," in Proceedings: Tripartite Technical Cooperation Program Panel $N-3$ (Thermal Radiation) Mass Fire Research Symposium, Defense Atomic Support Agency Special Report DASA 1949, pp. 170-196, October, 1967.

[10] Carrier, G. F., Fende11, F. E., and Feldman, P. S., "Firestorms," J. Heat Transfer 107 (1985) 19-27.

[11] Carrier, G. F. and Fende11, F. E., "Firestorm," Mechanical Engineering (December, 1986) 50-54.

[12] Waterman, T. E., Labes, W. G., Salzberg, F. Tammey, J. E., Vodvarka, F. J., "Prediction of Fire Damage to Installations and Built-Up Areas From Nuclear Weapons," IIT Research Institute Final Report - Phase 3 for the National Military Command System Support Center, Contract No. CDA-8, November, 1964.

[13] Brode, H. L. and Sma11, R. D., "Nucleax Weapon Effect Research at PSR-1982. Volume XIII--Fire Damage and Strategic Targeting," Defense Nuclear Agency Report DNA-TR-82-179-V13, June, 1983. 
[14] Broido, A., "Fire Effects of Thermonuclear Detonations," Fire Research Abstracts and Reviews $\underline{5}$ (1963) 1-11.

[15] Renner, R. H., Martin, S. B., and Jones, R. E., "Parameters Governing Urban Vulnerability to Fire From Nuclear Bursts," U. S. Naval

Radiological Defense Laboratory Report USNRDL-TR-1040, June, 1966.

[16] The Committee on Fire Research, "A Proposed Fire Research Program," Fire Research Abstracts and Reviews 1 (1958-1959) 1-8.

[17] Gains, E. M., "Background and General Progress on Project Flambeau," in Proceedings: Tripartite Technical Cooperation Program, Panel $\mathrm{N}-3$ (Thermal Radiation) Mass Fire Research Symposium, pp. 240-242, Defense Atomic Support Agency Special Report 59, DASA 1949, October, 1967.

[18] Miller, R. K., Jenkins, M. E., Keller, J. A., "Analysis of Four Models of the Nuclear-Caused Ignitions and Early Fires in Urban Areas," The Dikewood Corporation Final Report DC-FR-1210, August, 1970.

[19] Phung, P. V. and Willoughby, A. B., "Prediction Models for Fire Spread Following Nuclear Attacks," URS Corporation Report No. URS 641-6, January, 1965.

[20] Phung, P. V. and Willoughby, A. B., "Prediction Models for Fire Spread," Pyrodynamics 2 (1965) 39-52.

[21] Weisbecker, L. W. and Lee, H., "Evaluations of Systems of Fire Development," Stanford Research Institute Final Report for Office of Civi1 Defense Contract DAHC20-67-C-0116, August, 1970.

[22] Reitter, T. A., Kang, S-W., McCallen, D. B., "Civil Defense Research Priorities for Blast and Fire Effects of Nuclear Weapons on Urban Areas," Lawrence Livermore National Laboratory Final Report UCRL-53339, August, 1982 .

[23] Backovsky, J., Martin, S. B., and McKee, R。, "Experimental Extinguishment of Fire by Blast," SRI International Final Report for SRI Project DYU 3341, May, 1982.

[24] Rotherme1, R. C., "A Mathematical Model for Predicting Fire Spread in Wildland Fuels," U. S. Department of Agriculture Forest Service Research Paper INT-115, January, 1972.

[25] Stevenson, A. E., Schermerhorn, D. A., and Miller, S. C., "Simulation of Southern California Forest Fires," in Fifteenth Symposium (Internationa1) on Combustion, pp. 147-155, The Combustion Institute, Pittsburgh, 1975.

[26] Emmons, H. W., "The Prediction of Fires in Buildings," in Seventeenth Symposium (International) on Combustion, pp. 1101-1111, The Combustion Institute, Pittsburgh, 1979.

[27] Quintiere, J., "A Perspective on Compartment Fire Growth," Combust. Science Techno1. 39 (1984) 11-54. 
[28] Sasaki, H. and Tadahisa, J., "Probability of Fire Spread in Urban Fires and Their Simulations," Report of Fire Research Institute of Japan, No. $47,1979$.

[29] Horiuchi, S., "Section 10.2. The Speed of Fire Spreading in a Section of a Town Consisting of Wooden Buildings," in Architectural Fire Protection, a translation of the original 1972 Japanese document by the Department of Civil Engineering, Carnegie-Mellon University, May, 1981.

[30] "Report on Development of City Fire Prevention Methodology," Ministry of Construction Comprehensive Technology Development Project, Ministry of Construction, Tokyo, Japan, December, 1982. (In Japanese).

[31] Yamashita, K., "Experimental Study of Air Flow Around Fire in the Open," Report of the Fire Research Institute of Japan 48 (1979) 27-34. (In Japanese with English abstract and figure captions)

[32] Emori, R. I. and Saito, K., "Model Experiment of Hazardous Forest Fire Whir1," Fire Technology 18 (1982) 319-327.

[33] Soma, S. and Saito, K. "A Study of Fire Whirl on Mass Fires Using Scale Models," in Proceedings of the International Symposium on Scale Modeling, Tokyo, pp. 353-360, July 18-22, 1988 .

[34] Chandler, C. C., Storey, T. G., and Tangren, C. D., "Prediction of Fixe Spread Following Nuclear Explosions,"U. S. Forest Service Research Paper PSW-5, 1963.

[35] Brode, H. L., "Review of Nuclear Weapons Effects," Annual Rev. Nuclear Sci. 18 (1968) 153-202.

[36] Martin, S. and Hughes, P., "Flashover Modeling for Direct Course," in Proceedings: 17th Asilomar Conference on Fire and Blast Effects of Nuclear Weapons, Lawrence Livermore National Laboratory Report CONF8305107, pp. 189-194, July, 1983.

[37] Waterman, T. E. and Takata, A. N., "Modeling Urban Fire Growth," in Proceedings: 17th Asilomar Conference on Fire and Blast Effects of Nuclear Weapons, Lawrence Livermore National Laboratory Report CONF8305107 , pp. 176-182, July, 1983.

[38] Stanbury, G. R., "Ignition and Fire Spread in Uxban Areas Following a Nuclear Attack," in Proceedings: Tripartite Technical Cooperation Program, Panel N 3, Oct. 5-9, 1964, Dorking, England, pp. 16-1 to 16-24, Published by DISA, September, 1965.

[39] Bracciaventi, S., Feldman, S., and Newman, R. "Fue1 Array Survey of Providence, Rhode Island," Naval Applied Science Laboratory, Lab. Project 040-90, Progress Report 2, September, 1967.

[40] Bracciaventi, S., Feldman, S., and Newman, R. "Fuel Array Survey of Detroit, Michigan," Naval Applied Science Laboratory, Lab. Project 04090, Progress Report 3, March, 1968. 
[41] Martin, S., Ramstad, R., and Colvin, C., "Development and Application of an Interim Fire-Behavior Mode1," URS Research Company Final Report URS 674-3, April, 1968.

[42] Crowley, J. W., Smith, B. R., Avise, H. J., and Whitney, N. G., "Firefly: A Computer Model to Assess the Extent of Nuclear Fire Damage in Urbanized Areas," System Sciences, Inc., Supplemental Report for the Office of Civil Defense, Contract No. DAHC20-67-C-0147, May, 1968.

[43] Takata, A. N. and Salzberg, F., "Development and Application of a Complete Fire-Spread Model: Vol. I (Development Phase)," IIT Research Institute Final Report for Office of Civil Defense Contract N0022867C1498, June, 1968.

[44] Bracciaventi, J., "Fire Start Capabilities of Nuclear Detonations in Urban Areas- A Prediction Model, Final Report," Naval Applied Science Laboratory, Lab. Project 040-90, Progress Report 4, September, 1969.

[45] MacFarlane, C. J., "A Method Used to Predict Numbers of Urban Buildings Lost Due to Fire in A Nuclear Attack," in Proceedings: Tripartite Technical Cooperation Program. Panel $\cdot N-3$ (Thermal Radiation) Mass Fire Research Symposium, pp. 197-205, Defense Atomic Support Agency Special Report 59, DASA 1949, October, 1967.

[46] Albini, F. A. and Rand, S., "Statistical Considerations on the Spread of Fires," in Proceedings: Tripartite Technical Cooperation Program, Panel N3, Oct. 5-9, 1964, Dorking, England, pp. 13-1 to 13-32, Published by DISA, September, 1965.

[47] Schmidt, Jr., L. A., "A Parametric Study of Probabilistic Fire Spread Effects," Institute for Defense Analysis Paper P-1372, September, 1979.

[48] Reitter, T. A., "A Heat Conduction Analog Model of Urban Fire Spread," in Proceedings: 17th Asilomar Conference on Fire and Blast Effects of Nuclear Weapons, Lawrence Livermore National Laboratory Report CONF8305107, pp. 152-156, July, 1983.

[49] Reitter, T. A., "A Heat Conduction Analog Model of Urban Fire Spread," Lawrence Livermore Laboratory Report UCID-19933, November, 1983.

[50] Law, M., "Heat Radiation from Fires and Building Separation," Fire Research Technical Paper No. 5, Department of Scientific and Industrial Research and Fire Offices' Committee Joint Fire Research Organization, London: Her Majesty's Stationary Office, 1965.

[51] Tsukagoshi, I., "Measurement of Radiative Heat Emission from Wood Frame Building in Fire," Fire Science Technol. $\underline{8}$ (1988) 9-13.

[52] Reitter, T. A., Kang, S. -W., and Takata, A. N., "Toward Quantifying the Source Term for Predicting Climatic Effects of Nuclear War: Applications of Urban Fire Codes," Lawrence Livermore National Laboratory Report UCRL-53647, June, 1985. 
[53] Waterman, T. E., "Experimental Study of Firebrand Generation," IIT Research Institute Final Technical Report, IITRI Project J6130, January, 1969.

[54] Waterman, T. E. and Takata, A. N., "Laboratory Study of Ignition of Host Materials by Firebrands," IIT Research Institute Final Technical Report, IITRI Project J6142, June, 1969.

[55] Vodvarka, F. J., "Urban Burns-Ful1-Scale Field Studies," IIT Research Institute Final Technical Report, IITRI Project J6171, January, 1970.

[56] Vodvarka, F. J., "Firebrand Field Studies," IIT Research Institute Final Technical Report, IITRI Project J6148, September, 1969.

[57] Rodden, R. M., John, F. I., and Laurino, R., "Exploratory Analysis of Fire Storms," Stanford Research Institute Report prepared for the Office of Civil Defense, Contract N228-(62479)65419, May, 1965.

[58] Emmons, H. W. and Ying, S-J., "The Fire Whir1," in Eleventh Symposium (International) on Combustion, pp. 475-488, The Combustion Institute, Pittsburgh, 1967.

[59] Byram, G. M. and Martin, R. E., "The Modeling of Fire Whirlwinds," Forest Science 16 (1970) 386-399.

[60] Sma11, R. D. and Larson, D. A., "Analysis of the Large Urban Fire Environment," in Proceedings: 17th Asilomar Conference on Fire and Blast Effects of Nuclear Weapons, Lawrence Livermore National Laboratory Report CONF-8305107, pp. 71-77, JuIy, 1983.

[61] Small, R. D. and Larson, D. A., "Velocity Fields Generated by Large Fires," Israel J. Tech. $\underline{22}$ (1984/5) 173-186.

[62] Sma11, R. D., Larson, D. A., Remetch, D., and Brode, H. L., "Analysis of the Burning Region and Plume of a Large Fire," Defense Nuclear Agency Report DNA-TR-86-401, September, 1986.

[63] Weihs, D. and Smal1, R. D., "Swirl Induced by Large Area Fires," Defense Nuclear Agency Technical Report DNA-TR-86-80, October, 1985.

[64] Church, C. R., Snow, J. T., and Dessens, J., "Intense Atmospheric Vortices Associated with a 1000 MW Fire," Bull. Am. Meteor. Soc. 61 (1980) 682-711.

[65] Palmer, T. Y., "Large Fire Winds, Gases, and Smoke," Atmos. Envir. 15 (1981) 2079-2090.

[66] Morton, B. R., Taylor, G. I., and Turner, J. S., "Turbulent Gravitation Convection from Maintained and Instantaneous Sources," Proc. Royal Soc. London 1 24 (1956) 1-23.

[67] Corlett, R. C., "Fire Violence and Modeling," in Heat Transfer in Fires: Thermophysics, Social Aspects, Economic Impact (Blackshear, P. L., ed.), pp. 255-276, Scripta Book Company, Washington, 1974. 
[68] Emmons, H. W., "Fundamental Problems of the Free Burning Fire," in Tenth Symposium (International) on Combustion, pp. 951-964, The Combustion Institute, Pittsburgh, 1965.

[69] Smith, R. K., Morton, B. R., and Leslie, L. M., "The Role of Dynamic Pressure in Generating Fire Winds," J. Fluid Mech. 68 (1975) 1-19.

[70] Carrier, G., Fendel1, F., and Feldman, P., "Big Fires," Combust. Science Technol. $\underline{39}$ (1984) 135-162.

[71] Nielsen, H. J., "Mass Fire Data Analysis," IIT Research Institute Fina1 Report, IITRI Project J6099, January, 1970.

[72] Baum, H. R. and McCaffrey, B. J., "Fire Induced Flow Field--Theory and Experiment," in Proceedings of the Second International Symposium on Fire Safety, meeting held in Tokyo, June 13-17, 1988, Hemisphere Publishing Company, New York, to appear.

[73] McCaffrey, B. J., "Momentum Implications for Buoyant Diffusion Flames," Combust. Flame 52 (1983) 149-167.

[74] Adams, J. S., Williams, D. W., Tregellas-Williams, J., "Air Velocity, Temperature, and Radiant-Heat Measurements Within and Around a Large Free-Burning Fire," in Fourteenth Symposium (Internationa1) on Combustion, pp. 1045-1052, The Combustion Institute, Pittsburgh, 1973.

[75] Baum, H. R., National Institute of Standards and Technology, personal communication, September, 1988.

[76] Sanderlin, J. C., Ball, J.A., Johansom, G. A., "Mass Fire Model Concept," Defense Nuclear Agency Report DNA 5803F, Final Report, Mission Research Corporation, May, 1981.

[77] Dessens, J., "Man-Made Tornadoes," Nature 193 (1962) 13-14.

[78] Benech, B., "Experimental Study of Artificial Convective Plume Initiated from the Ground," J.Appl. Meteor. 15 (1976) 127-137.

[79] Countryman, C. M., "Project Flambeau...An Investigation of Mass Fire (1964-1967), Vol. 1," Final Report for Office of Civil Defense Order No. OCD-PS-65-26, 1969 .

[80] Palmer, T. Y., "Project Flambeau...An Investigation of Mass Fire (19641967), Vol. 2, Catalogue of Project Flambeau Fires, 1964-1967," Final Report for Office of Civil Defense Order No. OCD-PS-65-26, 1969.

[81] Storey, G., Leonard, J. J., and Yundt, W. H., "Project Flambeau...An Investigation of Mass Fire (1964-1967), Vol. 2, Appendixes," Final Report for Office of Civil Defense Order No. OCD-PS-65-26, 1969.

[82] Steward, F. R., "Fire Spread Through a Fuel Bed," in Heat Transfer in Fires: Thermophysics, Social Aspects, Economic Impact (Blackshear, P. L., ed.), pp. 315-378, Scripta Book Company, Washington, 1974. 
[83] Hottel, H. C., Williams, G. C., and Steward, F. R., "The Modeling of Firespread Through a Fuel Bed," in Tenth Symposium (International) on Combustion, pp. 997-1007, The Combustion Institute, Pittsburgh, 1965.

[84] De Ris, J., "Fire Radiation--A Review," in Seventeenth Symposium (Internationa1) on Combustion, pp. 1003-1016, The Combustion Institute, Pittsburgh, 1979.

[85] Chandler, C. C., "Fire Spread in a Rural Area," in Proceedings: Tripartite Technical Cooperation Program, Panel N 3, Oct. 5-9, 1964, Dorking, England, pp. 14-1 to 14-14, Published by DISA, September, 1965.

[86] Anderson, H. E., "Mechanisms of Fire Spread, Research Progress Report No.1," U. S. Forest Service Research Paper INT-8, 1964.

[87] Anderson, H. E. and Rothermel, R. C., "Influence of Moisture and Wind Upon the Characteristics of Free-Burning Fires," in Tenth Symposium (International) on Combustion, pp. 1009-1019, The Combustion Institute, Pittsburgh, 1965.

[88] Rotherme1, R. C. and Anderson, H. E., "Fire Spread Characteristics Determined in the Laboratory," U. S. Forest Service Research Paper INT $-30,1966$.

[89] Anderson, H. E., "Heat Transfer and Fire Spread,"U. S. Forest Service Research Paper INT-69, 1969.

[90] Fang, J. B. and Steward, F. R., "Flame Spread Through Randomly Packed Fuel Particles," Combust. Flame $\underline{13}$ (1969) 392.

[91] Wilson, Jr., R. A., "A Reexamination of Fire Spread in Free-Burning Porous Fuel Beds," U. S. Forest Service Research Paper INT-289, June, 1982.

[92] Fons, W. L., Clements, H. B., Elliott, E. R., and George, P. M., "Project Fixe Model, Summary Progress Report--II," U. S. Forest Service Pacific Southwest Forest Experimental Station, 1962.

[93] Fons, W. L., Clements, H. B., and George, P. M., "Scale Effects on Propagation Rate of Laboratory Crib Fires," in Ninth Symposium (Internationa1) on Combustion, pp. 860-866, Academic Press, New York, 1963.

[94] Byram, G. M., Clements, H. B., Elliott, E. R., and George, P. M., "An Experimental Study of Model Fires," Technical Report No. 3, U. S. Forest Service Southeastern Forest Experiment Station, June, 1964.

[95] McCarter, R. J. and Broido, A., "Radiative and Convective Energy From Wood Crib Fires," Pyrodynamics 2 (1965) 65-85.

[96] Thomas, P. H., Simms, D. L., and Wraight, H. G. H., "Fire Spread in Wooden Cribs. Part II. Heat Transfer Experiments in Still Air," Fire Research Station F.R. Note No. 599, June, 1965. 
[97] Vogel, M. and Williams, "Flame Propagation Along Matchstick Arrays," Combust. Science Technol. 1 (1970) 429-436.

[98] Steward, F. R. and Tennankore, K. N., "The Measurement of the Burning Rate of an Individual Dowel in a Uniform Fuel Matrix," in Eighteenth Symposium (Internationa1) on Combustion, pp. 641-646, The Combustion Institute, Pittsburgh, 1981.

[99] Steward, F. R., Wuest, L. J., Waibel, R. T., "Some Characteristics of Fires Within Uniform Fuel Matrices," ASME Publication No. 77-HT-71, Presented at the AIChE-ASME Heat Transfer Conference, Salt Lake City, UT, August, 1977.

[100] Steward, F. R. and Tennankore, K. N., "Fire Spread and Individual Particle Burning Rates for Uniform Fuel Matrices," Paper presented at the Western States Section Meeting of the Combustion Institute, Oakland, CA, October, 1979.

[101] Thomas, P. H., "Buoyant Diffusion Flames," Combust. Flame 4 (1960) 381 382 .

[102] Thomas, P. H., Webster, C. T., and Raftery, M. M., "Some Experiments on Buoyant Diffusion Flames," Combust. Flame 5 (1961) 359-367.

[103] Thomas, P. H., "The Size of Flames from Natural Fires," in Ninth Symposium (International) on Combustion, pp. 844-859, Academic Press, New York, 1963.

[104] Steward, F. R., "Prediction of the Height of Turbulent Diffusion Buoyant Flames," Combust. Science Technol. 2 (1970) 203-212.

[105] Heskestad, G., "Peak Gas Velocities and Flame Heights of BuoyancyControlled Turbulent Diffusion Flames," in Eighteenth Symposium (International) on Combustion, pp. 951-960, The Combustion Institute, Pittsburgh, 1981.

[106] Heskestad, G., "Luminous Heights of Turbulent Diffusion Flames," Fire Safety J. $\underline{5}$ (1983) 103-108.

[107] Thomas, P. H., Pickard, R. W., Wright, H. G. Wraight, "On the Size and Orientation of Buoyant Diffusion Flames and the Effect of Wind," Fire Research Station F.R. Note No. 516, January, 1963.

[108] Frandsen, W. H. and Rotherme1, R. C., "Measuring the Energy-Release Rate of a Spreading Fire," Combust. Flame 19 (1972) 17-24.

[109] Curry, J. R. and Fons, W. L., "Forest-Fire Behavior Studies," Mech. Eng. $\underline{62}$ (1940) 219.225.

[110] Fons, W. L., "Analysis of Fire Spread in Light Forest Fue1s," J. Agricultural Res. 72 (1946) 93-121. (Note: This article is abstracted in Fire Research Abstracts and Reviews 1 (1958) 23-27.) 
[111] Fang, J. B., An Investigation of the Effect of Controlled Wind on the Rate of Fire Spread, PhD Thesis, University of New Brunswick, August, 1969.

[112] Nelson, Jr., R. M. and Adkins, C. W., "Flame Characteristics of WindDriven Surface Fires," Can. J. For. Res. 16 (1986) 1293-1300.

[113] "Effect of Wind on Rate of Fire Spread," in Fire Research 1960, Department of Scientific and Industrial Research and Fire Offices' Committee Joint Fire Research Organization, pp. 18-22, Her Majesty's Stationery Office, London, 1961.

[114] Thomas, P. H. and Pickard, R. W., "Fire Spread in Forests and Heathland Materials," in Report on Forest Research 1961, pp. 105-112, Her Majesty's Stationery Office, London, 1961.

[115] Byram, G. M., Clements, H. B., Bishop, M. E., and Nelson, Jr., R. M., "Final Report: Project Fire Model. An Experimental Study of Model Fires," Final Report for Office of Civil Defense Study OCD-PS-65-40, June, 1966.

[116] Thomas, P. H., "Fire Spread in Wooden Cribs. Part III. The Effects of Wind," Fire Research Station F.R. Note No. 600, June, 1965.

[117] Rios, J., Interaction Effects of Wind-Blown Proximate Flames from Burning Wood Cribs, PhD Thesis, The University of Oklahoma, 1966.

[118] Rios, J., Welker, J. R., and Sliepcevich, C. M., "Interaction Effects of Wind-Blown Flames from Burning Wood Cribs," in Proceedings: Tripartite Technical Cooperation Program, Panel N-3 (Thermal Radiation) Mass Fire Research Symposium, pp. 26-38, Defense Atomic Support Agency Special Report 59, DASA 1949, October, 1967.

[119] Prahl, J. M. and T'ien, J. S., "Preliminary Investigations of Forced Convection on Flame Propagation Along Paper and Matchstick Arrays," Combust. Science Techno1. I (1973) 271-282.

[120] Fleeter, R. D., Fende11, F. E., Cohen, L. M., Gat, N., and Witte, A. B., "Laboratory Facility for Wind-Aided Firespread Along a Fuel Matrix," Combust. Flame 57 (1984) 289-311.

[121] Carrier, G. F., Fende11, F. E., Fleeter, R. D., Gat, N. Cohen, L. M., "Laboratory Modeling of Aspects of Large Fires," Defense Nuclear Agency Technical Report DNA-TR-84-18, April, 1984.

[122] Carrier, G. F., Fendel1, F. E., and Hsu, C. T., "Modeling of Aspects of Large-Area Fires," Defense Nuclear Agency Technical Report DNA-TR-85100, Apri1, 1985 .

[123] Beach, K. L., Carrier, G. F., Fendell, F. E., Gat, N., Hsu, C. T., Kwoh, D. S. W., Lake, B. M., Wagnex, R. N., Wolff, M. F., "Laboratory Fire Modeling: 1. Wind-Aided Fire Spread; 2. Wet Coagulation of Smoke," Defense Nuclear Agency Technical Report DNA-TR-86-248, November, 1986. 
[124] Fendel1, F. "Firespread: Model and Experiment," Progress Reports for Defense Nuclear Agency Contract DNA 001-86-C-0297, 1986-1988.

[125] Nelson, R. M. and Adkins, C. W., "A Dimensionless Correlation for the Spread of Wind-Driven Fires," Can. J. For Res. 18 (1988) 391-397.

[126] "Effect of Wind on Flame Length" in Fire Research 1960, Department of Scientific and Industrial Research and Fire Offices' Committee Joint Fire Research Organization, pp. 14-15, Her Majesty's Stationery Office, London, 1961.

[127] "Effect of Wind on Flames," in Fire Research 1961, Department of Scientific and Industrial Research and Fire Offices' Committee Joint Fire Research Organization, pp. 25-27, Her Majesty's Stationery Office, London, 1962 .

[128] Byram, G. M., "Combustion of Forest Fue1," in Forest Fires: Control and Use, Chap. 3, (K. P. Davis, ed.) McGraw-Hill, New York, 1959.

[129] Welker, J.R. and Sliepcevich, C. M., "Technical Report No. 2. The Effect of Wind on Flames," Report for Office of Civil Defense Contract OCD-OS-62-89, November, 1965.

[130] Welker, J.R., The Effect of Wind on Uncontrolled Buoyant Diffusion Flames from Burning Liquids, PhD Dissertation, The University of Oklahoma, 1965.

[131] Welker, J.R. and Sliepcevich, C.M., "Burning Rates and Heat Transfer from Wind-Blown Flames," Fire Technol. 2 (1966) 211-218.

[132] Putnam, A. A., "A Model Study of Wind-Blown Free-Burning Fires," in Tenth Symposium (International) on Combustion, pp. 1039-1046, The Combustion Institute, Pittsburgh, 1965.

[133] We1ker, J. R. and Sliepcevich, C. M., "Bending of Wind-Blown Flames from Liquid Pools," Fire Technol. 2 (1966) 127-135.

[134] Pipkin, O. A. and Sliepcevich, C. M., "The Effect of Wind on Buoyant Diffusion Flames," I\&EC Fundamentals $\underline{3}$ (1964) 147-154.

[135] Hamada, M., "Study of Inclination of Flame Due to Wind," Bulletin Fire Protection Soc. Japan 1 (1952) 41-43.

[136] Frandsen, W. H., "Fire Spread Through Porous Fuels from the Conservation of Energy," Combust. Flame 16 (1971) 9-16.

[137] Pagni, P. J. and Peterson, T. G., "Flame Spread Through Porous Fuels," in Fourteenth Symposium (International) on Combustion, pp. 1099-1107, The Combustion Institute, 1973.

[138] Albini, F. A., "A Model for the Wind-Blown Flame from a Line Fire," Combust. Flame 43 (1981) 155-174. 
[139] Albini, F. A., "Spot Fire Distance from Burning Trees-A Predictive Model," United States Department of Agriculture Forest Service General Technical Report INT-56, July, 1979.

[140] Berlad, A. L. and Lee, S. -L., "Long Range Spotting", Combust.Flame 12 (1968) $172-174$.

[141] Lee, S. L., "Fire Research," App1. Mech. Rev。 25 (1972) 503-509.

[142] Tarifa, C. S., Del Notario, P. P., Moreno, F. G., and Villa, A. R., "Transport and Combustion of Firebrands," Final Report for U. S. Department of Agriculture Forest Service Grants FG-SP-114 and FG-SP146, May, 1967.

[143] Tarifa, C. S., Del Notario, P. P., and Moreno, F. G., "On the Flight and Lifetimes of Burning Particles of Wood," in Tenth Symposium (International) on Combustion, pp. 1021-1037, The Combustion Institute, Pittsburgh, 1965.

[144] Albini, F. A., "Spot Fire Distance from Isolated Sources--Extensions of a Predictive Model," United States Department of Agriculture Forest Service Research Note INT-309, March, 1981.

[145] Albini, F. A., "Potential Spotting Distance From Wind-Driven Surface Fires," United States Department of Agriculture Forest Service Research Paper INT-309, 1983.

[146] Morris, G. A., "A Simple Method for Computing Spotting Distances From Wind-Driven Surface Fires," United States Department of Agriculture Forest Service Research Note INT-374, October, 1987.

[147] Muraszew, A. and Fedele, J. B., "Trajectory of Firebrands In and Out of Fire Whirls," Combust. Flame $\underline{30}$ (1977) 321-324.

[148] Muraszew, A., Fedele, J. B., and Kuby, W. C., "The Fire Whirl Phenomenon," Combust. Flame 34 (1979) 29-45.

[149] Lee, S.-L. and Hellman, J. M., "Study of Firebrand Trajectories in a Turbulent Swirling Natural Convection Plume," Combust. Flame 13 (1969) $645-655$.

[150] Lee, S.-L. and Hellman,. J. M., "Firebrand Trajectory Study Using an Empirical Velocity-Dependent Burning Law," Combust. Flame 15 (1970) $265-274$.

[151] Lohneiss, W. H., "Observations of a Fire-Generated Vortex," Fire Research Abstracts and Reviews," ㅇ (1966) 184-187.

[152] Evans, III, E. C. and Tracy, E. T., "Observations of Mass Fire 460-14 at Mono Lake," U. S. Radiological Defense Laboratory Report USNRDL-LR158, January, 1969.

[153] Ber1, W. G., "Current Fire Research Problems," Fire Research Abstracts and Reviews," $\underline{6}$ (1964) 1-16. 
[154] Palmer, T. Y., "Project Flambeau Experimental Fire Measurements," in Proceedings: 17th Asilomar Conference on Fire and Blast Effects of Nuclear Weapons, Lawrence Livermore National Laboratory Report CONF8305107, pp. 66-70, July, 1983.

[155] Lee, S.-L. and Garris, C. A., "Formation of Multiple Fire Whirls," in Twe1th Symposium (International) on Combustion, pp. 265-273, The Combustion Institute, Pittsburgh, 1968.

[156] Thomas, P. H., Baldwin, R., and Theobald, C. R., "Some Model-Scale Experiments with Multiple Fires," Fire Research Station F.R. Note No. 700, February, 1968.

[157] Martin, R. E., Pendleton, D. W., and Burgess, W., "Effect of Fire Whirlwind Formation on Solid Fuel Burning Rates," Fire Technol. 12 (1976) 33-40.

[158] Lee, S. L. and Otto, F. W., "Gross Vortex Activities in a Simple Simulated Urban Fire," in Fifteenth Symposium (International) on Combustion, pp. 157-162, The Combustion Institute, Pittsburgh, 1975.

[159] Putnam, A. A. and Speich, C. F., "A Model Study of the Interaction of Multiple Turbulent Diffusion Flames," in Ninth Symposium (International) on Combustion, pp. 867-877, Academic Press, New York, 1963.

[160] Baldwin, R., Thomas, P. H., and Wraight, H. G. H., "The Merging of Flames from Separate Fuel Beds," Fire Research Station F.R. Note No. 551. May, 1964.

[161] Huffman, K. G., Welker, J. R., and Sliepcevich, C. M., "Technical Report No. 1441-3: Wind and Interaction Effects on Free-Burning Fires," Report for Office of Civil Defense Contract OCD-OS-62-89, December, 1967.

[162] Counihan, J., "Adiabatic Atmospheric Boundary Layers: A Review and Analysis of Data From the Period 1880-1972," Atmos. Envir. 9 (1975) $871-905$.

[163] Poreh, M. and Cermak, J. E., "Scale-Mode1 Simulations of Large-Area Fire Plumes," in proceedings of the International Symposium on Scale Modeling, Tokyo, pp. 417-423, July 18-22, 1988.

[164] Albini, F. A., "Response of Free-Burning Fires to Nonsteady Wind," Combust. Science Technol. 29 (1982) 225-241.

[165] Vodvarka, F. J., "Ful1-Scale Burns in Urban Areas. Part I. Fire Spread Between Structures," IIT Research Institute Final Technical Report, IITRI Project J6009, June, 1969.

[166] Pope, A. and Harper, J. J., Low-Speed Wind Tunnel Testing, John Wiley \& Sons, New York, 1966.

[167] Reinhold, T. A., ed., Wind Tunnel Modeling for Civil Engineering Applications, Cambridge University Press, New York, 1982. 
[168] Wardlaw, R. L., "The Use of Scale Models for Aerodynamic Investigations into the Effects of Wind on Structures," in Proceedings of the International Symposium on Scale Modeling, Tokyo, pp. 155-163, July 1822,1988 .

[169] Faure, J., "Study of Convection Currents Created by Fires of Large Area," in The Use of Models in Fire Research (Berl, W.G., ed.), pp. 130-149, Publication 786, National Academy of Sciences--National Research Council, Washington, 1961.

[170] Hotte1, H. C., "Fire Modeling," in The Use of Models in Fire Research (Berl, W. G., ed.), pp. 32-47, Publication 786, National Academy of Sciences-National Research Council, Washington, 1961.

[171] Spalding, D. B., "The Art of Partial Modeling," in Ninth Symposium (International) on Combustion, pp. 833-843, Academic Press, New York, 1963.

[172] Heskestad, G. "Physical Modeling of Fire," J. Fire Flammability $\underline{6}$ (1975) 253-273.

[173] Kanury, A. M., "Considerations in Scale-Modeling of Large Urban Fires," Defense Nuclear Agency Technical Report DNA-TR-84-439, November, 1984.

[174] Quintiere, J. G., "Scaling Applications in Fire Research," in Proceedings of the International Symposium on Scale Modeling, Tokyo, pp. 361-372, July 18-22, 1988 .

[175] Williams, F. A., "Three Unconventional Approaches to Experimental Scaling of Mass Fires," in Proceedings: Tripartite Technical Cooperation Program, Panel N-3 (Thermal Radiation) Mass Fire Research Symposium, pp. 106-126, Defense Atomic Support Agency Special Report 59, DASA 1949, October, 1967.

[176] Williams, F. A., "Scaling Mass Fires," Appendix C in "Urban Mass Fire Scaling Considerations," by W. J. Parker, U.S. Naval Radiological Defense Laboratory Report USNRDL-TR-67-150, pp. 91-144, October, 1967.

[177] Williams, F. A., "Scaling Mass Fires," Fire Research Abstracts and Reviews," 11 (1969) 1-23.

[178] Parker, W.J., "Urban Mass Fire Scaling Considerations," U.S. Naval Radiological Defense Laboratory Report USNRDL-TR-67-150, October, 1967.

[179] Byram, G. M., "Scaling Laws for Modeling Mass Fires," Pyrodynamics 4 (1966) 271-284.

[180] Parker, W. J., Corlett, R. C., and Lee, B. T., "An Experimental Test of Mass Fixe Scaling Principles," U. S. Naval Radiological Defense Laboratory Report NRDL-TR-68-117, July, 1968.

[181] Pitts, W. M., "Assessment of Theories for the Behavior and Blow Out of Lifted Turbulent Jet Diffusion Flames," Twenty-Second Symposium (International) on Combustion, to appear. 
[182] Tieleman, H. W., "Simulation Criteria Based on Meterological or Theoretical Considerations," in Wind Tunnel Modeling for Civil Engineering Applications (Reinhold, T. A., ed.), pp. 73-96, Cambridge University Press, New York, 1982.

[183] Cermak, J. E., "Physical Modeling of the Atmospheric Boundary Layer $(A B L)$ in Long Boundary-Layer Wind Tunnels (BLWT)," in Wind Tunnel Modeling for Civil Engineering Applications (Reinhold, T. A., ed.), pp. 97-125, Cambridge University Press, New York, 1982.

[184] Marshal1, R. D., "Performance Requirements and Preliminary Design of a Boundary Layer Wind Tunnel Facility," National Bureau of Standards Internal Report NBSIR 85-3168, May, 1985.

[185] Milburn, R. A., The Design and Calibration of a Very Low Speed Open Circuit Wind Tunnel, Master's Thesis, University of Oklahoma, 1965.

[186] Rothermel, R. C., "Airflow Characteristics--Wind Tunnel and Combustion Facilities," Northern Forest Fire Laboratory, Northern Forest Fire Laboratory Report, Missoula, MT, 1967.

[187] Fons, W. L., "An Eiffel Type Wind Tunnel for Forest Research," J. Forestry 38 (1940) $881-884$.

[188] "Wind-Generating Installation," in Fire Research 1959, Department of Scientific and Industrial Research and Fire Offices' Committee Joint Fire Research Organization, pp. 42-43, Her Majesty's Stationery Office, London, 1960 .

[189] Welker, J. R. and Sliepcevich, C. M., "Technical Report No. 1. A Low Speed Wind Tunnel For Measuring the Effect of Wind on Buoyant Diffusion Flames," Report for Office of Civil Defense Contract OCD-OS-62-89, September, 1964.

[190] Kalghatgi, G. T., "Blow-Out Stability of Gaseous Jet Diffusion Flames. Part II: Effect of Cross Wind," Combust. Science Technol. 26 (1981) $241-244$.

[191] Kalghatgi, G. T., "The Visible Shape and Size of a Turbulent Hydrocarbon Jet Diffusion Flame in a Cross-Wind," Combust. Flame 52 (1983) $91-106$.

[192] Saito, K., Department of Mechanical Engineering, University of Kentucky, personal communication, September, 1988.

[193] Kashiwagi, T., Center for Fire Research, National Institute of Standards and Technology, personal communication, September, 1988.

[194] Rothermel, R. C., Intermountain Fire Sciences Laboratory, personal communication, June, 1988.

[195] Sliepcevich, C. M., Flame Dynamics Laboratory, University of Oklahoma, personal communication, June, 1988. 
[196] Melbourne, W. H., "Wind Tunnel Blockage Effects and Corrections," in Wind Tunnel Modeling for Civil Engineering Applications (Reinhold, T. A., ed.), pp. 197-216, Cambridge University Press, New York, 1982.

[197] Blick, E. F., Petroleum and Geological Engineering, University of Oklahoma, personal communication, June, 1988.

[198] Sherwood, A. W., Aerolab, Laurel, MD, personal communication, September, 1988 .

[199] Chen, C. M., Aerolab, Laurel, MD, personal communication, September, 1988 .

[200] "The 9M V/STOL Wind Tunne1--A Brief Description and Photographic Review of Products," National Research Council Canada, Ottawa, July, 1979.

[201] Bain, D. C., Baker, P. J., and Rowat, M. J., Wind Tunnels. An Aid to Engineering Structure Design, The British Hydromechanics Research Association, Cranfield, Bedford, England, 1971.

[202] Cook, N. J., "Simulation Techniques for Short Test-Section Wind Tunnels: Roughness, Barrier, and Mixing-Device Methods, "in Wind Tunnel Modeling for Civil Engineering Applications (Reinhold, T. A., ed.), pp. 126-136, Cambridge University Press, New York, 1982.

[203] Schon, J. P and Mery, P., "A Preliminary Study of the Simulation of Neutral Atmospheric Boundary Layer Using Air Injection in a Wind Tunnel,"Atmos. Envir. 5 (1971) 299-311.

[204] Teunissen, H. W., "Simulation of the Planetary Boundary Layer in a Multiple-Jet Wind Tunnel," Atmos. Envir. 9 (1975) 145-174.

[205] Marsha]1, R. D., Center for Building Technology, National Institute of Standards and Technology, personal communication, December, 1988. 
The objective of this study has been to recommend whether or not a new wind tunnel facility should be designed and constructed for the investigation of wind-aided fire spread. The focus is on the types of mass fire which can be expected following a nuclear detonation above an urban environment.

A very broad approach to the problem has been adopted. Extensive literature reviews of models developed for predicting fire behavior following a nuclear detonation and the current understanding of wind-aided fire spread are discussed. These literature reviews are utilized to reach the conclusion that the current understanding of fire spread and behavior in the urban environment is very poor and, for this reason, the models utilized for predicting fire behavior in the urban environment following a nuclear detonation are very likely to be inaccurate and will almost certainly underpredict the amount of fire damage resulting from the detonation of a large nuclear device.

It is argued that serious uncertainties exist concerning the mechanisms which are responsible for urban fire spread. These uncertainties range from the physical mechanisms responsible for nearby fire spread from structure to structure (generally believed to be due to flame radiation), to the behavior and importance of firebrands and fire whirls as sources of long-range fire spread, to the requirements and physical processes responsible for the development and behavior of mass fires. The effects of ambient and fireinduced winds are very poorly characterized.

Utilizing a highly-idealized representation of the urban environment immediately following a nuclear detonation, a scenario is provided for the development and spread of fire during the period following the detonation. It is argued that wind-aided fire spread will play a major and perhaps dominant 
role in determining the ultimate degree of fire damage. This scenario also allows a listing of important research areas which must be addressed before more accurate predictions of fire damage are possible.

An examination of past investigations of fire behavior and spread indicates that much can be learned from well-designed fire studies in wind tunnels. The extremely important point of whether scaling from the small. scale investigations which are possible in wind tunnels to the very large mass fires expected in the urban environment is appropriate is addressed. It is concluded that careful scaling will allow a number of the important research areas to be effectively investigated by wind tunnel studies, but that such experiments cannot effectively deal with all of the important problems.

Based on the deficiencies in the current state of knowledge of urban fire spread and behavior and the likelihood that wind tunnel fire investigations can contribute significantly to an improved understanding, it is concluded that such studies are not only appropriate, but essential.

Past investigations of fire behavior in wind tunnels are discussed. Currently existing facilities are reviewed. Based on the types of fire problems which must addressed, the characteristics of a hypothetical wind tunnel ideally suited for investigations of wind-aided urban fire spread problems are listed. Comparison of this ideal wind tunnel with existing wind tunnel facilities indicates that much would be gained by the construction of a new wind tunnel facility designed specially to deal with the unique problems associated with wind-aided urban fire spread. Many aspects of the problem which cannot be investigated in existing facilities would be amenable to study in such a carefully designed wind tunnel.

General specifications are provided for a wind tunnel facility which will allow a wide range of research problems to be effectively investigated. These 
recommendations are based on a careful balancing of the properties of the ideal wind tunnel and the requirement to design a physically and economically realistic facility. The importarce of providing for a stable, long-term research program utilizing the new facility is emphasized.

The final conclusions of the report are: 1) The need for an improved understanding of urban fire spread as it relates to nuclear weapon effects is overwhelming, 2) At the present time, predictive capabilities for estimating fire damage in an urban environment following a nuclear attack are very limited and uncertain, 3) Wind tunnel experiments will not provide all of the required information, but will offer the opportunity to improve substantially the understanding of the problem, 4) Most existing wind tunnels were designed decades ago and are not well-suited for the required experimentation, and 5) Some progress can be and is being made in existing facilities, but substantial improvements in understanding require a new facility and a sustained commitment for support. 
L.S. DEPT. OF COAAM.

SIBLIOGRAPHIC DATA

SHEET (See in structions)
1. PUBLICATION OR REPORT NO. NISTIR-89/4049
2. Performing Organ. Report No. 3. Publication Date

May 1989

4. TITLE AND SUBTITLE

Assessment of Need for and Design Requirements of a Wind Tunnel Facility to Study Fire Effects of Interest to DNA

5. AUTHOR(S)

William M. Pitts

6. PERFORMING ORGANIZATION (If joint or other thon NBS, see instructions)

National Institute of Standards and Technology

U.S. Department of Commerce

Gaithersburg, MD 20899

$\because$ SPONSORING ORGANIZATION NAME AND COMPLETE ADDRESS (Street. City. State. ZIP)

Defense Nuclear Agency

Washington, D.C. 20305

10. SUPPLEMENTARY NOTES

Document describes a computer program: SF-185, FIPS Software Summary, is attached.

11. ABSTRACT (A 200-word or less factual summary of most significant information. If document includes a significant tibliography or literaiure survey, mention it here)

The objective of this study is to recommend whether or not a new wind tunnel facility should be designed and constructed for the investigation of wind-aided fire spread. The focus is on the types of mass fire which can be expected following a nuclear detonation above an urban environment. The final conclusions of the report are: 1) the need for an improved understanding of urban fire spread as its relates to nuclear weapon effects is overwhelming, 2) we currently have essentially zero predictive capability for fire damage in an urban environment following a nuclear attack, 3) wind tunnel experiments will not provide all of the required information, but offer the opportunity to substantially improve the understanding of the problem, 4) most existing wind tunnels were designed decades ago and are not well-suited for the required experimentation, and 5) some progress can be and is being made in existing facilities, but substantial improvements in understanding require a new facility and a sustained commitment for support.

12. KEY WORDS (Six to twelve entries: alphaberical order: capitalize only proper names: and separare key words by semicolons) fire behavior; flame whirls; fire brands; fire spread; literature reviews; mass fires; nuclear explosions; nuclear fireballs; urban fires; wind effects; wind tunnels

\section{AVAILABILITY}

[X] Unlimited

Z For Official Distribution. Do Not Release to NTIS

- Order From Suderintendent of Documents, U.S. Government Printing Office, Washington, D.C.

20402.

X Order From National Technical Information Service (NTIS), Springfield, VA. 22161
14. NO. OF PRINTED PAGES

208

15. Price $\$ 19.95$ 

